\title{
Identification of a unique oligodendrocyte subpopulation in mouse brain
}

\author{
Dissertation \\ for the award of the degree \\ "Doctor rerum naturalium" (Dr.rer.nat.)
}
of the Georg August University Göttingen, Faculty of Biology
within the doctoral program
"Molecular Physiology of the Brain"

Submitted by:

Maryam Khojastehfard

From

Isfahan, Iran

Göttingen 2017 


\section{Examination board}

Prof. Dr. Mikael Simons (Reviewer)

Research Group of Cellular Neuroscience

Max Planck Institute for Experimental Medicine

Prof. Dr. Silvio O. Rizzoli (Reviewer)

Department for Neuro- and Sensory Physiology

University of Göttingen Medical Center

Prof. Dr. Henning Urlaub

Research group of Bioanalytical Mass Spectrometry

Max Planck Institute for Biophysical Chemistry

\section{Extended examination board:}

\section{Prof. Dr. Klaus-Armin Nave}

Department of Neurogenetics

Max Planck Institute for Experimental Medicine

Prof. Dr. Nils Brose

Department of Molecular neurobiology

Max Planck Institute for Experimental Medicine

Prof. Dr. Blanche Schwappach

Department of Molecular Biology

Max Planck Institute of Biophysical Chemistry

Date of oral examination: 04.12.2017 


\section{Table of Contents}

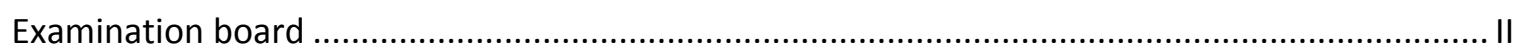

Extended examination board: ............................................................................................. II

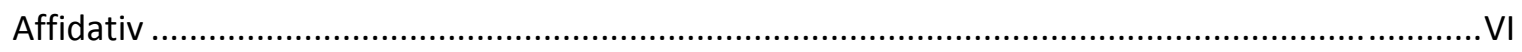

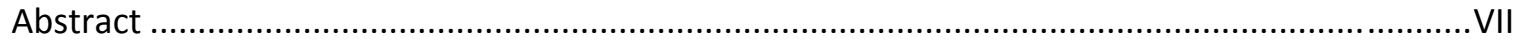

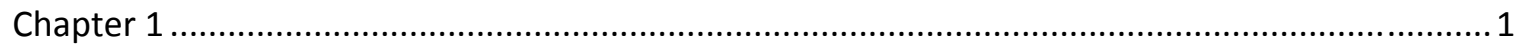

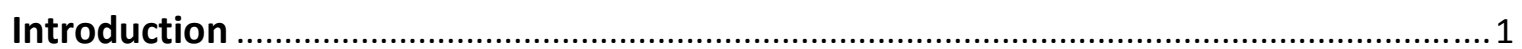

1. Oligodendrocytes; myelin forming cells of central nervous system ....................................... 1

1.1. Generation of myelin-forming oligodendrocytes from progenitor cells ..................... 1

1.2. Heterogeneity in oligodendrocyte lineage and peri-neuronal satellite

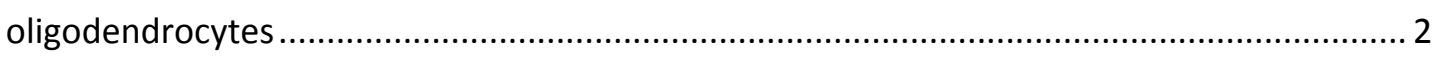

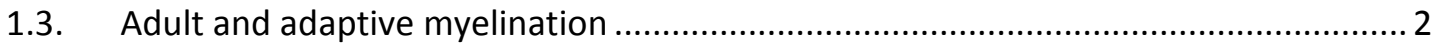

2. Myelin sheaths in central nervous system; highly specialized extension of oligodendrocytes ..... 3

2.1. Myelin structure and composition in the central nervous system .............................. 3

2.2. Maintenance and turnover of myelin sheaths ........................................................ 4

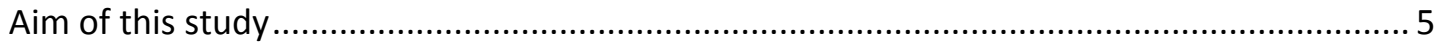

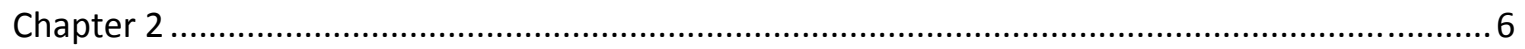

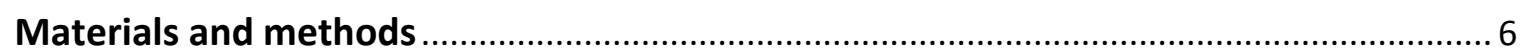

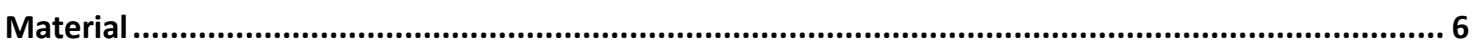

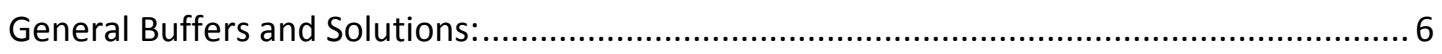

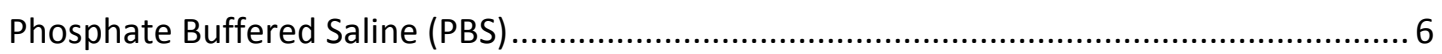

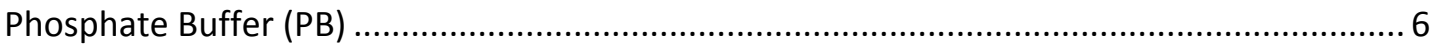

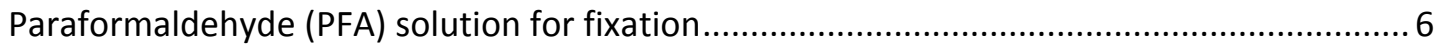

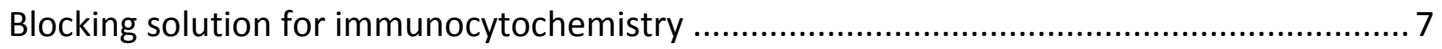

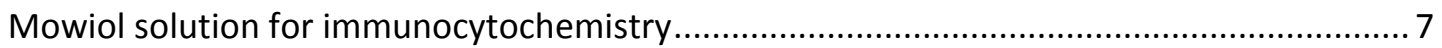

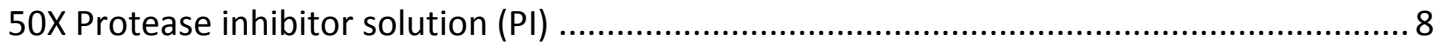

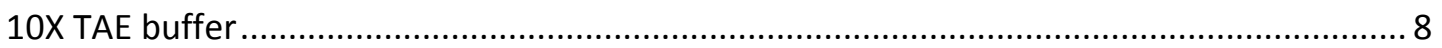

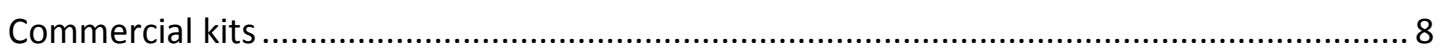

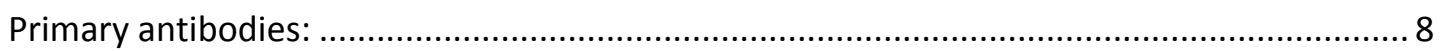

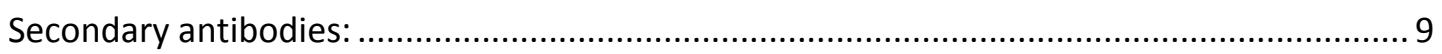

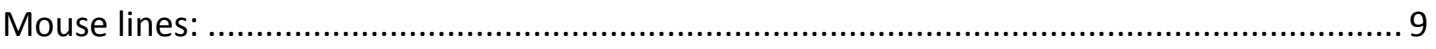

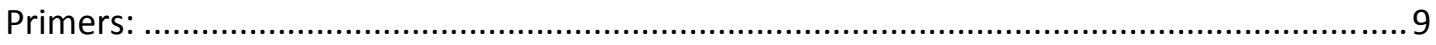

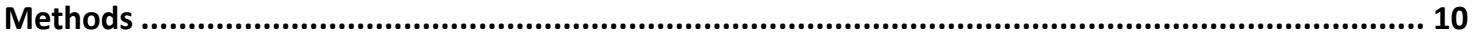

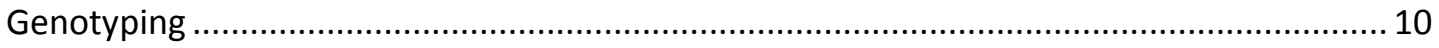


DNA extraction 10

PCR. 10

Agarose gel electrophoresis 10

PCR programs used for genotyping..... 11

Mice.

Tamoxifen administration 11

EDU labeling 12

Tissue preparation for immunohistochemistry. 12

Immunohistochemistry 12

EDU detection 12

Microscopy and cell quantifications .13

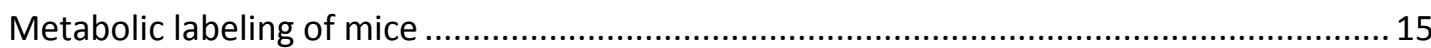

Preparation of brain fractions for proteomics ......................................................... 15

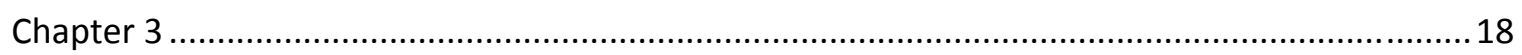

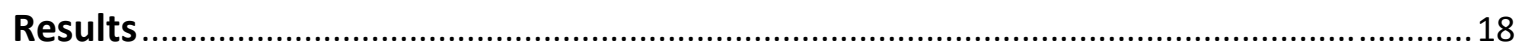

1. Identification of a unique subpopulation of oligodendrocytes ............................................ 18

1.1. BCAS1 $^{+}$immunoreactivity specifically labels cells of oligodendrocyte lineage ......... 18

1.2. $\mathrm{BCAS}^{+}{ }^{+}$immunoreactivity labels newly generated oligodendrocytes 19

1.3. BCAS1 uncover a pool of PLP- premyelinating oligodendrocytes in developing brain 20

1.4. BCAS1 labels nascent myelin sheaths

1.5. BCAS1 identifies two different pools of myelin-forming oligodendrocytes in developing and adult brain.....

1.6. BCAS1 mark premature myelin-forming oligodendrocytes in adult brain ............... 23

1.7. BCAS1 expression downregulates in fully mature oligodendrocytes.......................24

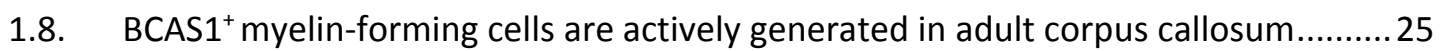

1.9. BCAS1 ${ }^{+}$myelin-forming cells are slowly generated in adult somatosensory cortex .. 27

1.10. Transient expression of BCAS1 provides a tool to map oligodendrogenesis ......... 28

1.11. BCAS1 label a subpopulation of peri-neuronal oligodendrocyte in adult somatosensory cortex

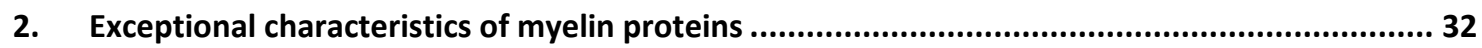

2.1. Biochemical isolation of myelin proteins ........................................................... 32

2.2. Purity of "myelin-enriched" fraction ................................................................ 33

2.3. Myelin proteins are exceptionally long-lived ................................................... 41

2.4. Myelin proteins are enriched in "light" fraction ................................................... 42 
2.1. Myelin proteins turover rate in different stage of mouse life .47

2.2. Exceptional characteristics of myelin proteins.

2.3. Identification of proteins with dual turnover rate in "light" versus "heavy" fraction50

\section{Discussion}

1. Identification of a unique subpopulation of oligodendrocytes

1.1. BCAS1: A cellular marker for premyelinating and early myelin-forming oligodendrocytes

1.2. BCAS1 uncover PLP- premyelinating oligodendrocytes during development and

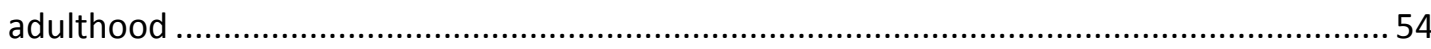

1.3. BCAS1+ myelin-forming oligodendrocytes in adult somatosensory cortex ................56

1.4. BCAS1+ perineuronal oligodendrocytes in adult somatosensory cortex .....................58

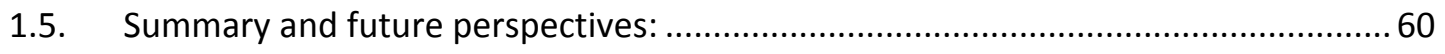

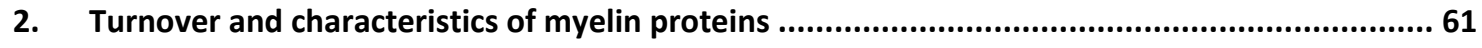

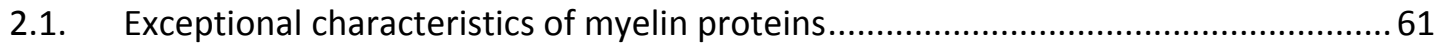

2.2. Maturation of developmentally-born myelin sheaths continues into late adulthood

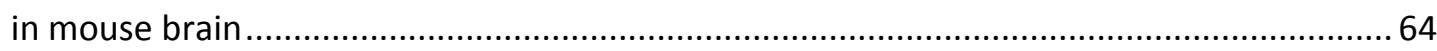

2.3. Different pools of myelin or different microdomains within myelin sheaths.............65

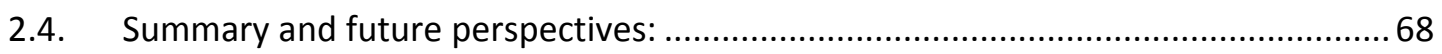

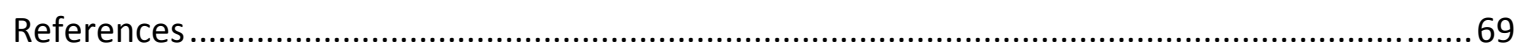

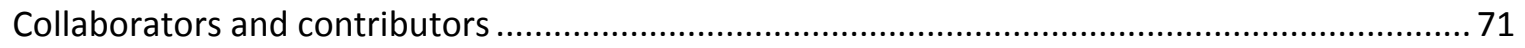

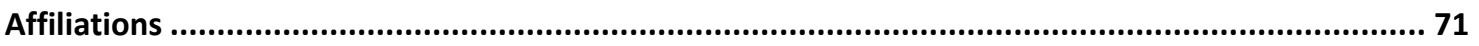

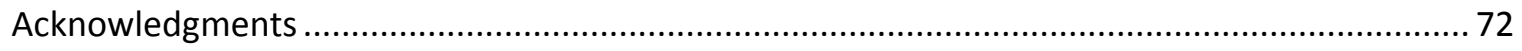

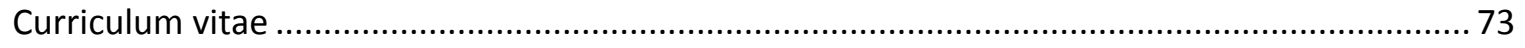




\section{Affidativ}

I hereby declare that this PhD thesis entitled "Identification of a unique oligodendrocyte subpopulation in mouse brain" has been written independently with no other aids or sources than quoted.

Maryam Khojastehfard

October, 2017

Göttingen, Germany 


\section{Abstract}

Oligodendrocytes in the central nervous system (CNS) ensheath axons with myelin and are originated from migratory and proliferative progenitor cells, so-called oligodendrocytes progenitor cells (OPCs). While immunoreactivity with chondroitin sulfate proteoglycan (NG2) and platelet-derived growth factor receptor A (PDGFR $)$ are used to recognize OPCS, APC/CC1 positivity (adenomatous polyposis coli protein-clone CC1) represents differentiated and mature oligodendrocytes. However, a tool to distinguish newly-formed and existing oligodendrocytes is still lacking which burdens various lines of research including remyelination studies. The first aim of this study was to characterize BCAS1 as a new oligodendroglia marker which recognize newlydifferentiated and early myelin-forming oligodendrocytes. We identified two different subpopulations of oligodendrocytes in developing brain, whereas only one pool continued oligodendrogenesis in adult and aged brain. By using EdU pulase-chase and transgenic reporter mice, we showed that newly-generated myelin-forming oligodendrocytes remain at a premature for relatively long time before their full maturation in adult somatosensory cortex. We also found a fraction of these premature myelin-forming cells attached to cell bodies of Tbr1-positive neurons. The second aim of this study was to address myelination at the molecular level and to define synthesis rate of myelin proteins in adult and aged mouse brain. We showed substantial increase in myelin content during adulthood which was not carried out by addition of new cells but by maturation of developmentally-born oligodendrocytes. In addition, we used biochemical characteristics of myelin proteins in order to provide a short list of true myelin proteins. So far, our knowledge about myelin composition is based on studying biochemically isolated myelin-enriched fraction. Nevertheless, a big pitfall in this approach is co-purification of any other proteins with similar floating properties to myelin. To overcome these limitations, we used different analysis to define criteria for myelin proteins and using them we provided an update into myelin proteome. Our study also provides evidences for existence of at least two different pools of myelin with different renewal rates. 


\section{Chapter 1}

\section{Introduction}

1. Oligodendrocytes; myelin forming cells of central nervous system

\subsection{Generation of myelin-forming oligodendrocytes from progenitor} cells

Myelin is produced by oligodendrocytes in the central nervous system which are originated from migratory and proliferative progenitor cells or so-called oligodendrocytes progenitor cells (OPCs). OPCs are usually recognized by their immunoreactivity with chondroitin sulfate proteoglycan (NG2) and (platelet-derived growth factor receptor A) PDGFR $\alpha$, their two most commonly used cellular markers. OPCs are described to be a very heterogeneous cell population in brain in terms of their morphology, behavior, and function(1). OPCs arise from multiple regions of the ventricular zones of the spinal cord, diencephalon, and telencephalon(2) and migrate away from these zones to populate grey and white matter and generate myelin-forming oligodendrocytes in the developing brain. PDGFR $\alpha$-expressing progenitors presumably originate by division of radial stem cell in VZ in the same way that migratory neuronal progenitors are produced. Even though PDGFR $\alpha$-expressing progenitors are shown to be a committed progenitor pool to generate oligodendrocytes in developing and adult brain, several studies provided evidences that they cannot be regarded as the only source of OLG generation. Studies in chicken and mouse embryo characterized a DM20/PLP-expressing pool of progenitors for oligodendrocytes (3-6). DM20 is an alternative spliced product of plp gene. In mouse brain, DM20/PLP-expressing progenitors are first detected in E9.5 in the basal plate of diencephalon. Spassky et al. 1998 examined the mitotic activity of DM20/PLP-expressing cells during embryonic development and developing brain during active phase of myelination. They showed that these cells proliferate, only, when located in the ventricular zone during embryonic stage. However, they start to proliferative again after birth during active phase of myelination(6). In 1997 DM20/PLP immunolabeling was used to characterize another 
pool of oligodendrocytes in developing rat brain which were morphologically distinct from both progenitor and myelin-forming oligodendrocytes; discussed as un- or premyelinating oligodendrocytes. These cells have symmetrically radiating process and are larger and morphologically more complex as compared with OPCs(7).

\subsection{Heterogeneity in oligodendrocyte lineage and peri-neuronal satellite oligodendrocytes}

Oligodendrocytes were discovered in 1928 by Pio del Rio Hortega as very morphologically heterogeneous cell population (8). A recent single-cell RNA-Seq study (9) identified up to 12 subclasses of OLG lineage in P21-P30 and P60 mice. These subclasses can be categorized into 4 major groups: progenitors (NG2 and PDGFR $\alpha$ expressing cells), committed progenitors (No expression for NG2 and PDGFR $\alpha$ and positivity NeuN4, Sox6 Bmp4 and GPR17 and lower levels of cell division markers), newly formed (low levels of GPR17 and induction of Tcf7/2 and Casr), mature/myelin-forming OLGs (Mal, Mog, Plp1, Opalin, and Serinc5). The authors described these cells as oligodendrocytes at different stages of their differentiation; they also suggested presence of several subclasses of myelin-forming OLGs based in on their molecular gene expression profiles. It is not yet investigated whether these differences indeed reflect different functional importance in oligodendrocyte subpopulations. It is also still unknown if this heterogeneity is intrinsically regulated, e.g., due to their different origins or if they become heterogeneous in response to their different environments and locations. On the other hand existence of a peri-neuronal and satellite subpopulation of oligodendrocytes in adult cerebral cortex has been long debated(10), however characterization of these cell has been very controversial, and they have been characterized both as non-myelinating $(10,11)$ and myelin-forming oligodendrocytes $(12)$ in mouse cortex.

\subsection{Adult and adaptive myelination}

OPCs makeup around 5-10\% whole cell population in CNS and comprise around $70 \%$ the cycling cells in the adult parenchyma. Even though oligodendrogenesis and myelination declines after first postnatal weeks in rodents, OPCs remain with a substantial density as a proliferative pool and continue generation of new myelin-forming oligodendrocytes in adult and aged brain (13-18). Increasing body of evidences both in human and rodents 
showed alterations in white matter structure upon learning and training which highlight the possible role of myelination process in neural plasticity. It is suggested that suggested that adult myelination is a dynamic and adaptive process which refines CNS circuity in response to environmental and physiological stimuli and synthesis of new myelin (by existing oligodendrocytes or by generation of new oligodendrocytes) is associated and might be prerequisite for different types of learning $(19,20)$. In principle, adaptive myelination in adult brain can occur not only via alterations in proliferation of OPCs and their differentiation into adult-born myelin-forming oligodendrocytes, but also it can occur by changes in number and length of the pre-existing oligodendrocytes processes (19-22). Different ultrastructure alterations in the myelin structure can influence the salutatory role of myelin and hence are all potential mechanisms of neural plasticity. Change in number of myelin wraps, axonal coverage pattern, nodal density of voltage-gated channels as well as lengths of nodes, internodes, and paranodes are among these ultrastructure modulations.

\section{Myelin sheaths in central nervous system; highly specialized extension of oligodendrocytes}

\subsection{Myelin structure and composition in the central nervous system}

Myelin is a unique specification of glial cells in vertebrates in order to overcome the pressure of increasing nervous system size. Increasing evidences suggest that myelin cannot be seen as a sole insulator for axons, rather it must be regarded as a dynamic, protective structure providing trophic support for axons(23). The molecular composition of myelin differs from any other eukaryotic plasma membranes because of its unusual high content of lipids (70-75\% of myelin dry weight)(24) and little amount of cytoplasm. Our understanding about myelin composition in large comes from studying the biochemically isolated "myelin-enriched fraction" using sequential ultracentrifugation together with osmotic shocks. Myelin-enriched fraction accumulates as the lightweight membranous material at the interface between 0.32 and $0.85 \mathrm{M}$ sucrose and is enriched in the most abundant proteins of compact myelin, proteolipid protein (PLP), and myelin basic protein (MBP) which together account for up to $80 \%(25)$ or $20-30 \%(26)$ of myelin protein content. Electron microscopy revealed that myelin-enriched fraction mainly contains multilamellar membranes with comparable morphological characteristics to 
that of myelin in native or perfused brains $(27,28)$. Due to its very unique composition, myelin is compartmented in very specialized structural (cytosol-depleted compacted regions and cytosol-enriched non-compacted regions) and functional (interenodal, juxtaparanodal, and paranodal) domains. The compacted domains of myelin provide rapid salutatory conduction on one hand by increasing the resistance and decreasing the capacitance across the axonal membrane and on the hand by clustering voltage-gated sodium channels at nodes of Ranvier. Uncompacted regions are cytosol-enriched opening within myelin architecture localized at the innermost and outermost tongues of myelin membranes along the internodes, the paranodes, and the cytoplasmic channels in central nervous system(29).

\subsection{Maintenance and turnover of myelin sheaths}

Correct myelin assembly is crucial for its maintenance and functional integrity as shown by axonal pathology in PLP knock-out mice.and tremor, seizures followed by premature death in shiverer mice; natural mutant of MBP protein. However, our knowledge about the true components of myelin and their abundance is still very limited and controversial. Earlier studies on the isolated lightweight membranous material obtained from discontinues ultracentrifugation, or so-called the "myelin-enriched" showed that PLP and its shorter isoform DM20 together with MBP comprise approximately $80 \%$ of the total myelin proteins(25). By using mass spectrometry approaches, more proteins were identified in this fraction and hence this number reduced down to $20-30 \%$ of myelin proteins(26). Myelin biogenesis requires synthesis and trafficking of vast amounts of membrane by OLGs. Transport of newly synthesized myelin proteins and lipids is not only important for biogenesis of myelin during development and active phase of myelination but also is highly crucial later throughout the lifetime of each individual OLG in order to grantee maintenance and functional integrity of myelin and OLGs. In order to provide a functional proteome and lipidome throughout a cell's lifetime, all the cellular proteins and lipids should constantly be degraded and replaced by newly synthesized copies. Recent studies using in vivo stable isotope labeling with amino acids followed by mass spectrometry of sorted neuroglia cells identified the most long-lived proteins in brain and among them were myelin proteins with a very slow rate of turnover (30). Limited turnover of myelin components may be due to their specific 
localizations and thus, their restricted access to cellular machineries for protein and lipid synthesis and degradation.

\section{Aim of this study}

This study consists of two different projects and two main objectives. The first aim of this study was to characterize, BCAS1, as a new oligodendroglia marker which distinguishes newly-formed oligodendrocytes from the pre-existing pool of mature, myelin-forming oligodendrocytes. Thus far there has not been any cellular marker that transiently labels oligodendrocytes at the intermediate stage. Therefore, identification of newly formed oligodendrocytes has not been possible. This is a limiting factor in various lines of research including studying the oligodendrocyte lineage and the de-/remyelination models.

The second aim of this study was to address myelination at the molecular level and to define synthesis rate of myelin proteins in adult and aged brain. So far, our understanding about myelin composition by large has come from studies on biochemically isolated myelin-enriched fraction (24). Nevertheless, a big pitfall in this approach is its lack of specificity and co-purification of any proteins with similar floating properties to myelin. We aimed to use biochemical characteristics of myelin proteins in order to provide a short list of true myelin proteins. 


\section{Chapter 2}

\section{Materials and methods}

\section{Material}

\section{General Buffers and Solutions:}

Phosphate Buffered Saline (PBS)

10X PBS was prepared as follows:

\begin{tabular}{|l|l|}
\hline \multicolumn{1}{|c|}{ 10X PBS } & \multicolumn{1}{c|}{ (1L) } \\
\hline $\mathrm{NaCl}$ & $80.0 \mathrm{~g}$ \\
\hline $\mathrm{KCL}$ & $2.0 \mathrm{~g}$ \\
\hline $\begin{array}{l}\mathrm{Na} 2 \mathrm{HPO} 4 \\
\text { (or Na2HPO4_2H2O) }\end{array}$ & $14.4 \mathrm{~g}$ \\
\hline $\mathrm{KH} 2 \mathrm{PO} 4$ & (or $18.05 \mathrm{~g}$ ) \\
\hline
\end{tabular}

To obtain 1X PBS, 10X PBS was diluted 10 times with ddH2O. $\mathrm{pH}$ value was adjusted to 7.4 and stored at RT.

\section{Phosphate Buffer (PB)}

0.1M Phosphate buffer (PB) was prepared as follows:

\begin{tabular}{|l|l|}
\hline \multicolumn{1}{|c|}{ PB (0.1M) } & \multicolumn{1}{c|}{$\mathbf{2 0 0} \mathbf{~ m L}$} \\
\hline $\mathrm{NaH}_{2} \mathrm{PO}_{4}-\mathrm{H}_{2} \mathrm{O}$ & $0.36 \mathrm{~g}$ \\
\hline $\mathrm{Na}_{2} \mathrm{HPO}_{4}-2 \mathrm{H}_{2} \mathrm{O}$ & $3.1 \mathrm{~g}$ \\
\hline $\mathrm{ddH}_{2} \mathrm{O}$ & $200 \mathrm{~mL}$ \\
\hline
\end{tabular}

The solution was always made freshly or kept in $4{ }^{\circ} \mathrm{C}$ and used within a few days.

Paraformaldehyde (PFA) solution for fixation

\begin{tabular}{|l|l|}
\hline \multicolumn{1}{|c|}{ 16\% PFA } & \multicolumn{1}{c|}{$\mathbf{1 0 0 m L}$} \\
\hline Paraformaldehyde (PFA) & $16 \mathrm{~g}$ \\
\hline Water & $70 \mathrm{~mL}$ \\
\hline PBS 10X & $10 \mathrm{~mL}$ \\
\hline
\end{tabular}

After dissolving PFA in water, the solution was heated at $60{ }^{\circ} \mathrm{C}$, and $\mathrm{NaOH}$ pellets were added until the solution became clear. 10X PBS were added, and pH was adjusted to 7.4. 
The final volume of $100 \mathrm{~mL}$ was obtained by adding water. The solution was aliquoted and stored at $-20{ }^{\circ} \mathrm{C}$. Working solution of $4 \%$ was prepared in freshly prepared $1 \mathrm{X}$ phosphate buffer and stored at $4{ }^{\circ} \mathrm{C}$ for at most a week.

\section{Blocking solution for immunocytochemistry}

\begin{tabular}{|l|l|}
\hline Blocking solution (5X) & $\mathbf{1 0 0 m L}$ \\
\hline FCS & $10 \mathrm{~mL}$ \\
\hline BSA & $10 \mathrm{~g}$ \\
\hline fish gelatin & $10 \mathrm{~g}$ \\
\hline $1 X$ PBS & $90 \mathrm{~mL}$ \\
\hline
\end{tabular}

The solution was filtered, aliquoted and stored at $-20^{\circ} \mathrm{C}$.

The working solution of $1 \mathrm{X}$ was prepared in $1 \mathrm{X}$ PBS and stored at $4{ }^{\circ} \mathrm{C}$ until the solution was clear. 1X solution was used for blocking steps of immunocytochemistry and immunohistochemistry.

\section{Mowiol solution for immunocytochemistry}

Mowiol was used as the mounting medium after immunocytochemistry and immunohistochemistry.

\begin{tabular}{|l|l|}
\hline \multicolumn{1}{|c|}{ Mowiol } & \\
\hline Mowiol 4-88 (Calbiochem) & $2.4 \mathrm{~g}$ \\
\hline glycerol & $6 \mathrm{~g}$ \\
\hline $\mathrm{ddH}_{2} \mathrm{O}$ & $6 \mathrm{~mL}$ \\
\hline Tris- $\mathrm{HCl} \mathrm{0.2M} \mathrm{(pH} \mathrm{8.5)}$ & $12 \mathrm{~mL}$ \\
\hline DABCO & $2.5 \%$ \\
\hline
\end{tabular}

After adding Mowiol in Glycerol, solution was stirred on maximum speed.

Water was added, and the solution was stirred for at least 2 hours at room temperature.

Tris- $\mathrm{HCl}$ was added, and the solution was heated on $50{ }^{\circ} \mathrm{C}$ for at least 10 minutes and was stirred time to time. The solution then was centrifuged at $4000 \mathrm{~g}$ for $15 \mathrm{~min} .1 .25 \mathrm{~mL}$ DABCO was added in order to prevent loss of fluorescence. DABCO can be added after preparing the Mowiol solution, or just before start to use a new aliquot. The solution was aliquoted and for long-term use stored in $-20^{\circ} \mathrm{C}$ or for short-term use (maximum 2weeks) in $4{ }^{\circ} \mathrm{C}$. 


\section{X Protease inhibitor solution (PI)}

One tablet of Complete Mini (Roche Applied Science, Mannheim, Germany) was dissolved in $1 \mathrm{~mL}$ ice-cold $\mathrm{ddH}_{2} \mathrm{O}$ and aliquots were stored at $-20{ }^{\circ} \mathrm{C}$. Afterwards 1:50 dilution of this stock was added to the solution directly before use.

10X TAE buffer

\begin{tabular}{|l|l|}
\hline \multicolumn{1}{|c|}{ 10X TAE } & \multicolumn{1}{c|}{$(\mathbf{1 ~ L )}$} \\
\hline Tris base & $48.4 \mathrm{~g}$ \\
\hline Acetic acid & $11.4 \mathrm{~mL}$ \\
\hline EDTA $0.5 \mathrm{M}$ & $20.0 \mathrm{~mL}$ \\
\hline $\mathrm{ddH}_{2} \mathrm{O}$ & Fill up to $1 \mathrm{~L}$ \\
\hline
\end{tabular}

After mixing all the reagents, the final volume of $1 \mathrm{~L}$ was obtained by adding $\mathrm{ddH} 2 \mathrm{O}(\mathrm{pH}$ 8.5).

\section{Commercial kits}

\begin{tabular}{|c|c|c|c|}
\hline Kit & Application & Company & Cat. Number \\
\hline Spin Tissue Midi Kit & DNA extraction for genotyping & Invitek & \\
\hline Click-iT $^{\circledR}$ EdU Alexa Fluor $^{\circledR}$ & Proliferation assay & ThermoFisher & C10340 \\
647 Imaging Kit & & Scientific & \\
\hline
\end{tabular}

Primary antibodies:

\begin{tabular}{|c|c|c|c|c|}
\hline Name & Host/Isotype & Cat. Number & Dilution & Company \\
\hline MBP & Monoclonal /Mouse & SMI-99P & $1: 500$ & Covance \\
\hline GFP & Monoclonal/Rabbit & G10362 & $1: 1000$ & Thermo Fisher \\
\hline GFP & Polyclonal/Chicken & GFP-1020 & $1: 1000$ & Aves \\
\hline APC/CC-1 & Monoclonal/ Mouse & OP80 & $1: 300$ & Calbiochem \\
\hline SOX10 & Polyclonal/Rabbit & SI058R06 & $1: 100$ & DCS \\
\hline NFM & Polyclonal/ Chicken & ab4680 & $1: 6000$ & Abcam \\
\hline Caspr (K65/35) & Monoclonal/ Mouse & $75-001$ & $1: 500$ & NeuroMab \\
\hline NABC1 & Monoclonal/Mouse & sc-136342 & $1: 500$ & Santa Cruz \\
\hline BCAS1 & $\begin{array}{l}\text { Polyclonal/ Rabbit } \\
\text { (Custom-made) }\end{array}$ & - & $1: 300$ & Synaptic Systems, Göttingen \\
\hline $\operatorname{MAG}(5 / 3)$ & Monoclonal/ Mouse & - & $1: 100$ & \multirow{3}{*}{$\begin{array}{l}\text { Kind gift of K.-A. Nave, } \\
\text { Göttingen }\end{array}$} \\
\hline PLP (AA3) & Monoclonal/ Mouse & - & $1: 400$ & \\
\hline $\operatorname{PLP}(431 \mathrm{~A})$ & Polyclonal/ Rabbit & - & $1: 1000$ & \\
\hline AN2/NG2 & Monoclonal/ Rat & - & $1: 100$ & $\begin{array}{l}\text { kind gift of J. Trotter, Mainz, } \\
\text { Germany }\end{array}$ \\
\hline
\end{tabular}




\section{Secondary antibodies:}

Corresponding secondary antibodies were conjugated with Alexa 488, 555 or 647(1:5001:1000, all Life Technologies) and chosen as suitable.

Mouse lines:

\begin{tabular}{|l|l|}
\hline Mouse strain & Reference \\
\hline NG2-CreERT2 & W. Huang et al., Glia (2014) \\
\hline PLP-CreERT2 & D. P. Leone et al., (2003) \\
\hline R26R-td-tomato-mEGP & L. Madisen et al., Nat Neurosci (2010) \\
\hline PLP-EGFP & N. Spassky et al., Dev Neurosci (2001) \\
\hline Esco2:Sox10-iCreERT2:CAG-eGFP & \\
\hline
\end{tabular}

\section{Primers:}

Following primers were used in this study for genotyping of different mouse lines:

\begin{tabular}{|l|l|l|}
\hline PCR & 5' to 3' primer sequence & Primer ID \\
\hline NG2CreERT2 & Fwd: GGCAAACCCAGAGCCCTGCC & 19398 \\
& wT Rev:GCTGGAGCTGACAGCGGGTG & 19399 \\
& CreERT Rev: GCCCGGACCGACGATGAAGC & 19400 \\
\hline PLP1Cre ERT2 & Fwd:TGGACAGCTGGGACAAAGTAAGC & 10099 \\
& Rev:CGTTGCATCGACCGGTAATGCAGGC & 7963 \\
\hline ROTO & Rosa4: TCAATGGGCGGGGGTCGTT & 14024 \\
& Rosa10: CTCTGCTGCCTCCTGGCTTCT & 14025 \\
& Rosa11: CGAGGCGGATCACAAGCAATA & 14026 \\
\hline PLPG & Fwd: ATGCGTACCTGACTTTCTCCTTCT & 11111 \\
& Rev: ACTGGGTGCTCAGGTACTGGTTGT & 11112 \\
\hline
\end{tabular}




\section{Methods}

\section{Genotyping}

\section{DNA extraction}

The genomic DNA was extracted from the lysate of mouse tail biopsies using the Invitek Spin Tissue Kit according to the manufacturer's instruction. The DNA was then eluted in $100 \mu$ l elution buffer. The DNA concentration was measured according to absorbance of double-stranded DNA at 260nm with a BioPhotometer plus spectrophotometer (Eppendorf).

\section{PCR}

\begin{tabular}{|l|l|}
\hline Master mix components & For $25 \boldsymbol{\mu l}$ reaction \\
\hline milli $\mathrm{Q} \mathrm{H}_{2} \mathrm{O}$ & $15.35 \mu \mathrm{l}$ \\
\hline $5 X$ Taq buffer & $5 \mu \mathrm{l}$ \\
\hline $\mathrm{dNTPs} 10 \mathrm{mM}$ & $0.5 \mu \mathrm{l}$ \\
\hline $\mathrm{MgCl}_{2} 25 \mathrm{mM}$ & $0.5-1 \mu \mathrm{l}$ \\
\hline Primers (Fwd) $10 \mathrm{pmol} / \mu \mathrm{l}$ & $1 \mu \mathrm{l}$ \\
\hline Primers (Rev) $10 \mathrm{pmol} / \mu \mathrm{l}$ & $1 \mu \mathrm{l}$ \\
\hline Taq DNA Polymerase & $0.15 \mu \mathrm{l}$ \\
\hline DNA & $1 \mu \mathrm{l}$ \\
\hline
\end{tabular}

The PCR was performed using a T3000 Thermocycler.

\section{Agarose gel electrophoresis}

1\% Agarose gel in 1X TAE buffer containing 1X SYBR safe DNA gel stain (10000X, stock, Invitrogen) was prepared. Electrophoresis was done in the Chambers assembled by the Feinmechanik Service Department at the Max Planck Institute for Experimental Medicine containing $1 \times$ TAE buffer. The PCR products were visualized by transillumination using Intas Gel Documentation System (Intas Science Imaging Instruments $\mathrm{GmbH}$ ). 
PCR programs used for genotyping

\begin{tabular}{|c|c|c|c|}
\hline NGCE PCR & PCET PCR & ROTO PCR & PLPG PCR \\
\hline $95^{\circ} \mathrm{C}$ Pause & $96^{\circ} \mathrm{C} 3 \mathrm{~min}$ & $94^{\circ} \mathrm{C} 3 \mathrm{~min}$ & $94^{\circ} \mathrm{C} 2 \mathrm{~min}$ \\
\hline $95^{\circ} \mathrm{C} 3 \min$ & $96^{\circ} \mathrm{C} 30 \mathrm{sec}$ & $94^{\circ} \mathrm{C} 30 \mathrm{sec}$ & $58^{\circ} \mathrm{C} 30 \mathrm{sec}$ \\
\hline $62^{\circ} \mathrm{C} 30 \mathrm{sec}$ & $60{ }^{\circ} \mathrm{C} 45 \mathrm{sec}$ & $58{ }^{\circ} \mathrm{C} 30 \mathrm{sec}$ & $72^{\circ} \mathrm{C} 1 \mathrm{~min} 20 \mathrm{sec}$ \\
\hline $72{ }^{\circ} \mathrm{C} 1 \mathrm{~min}$ & $72{ }^{\circ} \mathrm{C} 1 \mathrm{~min}$ & $72{ }^{\circ} \mathrm{C} 45 \mathrm{sec}$ & $95^{\circ} \mathrm{C} 30 \mathrm{sec}$ \\
\hline 35 cycles & 32 cycles & 35 cycles & \\
\hline $62{ }^{\circ} \mathrm{C} 1 \mathrm{~min}$ & $72{ }^{\circ} \mathrm{C} 5 \mathrm{~min}$ & $58^{\circ} \mathrm{C} 1 \mathrm{~min}$ & $72{ }^{\circ} \mathrm{C} 2 \mathrm{~min}$ \\
\hline $72^{\circ} \mathrm{C} 10 \mathrm{~min}$ & $8{ }^{\circ} \mathrm{C}$ inf & $72{ }^{\circ} \mathrm{C} 5 \mathrm{~min}$ & $4{ }^{\circ} \mathrm{C}$ Pause \\
\hline $4{ }^{\circ} \mathrm{C}$ Pause & & $4^{\circ} \mathrm{C}$ Pause & \\
\hline
\end{tabular}

\section{Mice}

R26R-td-tomato-mEGP mice were bred together with NG2-CreERT2 and PLP1-Cre ERT2 in order to generate NG2-CreERT2:R26R-td-tomato-mEGP and PLP-CreERT2:R26R-tdtomato-mEGFP double transgenic mice. All the NG2-CreERT2:R26R-td-tomato-mEGP animals used in this study were double heterozygous and all the PLP-CreERT2:R26R-tdtomato-mEGFP mice were heterozygous in Rosa locus and carried one or two PLPCreERT2 alleles. PLPG mice used in this study were all homozygous.

\section{Tamoxifen administration}

Tamoxifen (T5648, Sigma-Aldrich, St. Louis, MO) was dissolved in corn oil (Sigma, St. Louis, MO) at a concentration of $15 \mathrm{mg} / \mathrm{ml}$. For NG2CreERT2:R26R-td-tomato-mEGP, mice were injected intraperitoneally with tamoxifen at a dosage of $75 \mathrm{mg} / \mathrm{kg}$ body weight, once per day for 5 consecutive days. Two different protocols were used for PLPCreERT2:R26R-td-tomato-mEGFP mice in order to achieve high and low Cre recombination efficiency. The low efficiency, in particular, was more favorable for the aging experiment and fate-mapping of developmental born OLGs. By using lower Cre recombination efficiency, fewer cells were labeled with GFP which made the single-cell fate-tracking experiment feasible. We injected the animals with tamoxifen for 2 consecutive days at dosages of 75 and $50 \mathrm{mg} / \mathrm{kg}$ body weight in order to achieve high and low efficiency of Cre recombination, respectively. For experiments using the 
Esco2:Sox10iCreERT2:CAG-eGFP, $40 \mathrm{mg} / \mathrm{ml}$ tamoxifen was dissolved in corn oil and $10 \%$ EtOH and given orally by gavage every second day for three times.

\section{EDU labeling}

EdU (Invitrogen) was dissolved in the drinking water of C57BL/6 wildtype mice for 10 days at $0.2 \mathrm{mg} / \mathrm{ml}$ concentration. The water was exchanged every $48 \mathrm{hr}$. The animals were sacrificed by transcardially perfusions at different time points after EDU labeling.

\section{Tissue preparation for immunohistochemistry}

Animals were deeply anesthetized by injection of $14 \%$ chloral hydrate and transcardially perfused with $4 \%$ paraformaldehyde (PFA) in phosphate buffer $(\mathrm{pH}=7.4)$. After perfusion, the brains were dissected and post-fixed in the same fixative overnight at $4^{\circ} \mathrm{C}$. For immunostaining of NG2, only $2 \%$ paraformaldehyde was used for post-fixation and the post-fixation time was shortened to $8 \mathrm{~h}$. The dissected brains were then cryoprotected in $30 \%(\mathrm{w} / \mathrm{v})$ sucrose (Sigma) in PBS before freezing in OCT on the surface of dry ice. 20-30 $\mu \mathrm{m}$ cryosections of the brain (coronal) were collected and used for freefloating IHC.

\section{Immunohistochemistry}

For immunolabeling sections were blocked in blocking solution (2.5\% FCS, 2.5\% BSA, 2.5\% fish gelatin in PBS) for one hour in room temperature and after that were incubated for one or two nights in the primary antibody cocktail in $10 \%$ of the same blocking solution. Brain slices were washed with PBS after the incubation of primary and sequentially treated with fluorescent secondary antibodies diluted again in $10 \%$ of blocking solution for $1 \mathrm{~h}$ at RT. All sections were incubated in 4',6-Diamidino-2phenylindole (DAPI) at a final concentration of $0.025 \mu \mathrm{g} / \mathrm{ml}$ for 10 minutes before mounting on the slide.

\section{EDU detection}

The brain sections were washed with PBS after incubation in secondary antibody cocktails and were incubated in freshly prepared EdU developing cocktail (Invitrogen AlexaFluor-647 Click-iT EdU Cell Proliferation Assay Kit) for 40minutes in the dark at 
room temperature. Tissues were washed several times with PBS and post-stained with DAPI before mounting on coverslips.

\section{Primary mouse cell culture}

Primary cultures of mouse oligodendrocytes were prepared from postnatal day 1. Neonatal brain hemispheres were stripped free of meninges, trypsin digested and cultured in Eagle 's basal medium with $10 \%$ horse serum on poly-L-lysine-coated flask at $37^{\circ} \mathrm{C}$. After 8-10 days, oligodendrocytes were harvested from mixed glial culture using mechanical dissociation. Isolated cells were then cultured in Dulbecco's Modified Eagle's Medium (DMEM) containing B-27 supplement, 1\% horse serum, triiodothyronine, Lthyroxine, pyruvate, glutamine, and penicillin/streptomycin on poly-L-lysine-coated glass coverslips or dishes. After 10 days of culture and removing of oligodendrocytes, the remaining cells were trypsinized and plated on poly-L-lysine-coated glass coverslips in DMEM containing 10\% FCS, glutamine, and penicillin/streptomycin.

\section{Transfection}

N2a (neuroblastoma) cells transfection was performed using lipofectamine transfection reagent (Gibco/Invitrogen). $1 \mu \mathrm{g}$ of plasmid DNA (BCAS1-myc3) and $3 \mu \mathrm{l}$ of lipofectamine were added to $100 \mu \mathrm{l}$ Opti-MEM and incubated for $25 \mathrm{~min}$ at RT and were then added to N2a cells for 24 hours. Transfected and non-transfected cells were then fixed with $4 \%$ PFA for $15 \mathrm{~min}$ at RT and kept at $4^{\circ} \mathrm{C}$ for further analysis.

\section{Microscopy and cell quantifications}

For all experiments at least 3 different animals from the same litter were analyzed. Only for the $6 \mathrm{wpi}$ time point of the OPC depletion experiment, 2 animals per genotype were used. $20-30 \mu \mathrm{m}$ z-stacks with $1 \mu \mathrm{m}$ spacing were scanned with a $40 \times$ objectives of a Leica TCS SP5 confocal microscope. 6-9 non-adjacent randomly selected ROIs from 3 nonadjacent brain sections were quantified. All the quantifications were performed manually using Imaris (64× version 8.3.1) and ImageJ 1.41 image processing software with investigators blind to the experimental conditions. Each channel was quantified independent of the other channels using DAPI nuclei labeling as a reference, except for 
the quantification of paranodes, in which CASPR labeling was used as the reference. The cell densities were reported as cells $/ \mathrm{mm}^{2}$ or cells $/ \mathrm{mm}^{3}$ as indicated in the legend.

\section{Statistical analysis}

All statistics were calculated using the GraphPad Prism 6 software (GraphPad Software). To compare the two groups, a Student's two-tailed t test was applied. One-way analysis of variance (ANOVA) followed by Bonferroni's, Tukey's, or Newman-Keuls' posthoc test was performed for comparison of three and more than three groups were used as indicated in the figure legends. Data are means \pm SEM if not stated otherwise. Asterisks correspond to P values of $<0.05(*),<0.01\left(^{* *}\right)$, and $<0.001(* * *)$. 


\section{Metabolic labeling of mice}

C57BL/6 wildtype male mice of different ages of 1-, 4-, 18- and 26-month-old were fed with an isotopically labeled ${ }^{13} \mathrm{C}$-lysine SILAC diet (Silantes, Martinsried, Germany). Mice were housed in groups of 4 in standard plastic cages and maintained in a temperaturecontrolled environment $\left(21 \pm 2{ }^{\circ} \mathrm{C}\right)$ on a $12 \mathrm{~h}$ light dark cycle with food and water available ad libitum. The mice were then sacrificed after 30 or 60 days of feeding with the SILAC diet, and the brains were collected and snap frozen in liquid nitrogen and kept in $-80^{\circ} \mathrm{C}$.

\section{Preparation of brain fractions for proteomics}

The "myelin-enriched" fraction was prepared from C57BL/6 mouse brains by sequential centrifugation on a discontinuous sucrose gradient according to a protocol previously described. In brief, the brain tissues were homogenized with an ice-cold glass Dounce homogenizer in ice-cold 0,32 $\mathrm{M}$ sucrose and the homogenized tissue was then layered on the same volume of $0.85 \mathrm{M}$ sucrose. All the solutions were prepared in ice-cold distilled water supplemented with protease inhibitor. The crude myelin fraction was collected from the interface after centrifugation at $75,000 \mathrm{~g}$ for 30 min with low deceleration and acceleration and suspended in distilled water and centrifuged again at $75,000 \mathrm{~g}$ for $15 \mathrm{~min}$. The pellet then was subjected to two rounds of hypo-osmotic shock by resuspension in $10 \mathrm{ml}$ ice-cold water, with centrifugation at 12,000g for $10 \mathrm{~min}$. For purification of myelin, the pellet obtained from the last step was dissolved in $0,32 \mathrm{M}$ sucrose solution one more time, and all the centrifugation steps and hypo-osmotic shocks were then repeated as before. Eventually, the purified myelin pellet was resuspended in $200 \mu$ IBS buffer supplemented with protease inhibitor and snap frozen in liquid nitrogen and stored at $-80^{\circ} \mathrm{C}$. The ultracentrifugation was done using a SW41 $\mathrm{Ti}$ rotor. To prepare the "myelin-depleted" fraction, we collected the pellet from the first ultracentrifugation and subjected it to 4 extra rounds of myelin isolation including all the ultracentrifugations and followed by osmotic shocks steps. In each round pellet was collected and used for the next purification step. 


\section{Mass spectrometry}

The protein concentration of samples was determined using a BCA kit (ThermoFisher Scientific). For each sample, $100 \mu \mathrm{g}$ of total protein amount was loaded on pre-casted NuPAGE gels (4-12\%, ThermoFisher Scientific). The gel electrophoresis was performed at constant voltage $(200 \mathrm{~V})$ for $50 \mathrm{~min}$. After staining with Coomassie G-250 and destaining, each lane was cut using a custom-made gel cutter into 23 equal gel pieces. The gel slices were further cut into 8 smaller pieces ( $1 \mathrm{~mm}^{2}$ each) and processed for ingel digestion using trypsin (Serva, Germany) (31). The eluted peptides were dried and resuspended in $20 \mu \mathrm{l}$ of $5 \%$ acetonitrile, $0.1 \%$ formic acid solution, and were further processed for LC-MS in an online UltiMate 3000 RSLCnano HPLC system (ThermoFisher Scientific) coupled online to the Q Exactive HF. Peptides were desalted on a reverse phase C18 pre-column ( $3 \mathrm{~cm}$ long, $100 \mu \mathrm{m}$ inner diameter $360 \mu \mathrm{m}$ outer diameter) for 3 minutes. After 3 minutes, the pre-column was switched online with the analytical column (30 cm long, $75 \mu \mathrm{m}$ inner diameter) prepared in-house using ReproSil-Pur C18 AQ $1.9 \mu \mathrm{m}$ reversed phase resin (Dr. Maisch GmbH, Ammerbuch-Entringen, Germany). The peptides were separated with a linear gradient of 5-30\% buffer B (80\% acetonitrile and $0.1 \%$ formic acid) at flow rate of $10 \mathrm{nl} / \mathrm{min}$ over $88 \mathrm{~min}$ gradient time. The temperature of the pre-column and of the column was set to $50^{\circ} \mathrm{C}$ during chromatography. The MS data was acquired by scanning the precursors in mass range from 350 to $1600 \mathrm{Da}$ at a resolution of 60,000 at $\mathrm{m} / \mathrm{z} 200$. The top 30 precursor ions were chosen for MS1 by using data-dependent acquisition (DDA) mode at a resolution of 15,000 at $\mathrm{m} / \mathrm{z} 200$ with maximum IT of $50 \mathrm{~ms}$. For MS2, HCD fragmentation was performed with the AGC target fill value of $1 \mathrm{e} 5$ ions. The precursors were isolated with a window of $1.4 \mathrm{Da}$. The lock mass option (m/z 445.1200 (32)) was used for internal recalibration. The acquired RAW files were analyzed using MaxQuant software'(33) version 1.5.2.8 based on the Andromeda search engine (34) against UniProt mus musculus database (downloaded on November 2015; containing 16,727 reviewed entries). For defining the label on peptides, the multiplicity tab was selected to " 2 " and the label ${ }^{13} \mathrm{C} 6$-lysine was ticked as heavy. Protein quantification was based on "unique and razor peptides" for a protein. For time pulse of heavy label ${ }^{13} \mathrm{C} 6$-lysine (30 and 60 days), four biological replicates were measured, each with three instrumental repeats. The mean of $\mathrm{H} / \mathrm{L}$ (heavy-to-light ratios) for each protein was used to determine the 
newly synthesized protein. Data was normalized to the heavy-to-light ratio of mitochondrial proteins that co-purify in the myelin fraction, to account for differences in the incorporation of ${ }^{13} \mathrm{C}$-lysines. 


\section{Chapter 3}

\section{Results}

\section{Identification of a unique subpopulation of oligodendrocytes}

\subsection{BCAS1+ immunoreactivity specifically labels cells of oligodendrocyte lineage}

We examined our previously generated proteome database (35) and identified proteins enriched in oligodendrocytes. BCAS1 was one of the proteins highly enriched in newly formed oligodendrocytes. We used a custom-made polyclonal antibody against BCAS1, to perform immunofluorescence staining on mouse brain cryosections. First, we examined the specificity of the antiserum raised against BCAS1 via different approaches. We performed antibody-antigen pre-absorption control experiments (using recombinant BCAS1 protein) and labeling of BCAS1-knockout mouse brain sections. We showed abolished immunostaining when the experiment was done using pre-absorbed antibody (Figure.1.1.1. A) and in the knock-out adult brain (Figure.1.1.1. B). We also confirmed specificity of the BCAS1 antiserum with enhanced BCAS1 labeling in neuroblastoma cells after transfection with Bcas1 CDNA and hence BCAS1 overexpression in these cells (Figure.1.1.1. C). Using co-labeling of BCAS1 together with different lineage markers, including Sex Determining Region Y Box 10 protein (SOX10), Oligodendrocyte Transcription Factor 1 (OLIG1) and Oligodendrocyte Transcription Factor 2 (OLIG2) we showed that all BCAS1 ${ }^{+}$cells belonged to the oligodendrocyte lineage (Figure.1.1.2. A-D). We also co-labeled with antibodies against Neural/Glial Antigen 2 (NG2; a marker for oligodendrocyte progenitor cells) and found out that a small fraction $(16.5 \% \pm 2.8$ SEM overlap) of the $\mathrm{BCAS1}^{+}$cells in young animals were oligodendrocyte progenitor cells (Figure.1.1.2. E). While the majority of the cells (76.2 \% \pm 3.5 SEM overlap) were more differentiated as shown by their reactivity with antibodies against Adenomatous Polyposis Coli protein, the most commonly used marker for mature oligodendrocytes (anti-Adenomatous Polyposis Coli antibody, clone CC-1), almost half (47.5 \% \pm 3.2 SEM) of them were also positive for Myelin-Associated Glycoprotein (MAG) a protein involved in oligodendrocyte and axon contact (Figure.1.1.2. E). 


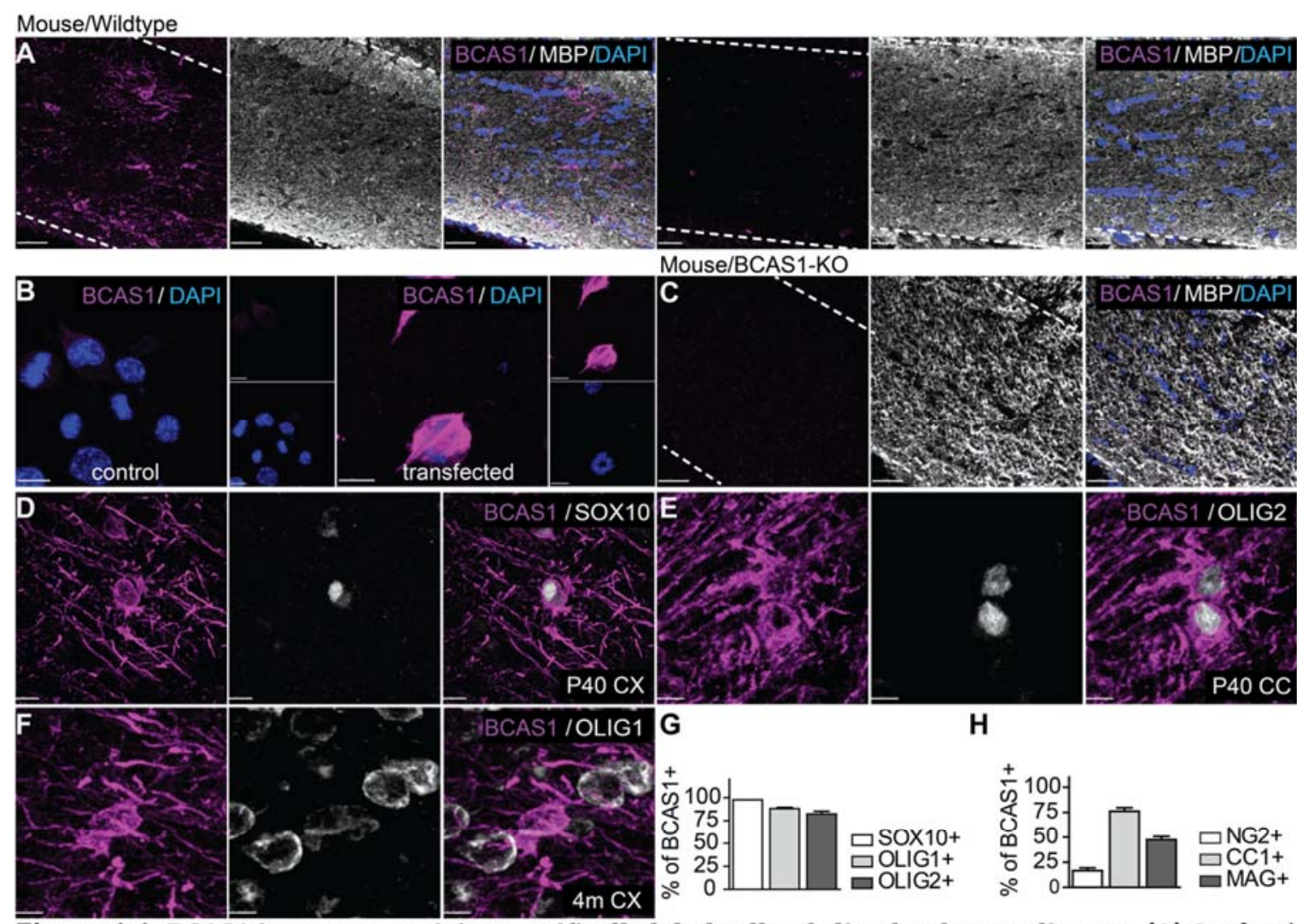

Figure.1.1. BCAS1 immunoreactivity specifically label cells of oligodendrocyte lineage. (A) Confocal images of BCAS1/MBP/DAPI labelling in adult wildtype (left image) and BCAS1/MBP/DAPI labelling in adult

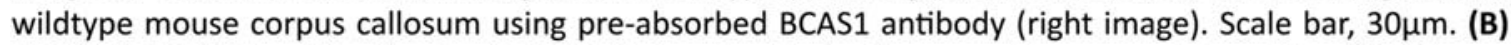
BCAS1/MBP/DAPI co-labelling in adult BCAS1 knock-out mice (corpus callosum, scale bar, 30 $\mu \mathrm{m}$ ) (C) Neuroblastoma (N2a) cells were transfected by plasmid encoding for a myc-tagged BCAS1 and stained for BCAS1 and DAPI. Confocal images of (D) BCAS1/SOX10 (somatosensory cortex-at P40) (E) BCAS1/OLIG2 (corpus callosum-at P40) (F) BCAS1/OLIG1 (somatosensory cortex-at 4 months) Scale bar, 10 $\mathrm{mm}$. (G) Bar graph shows the percentage of BCAS1 + cells expressing SOX10, OLIG1 or OLIG2 (H) Bar graph shows the percentage of BCAS1+ cells expressing NG2, CC1 or MAG (corpus callosum- at P40).

\subsection{BCAS1+ immunoreactivity labels newly generated oligodendrocytes}

To further analyze whether BCAS1 cells were originated from oligodendrocyte progenitor cells, we performed fate mapping experiments to track the fate of OPCs. We used double transgenic mice, NG2-CreERT2x R26R-td-tomato-mEGFP, expressing a tamoxifen-inducible Cre DNA recombinase inserted into the NG2 locus (36)and a membrane-targeted Enhanced Green Fluorescent Protein (EGFP) gene inserted into the Gt(ROSA)26Sor locus(37). Mice were injected with tamoxifen at postnatal day 30 (P30) to induce Cre recombination followed by GFP expression in oligodendrocyte progenitor cells (Figure.1.2. A). We analyzed the progenies of the labeled cells at 7, 18 and 40 days post-injection by immunostaining and observed that the BCAS1 positivity increases in the recombined cells from day 7 until day 18 and remained unchanged from day 18 until 
day 40 (Figure.1.2. B). These results indeed indicate that $\mathrm{BCAS}^{+}{ }^{+}$cells differentiate from oligodendrocyte progenitor cells and are newly formed oligodendrocytes.

Figure.1.2. BCAS1 expression identifies newly generated oligodendro-
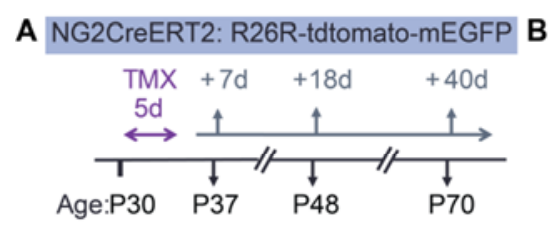

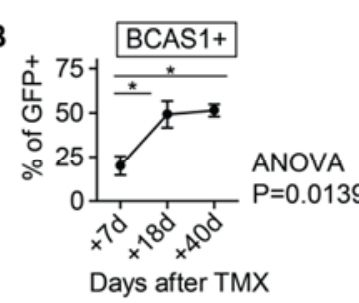

cytes. (A) Experimental plan: Tamoxifen (TMX) was used at P30 to induce he expression of mEGFP in NG2CreERT2:R26Rtdtomato-mEGFP mice as illustrated. (B) Quantification shows the percentage of double positive (EGFP+ and BCAS1+) cells over time. One-way ANOVA, followed by Bonferroni's post hoc test, ${ }^{*} \mathrm{p}<0.05 ; \mathrm{n}=3,3$ sections per animal. Quantitative data are presented as mean \pm SEM.

\subsection{BCAS1 uncover a pool of PLP- premyelinating oligodendrocytes in developing brain}

BCAS1 immunoreactivity marks cells with different morphologies - cells with multiple, symmetrically radiating processes and cells with several segments aligned in parallel (Figure.1.3. A,B) all of which were also positive for CC1. Cells with numerous symmetrically had similar morphology to premyelinating oligodendrocytes previously described by expression of Proteolipid Protein (PLP) in the developing rat brain (7). In order to determine if these cells were indeed the previously characterized cells, we used transgenic PLP-GFP mice, in which the PLP promoter drives the expression of cytosolic GFP. We compared GFP' and BCAS1 ${ }^{+}$premyelinating oligodendrocytes in early postnatal development (P9 and P14) and adult (4-months) in somatosensory cortex. At P9 and P14, all of the cells with premyelinating morphology expressed BCAS1; however, the majority $(70.5 \% \pm 8.1$ SEM at P9; $76.3 \% \pm 1.7$ SEM at P14) of them were GFPdemonstrating that BCAS1 visualize a larger pool of premyelinating oligodendrocytes (Figure.1.3. C,D). When we performed this analysis in adult brain (4 months), we could not find GFP+ premyelinating oligodendrocytes anymore while they were all of BCAS1 ${ }^{+}$. These results indicate that the previously characterized PLP-expressing premyelinating cells only represent a subpopulation $(29.5 \% \pm 8.1$ SEM at P9, $23.7 \% \pm 1.7$ SEM at P14 and $0 \%$ at 4 months) and are restricted to developmental stage (Figure.1.3. C,D). 


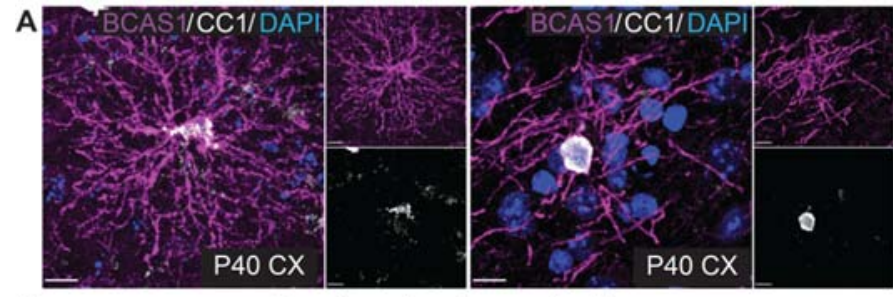

B

Two-dimentional reconstruction

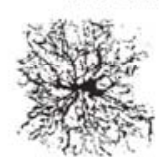

pre-mOLG

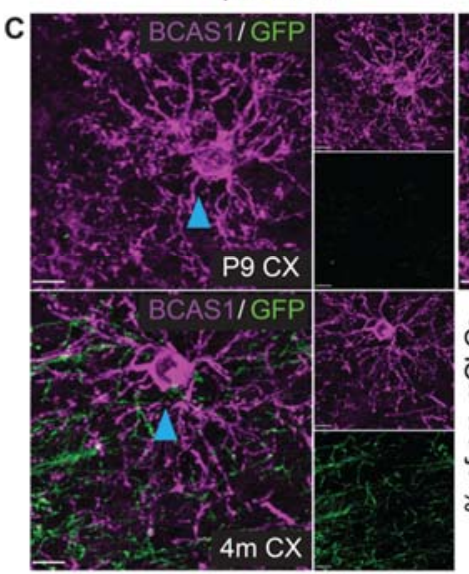

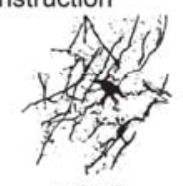

MOLG

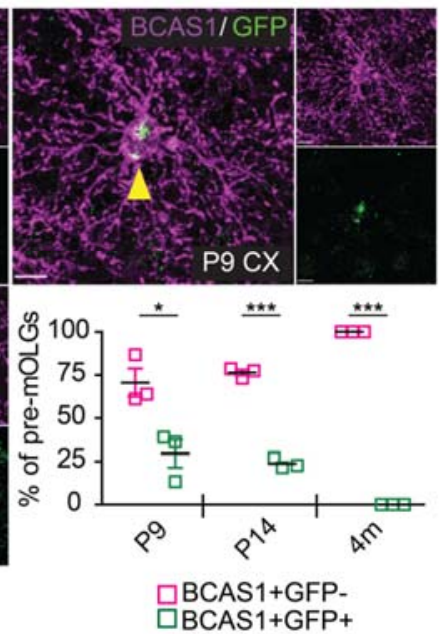

Figure.1.3. BCAS1 immunoreactivity define a pool of PLP- pre-mOLGs in mouse brain. (A) Confocal images show two different morphologies of BCAS1+ oligodendrocytes co-labeled with $\mathrm{CC} 1$ and DAPI in the somatosensory cortex (CX) of P40 mice. Scale bar, $10 \mu \mathrm{m}$. (B) Twodimentional reconstruction of confocal images were generated for better visualization of BCAS1+ cells morphologies. Left: Cells with numerous, symmetrically radiating process resembling morphology of premyelinating oligodendrocytes. Right: Cells with several T-shape segments aligned in parallel resembling morphology of myelin froming oligodendrocytes. (C) Confocal images show BCAS1/GFP co-labeling of premyelinting oligodendrocytes in PLP-GFP transgenic mice in the developing and adult somatosensory cortex of P9 and 4 months old mice. Blue and yellow arrows indicate BCAS1+/GFPand BCAS1+/GFP+ cells. Scale bar, $10 \mu \mathrm{m}$. Quantifications show the percentage of pre-mOLG positive for GFP, BCAS1 or both, in somatosensory cortex of P9, P14 and 4 month old mice. Student's two-tailed t test, unpaired, ${ }^{*} p<0.05,{ }^{* * *} p<0.001$.

\subsection{BCAS1 labels nascent myelin sheaths}

The other major morphology of BCAS1-positive was cells with several segments aligned alongside axons. We refer to these cells as myelin-forming oligodendrocytes. First, to verify myelin formation by these cells, we used co-labeling of BCAS1 and neurofilament and showed ensheathment of neuronal fibers by $\mathrm{BCAS}^{+}$segments using high-resolution confocal images (Figure.1.4. A). Some of these BCAS1 ${ }^{+}$segments were arranged in a patchy pattern along axons (38) (Figure.1.4. A). In addition, we immunostained the somatosensory cortex for paranodal Contactin-Associated Protein 1 together with BCAS1 and quantified the number of $\mathrm{BCAS}^{+}{ }^{+}$segments flanked by Contactin-Associated Protein 1 clusters. We used P15 mice where few nodes were established in this region. Quantification revealed that majority (one BCAS1+CASPR+ paranode, $17.1 \% \pm 1.9$ SEM and two BCAS1+CASPR+ paranodes $62.2 \% \pm 2.9 \mathrm{SEM}$ ) of nodes at this time-point was flanked with at least one BCAS1 ${ }^{+}$CASPR+ segment (Figure.1.4. C). These results verified that $\mathrm{BCAS}^{+}$cells with segments aligned in parallel enwrap axons and form myelin segments. 

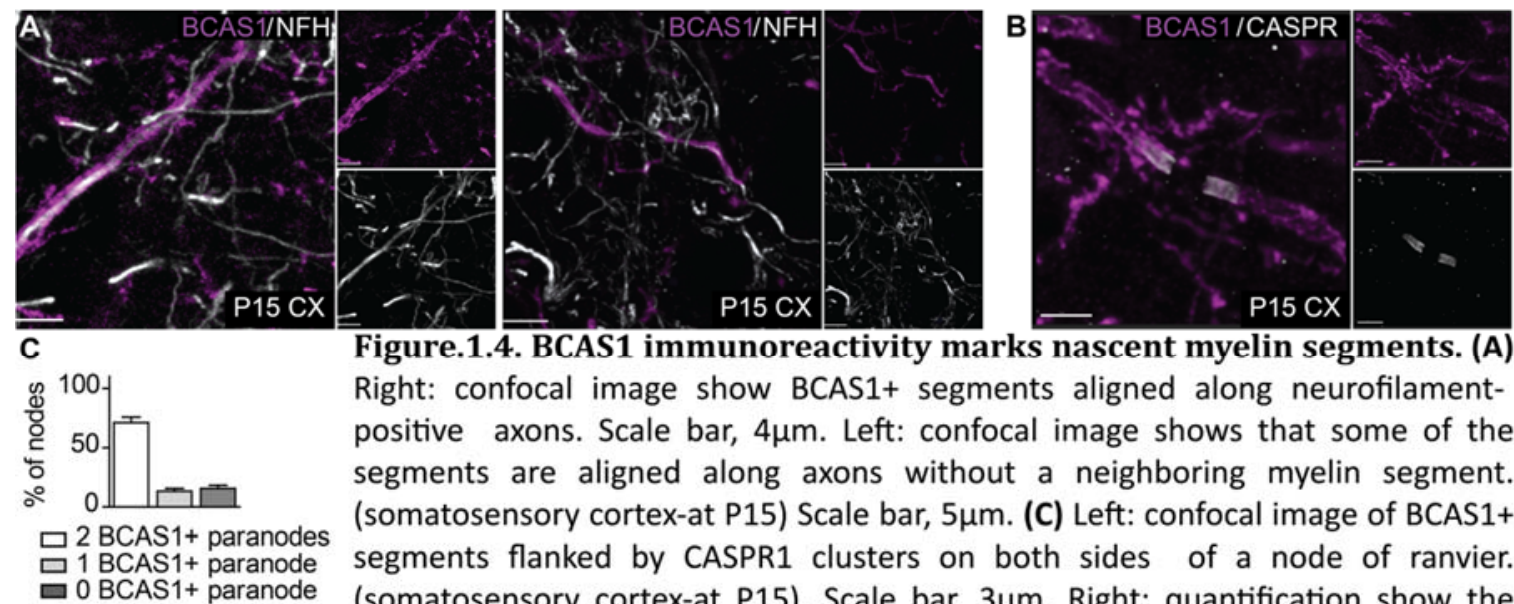

Figure.1.4. BCAS1 immunoreactivity marks nascent myelin segments. (A) Right: confocal image show BCAS1+ segments aligned along neurofilamentpositive axons. Scale bar, $4 \mu \mathrm{m}$. Left: confocal image shows that some of the segments are aligned along axons without a neighboring myelin segment. (somatosensory cortex-at P15) Scale bar, $5 \mu \mathrm{m}$. (C) Left: confocal image of BCAS1+ segments flanked by CASPR1 clusters on both sides of a node of ranvier. (somatosensory cortex-at P15). Scale bar, $3 \mu \mathrm{m}$. Right: quantification show the percentage of nodes flancked by 0,1 or 2 BCAS1+CASPR + segment (BCAS1+ paranode); $n=3$, 3 sections per animal. Quantitative data are presented as mean \pm SEM.

\subsection{BCAS1 identifies two different pools of myelin-forming oligodendrocytes in developing and adult brain}

After confirming myelin formation by $\mathrm{BCAS}^{+}$cells, we used the PLP-GFP reporter mice to analyze these cells further. Similar to the results for premyelinating oligodendrocytes, we found that at P9 when myelin-forming cells just start to appear in the somatosensory cortex, all the cells with myelin-forming morphology were positive for BCAS1 whereas only a subpopulation of them were $\mathrm{GFP}^{+}$(Figure.1.5. A,B) However, later at P14, we detected emergence of a third population of myelin-forming oligodendrocytes that lacked BCAS1 expression and were $\mathrm{GFP}^{+}$(Figure.1.5. A,B). When we performed the experiment at 4 months, we could only detect two pools myelin-forming oligodendrocytes, one expressing BCAS1 and one expressing GFP (Figure.1.5. A,B). These results suggest that BCAS1 immunoreactivity is lost when oligodendrocytes mature into later stages of oligodendrocyte differentiation. Moreover, it indicates that oligodendrogenesis is continued in adult brain only by $\mathrm{PLP}^{-} / \mathrm{BCAS}^{+}$premyelinating oligodendrocytes (Figure.1.5. C,D). 


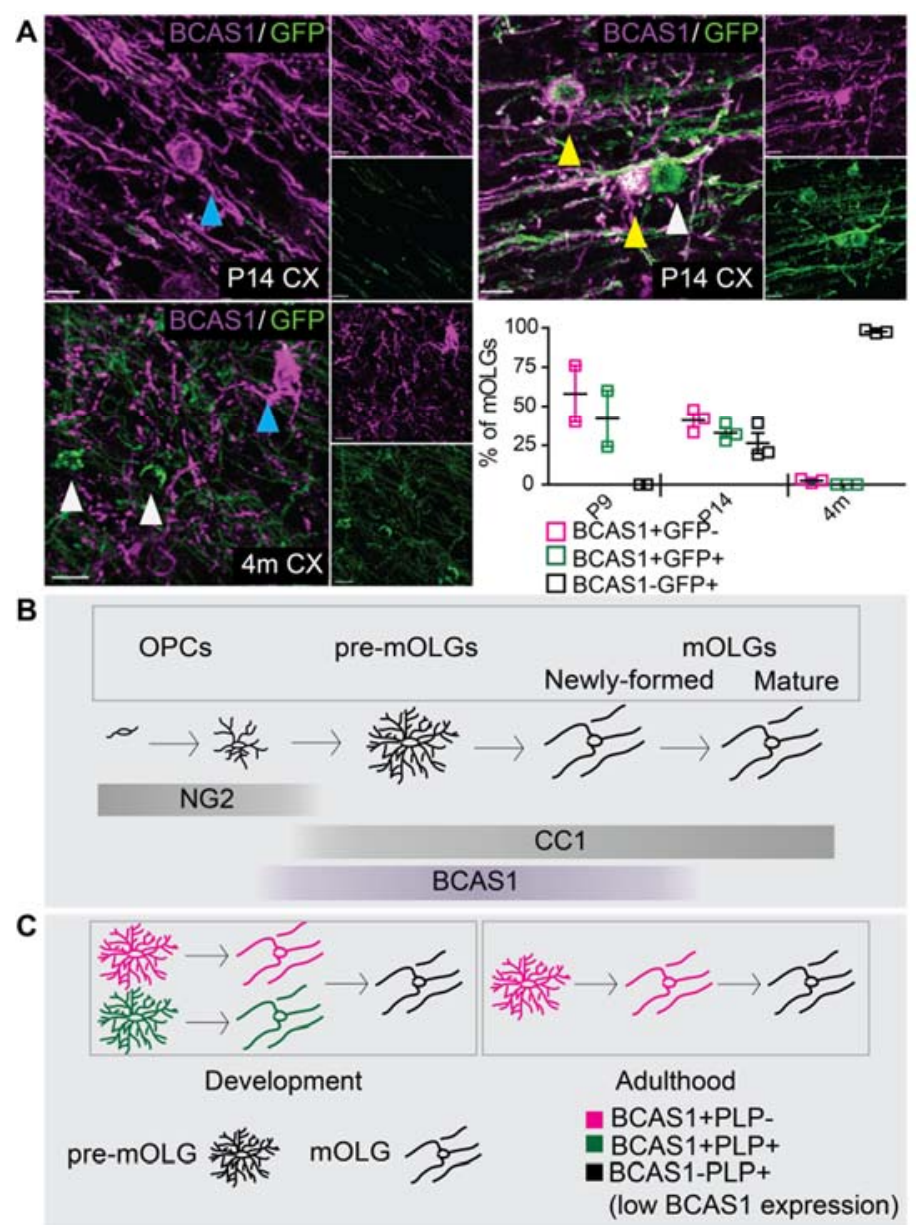

Figure.1.5. BCAS1 immunolabeling identifies two different pools of myelin forming oligodendrocytes in developing mouse brain. (A) Confocal images show BCAS1 and GFP expression in myelin-forming oligodendrocytes (mOLGs) in the developing and adult somatosensory cortex of P9, P14 and 4 months old PLP-GFP mice. Blue, yellow and white arrows show BCAS1+/GFP-, BCAS1+/GFP+ and BCAS1-/GFP+ respectively in mOLG. Scale bar, $10 \mu \mathrm{m}$. Quantification show the percentage of myelinforming oligodendrocytes (mOLGs) positive for GFP, BCAS1 or both, in somatosensory cortex of P9, P14 and 4 month old mice. Student's two-tailed t test, unpaired, ${ }^{*} p<0.05,{ }^{* * *} p<0.001$. (B) Schematic illustration represent relative expression of NG2, CC1 and BCAS1 at different stages of maturation in oligodendrocyte lineage. (C) Schematic illustration summerizes the pattern of BCAS1 and PLP expression during development and in adulthood. $n=3,3$ sections per animal. (only for P9 in bar graph B, $n=2$ ). Quantitative data are presented as mean \pm SEM.

\subsection{BCAS1 mark premature myelin-forming oligodendrocytes in adult} brain

To verify $\mathrm{BCAS1}^{+}$and $\mathrm{PLP}^{+}$oligodendrocytes segregation in adult mice, we used another double transgenic mouse line expressing a tamoxifen-inducible Cre inserted into the PLP locus (PLP-CreERT2) with GFP reporter mice (R26R-td-tomato-mEGFP). Upon tamoxifen injection, at P110 mice Cre recombination and GFP expression was induced in differentiated oligodendrocytes. We analyzed brain sections 18 days after injection by immunohistochemistry and no $\mathrm{BCAS1}^{+} \mathrm{GFP}^{+}$were detected in adult mice (Figure.1.6. A). Next, we tested expression of other myelin proteins, MAG and Myelin Basic Protein (MBP) in $\mathrm{BCAS1}^{+}$myelin-forming oligodendrocytes in adult cortex. We observed while they were all positive for MAG, they rarely expressed Myelin Basic Protein (MBP) suggesting that these cells represent immature myelin-forming oligodendrocytes (Figure.1.6. B-E). 

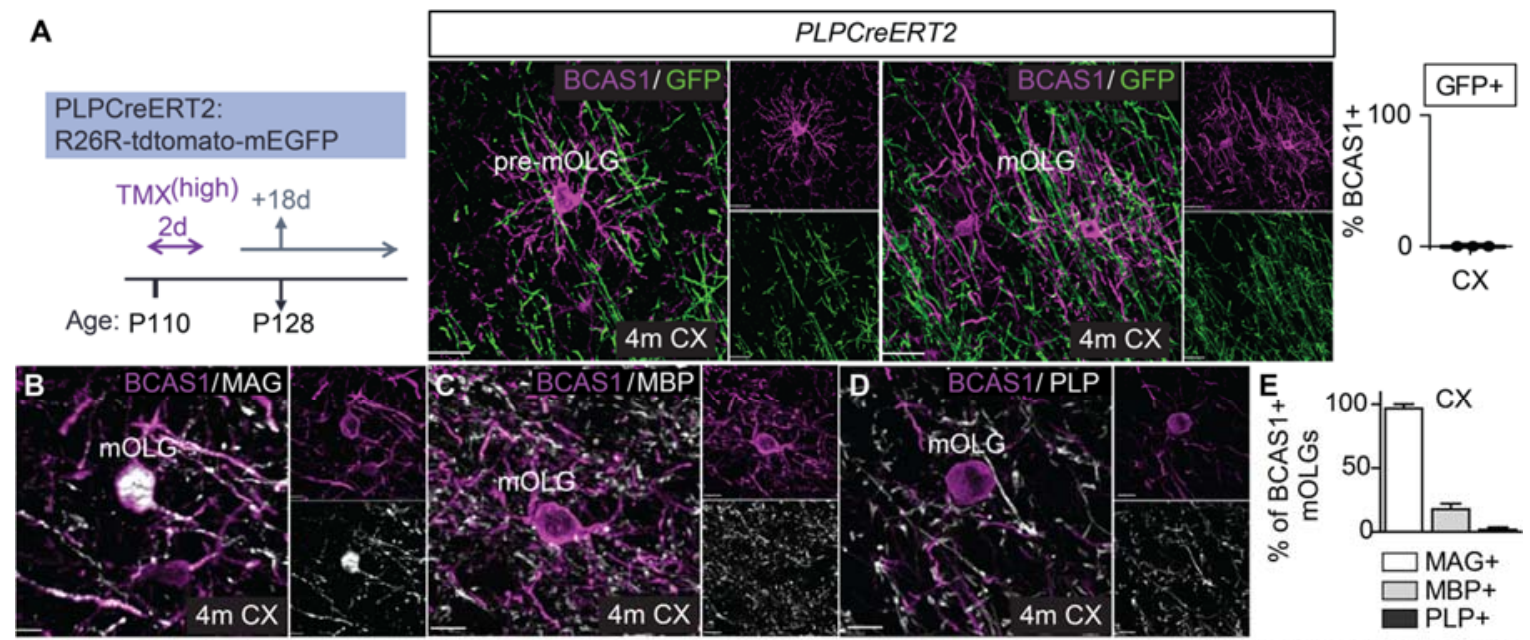

Figure.1.6. BCAS1 marks premature myelin forming oligodendrocytes in adult somatosensory cortex. (A) Left: Experimental design: tamoxifen (TMX) was used at P110 to induce the expression of mEGFP in oligodendrocytes in PLP-CreERT2:R26Rtdtomato-mEGFP mice as illustrated in the scheme. GFP expression was analyzed 18 days after TMX injection. Middle: Confocal images show GFP-/BCAS1+ premyelinating (pre-mOLGs) and myelin-forming (mOLGs) oligodendrocytes in somatosensory cortex of adult mice. Right: Quantification of BCAS1 and GFP double positive cells in somatosensory cortex shows no overlap between GFP and BCAS1 expression. Scale bar, 20 $\mu \mathrm{m} . \mathrm{CX}=$ somatosensory cortex; $\mathrm{n}=3 ; 3$ sections per animal. Quantitative data are represented as mean \pm SEM. (B-D) Confocal images show (B) MAG, (C) MBP, (D) and PLP expression in BCAS1+ myelin forming oligodendrocytes (mOLGs) in somatosensory cortex of wildtype 4-month-old mice. Scale bar, $15 \mu \mathrm{m}$. (E) Quantifications show percentage of BCAS1+ cells myelin-forming oligodendrocytes (mOLGs) with T-shaped segments in somatosensory cortex coexpressing MAG, PLP or MBP. CX = somatosensory cortex; $n=3 ; 3$ sections per animal. Quantitative data are represented as mean \pm SEM.

\subsection{BCAS1 expression downregulates in fully mature oligodendrocytes}

Our in vivo results suggested that BCAS1 expression up-regulation in newly formed oligodendrocytes is followed by marked down-regulation as cells fully mature. To verify this conclusion, we used primary cultures of oligodendrocytes to determine BCAS1 expression during oligodendrocyte differentiation. After 1-2 days in culture, oligodendrocyte progenitor cells start to differentiate into cells with multiple, symmetrically radiating star-shaped processes and cells with flat myelin-like membrane sheets. We first tested co-expression of BCAS1 together with MBP and O4, an antibody to recognize galactosylceramide/sulfatide commonly used to identify immature oligodendrocytes. Almost the entire population of process-forming $04^{+}(85.9 \% \pm 2.2$ SEM) oligodendrocytes expressed BCAS1 when the analysis was performed at 3 days in vitro (Figure.1.7. A). In contrast to $\mathrm{O} 4$ expression, BCAS1 was down-regulated after oligodendrocytes started to form sheets, whereas MBP expression increased as the cells matured (Figure.1.7. B). We also performed a "line scan" analysis in order to show localization of BCAS1 signal compared to MBP (in compacted domains of myelin) in 
sheet-forming oligodendrocytes at day 5 in vitro. The analysis showed that MBP and BCAS1 signal are rarely found together which indicates localization of these two proteins in different myelin domains (Figure.1.7. C).

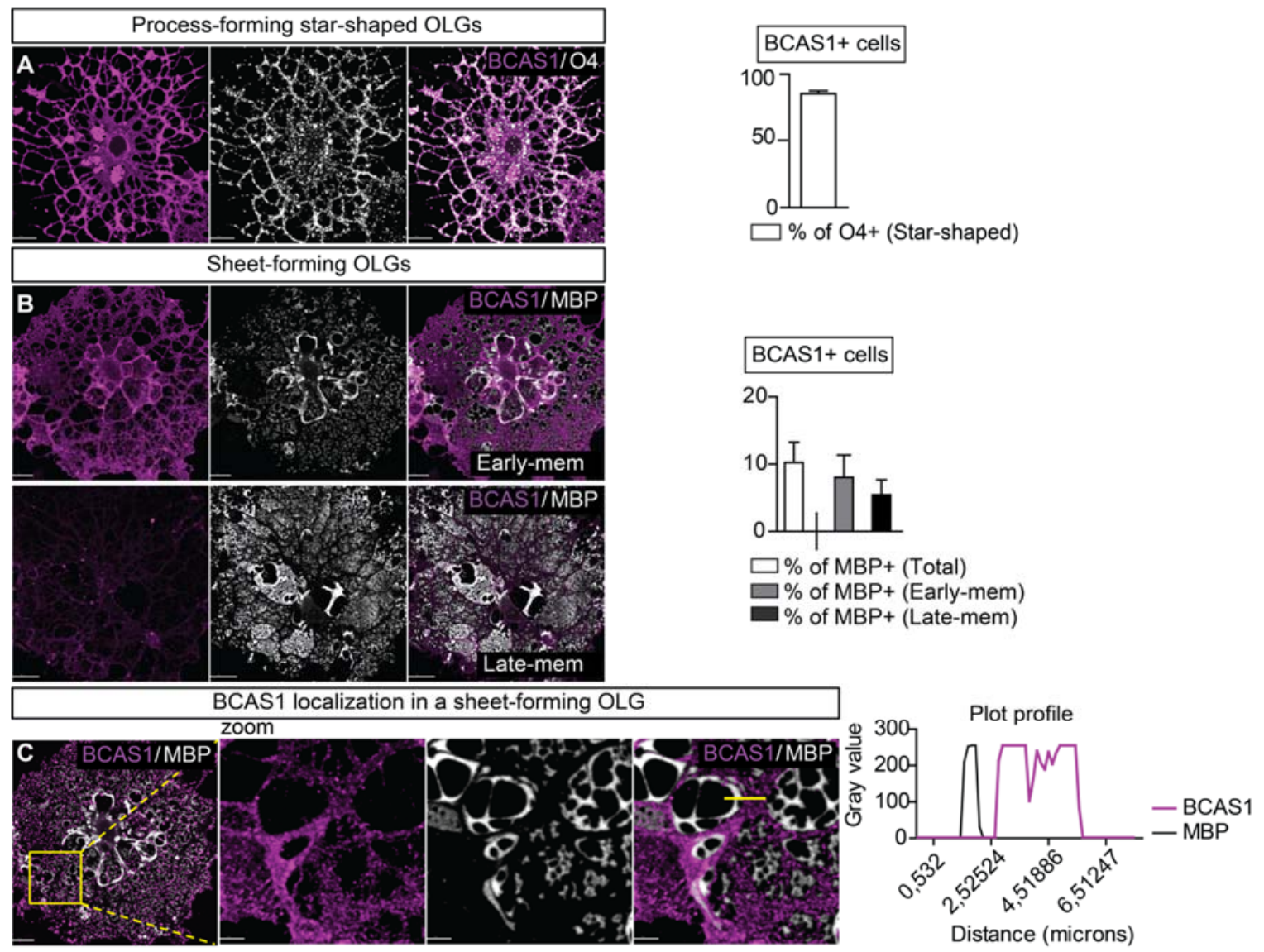

Figure.1.7. BCAS1 is downregulated in fully matured oligodendrocytes prepared from mice (A) Left: confocal images of day 3 in vitro (DIV3) process-forming star-shaped oligodendrocytes labeled with $\mathrm{O} 4$ and BCAS1 in primary mouse oligodendrocyte. Right: quantification show \% of star-shaped $04+$ cells positive for BCAS1. Scale bar, 10 $\mu \mathrm{m}$. (B) Left: confocal images show BCAS1 and MBP expression in day 5 in vitro sheet-forming mouse. Cells were categorized into two groups: cells with small membrane sheets without cytoplasmic veins (early-mem) and into cells with membrane sheets with cytoplasmic veins (latemem). Right: quantification show \% BCAS1+ cells in total MBP+ cells, in $\mathrm{MBP}+$ cells with early membrane and in MBP+ cells with late membrane morphology. Scale bar, $10 \mu \mathrm{m}$ (early-mem) and $20 \mu \mathrm{m}$ (late-mem). Student's two-tailed $t$ test, unpaired. $n=3$ replicates, for each replicate 3 different coverslips were analyzed. (108-203 total 04+ and 99-107 total MBP+ cells were analyzed). Quantitative data are represented as mean \pm SEM. (C) Confocal image show BCAS1 and MBP co-labeling in a sheet-forming oligodendrocyte. Scale bar, $10 \mu \mathrm{m}$. Higher magnifications are shown for the boxed area. Scale bar, $3 \mu \mathrm{m}$. Quantification shows mean grey values for BCAS1 and MBP signals along the yellow line demonestrating different subcellular localization of BCAS1 and MBP.

\subsection{BCAS1 ${ }^{+}$myelin-forming cells are actively generated in adult corpus callosum}

Next, we used 5-ethynyl-2'-deoxyuridine (EdU) proliferation assay and followed the progenies of divided cells at different time-points during 40 days of chase. EdU is a thymidine analog which incorporates into dividing cells during the administration period. 
We applied EdU for 10 days via the drinking water to 4-month-old mice and analyzed the brain sections $0,7,18$ and 40 days post labeling (Figure.1.8. A). When we quantified the number of the $\mathrm{BCAS1}^{+}$cells incorporated EdU right after the labeling (day0) we found as many as ( $65 \% \pm 2.7 \mathrm{SEM}$ ) of the cells were EdU-positive in corpus callosum and only few (12.1 \% $\pm 1.5 \mathrm{SEM}$ ) in somatosensory cortex (Figure.1.8. B). When the analysis was performed after 40-days of a 'chase' hardly any EdU ${ }^{+}$BCAS1 $1^{+}$cells $(7.7 \% \pm 1.3$ SEM) were left in corpus callosum, while the fraction of $\mathrm{EdU}^{+} / \mathrm{BCAS} 1^{+}$cells increased slightly (17.9 \% $\pm 1.1 \mathrm{SEM}$ ) in somatosensory cortex (Figure.1.8. C). In addition, we quantified EdU incorporation in $\mathrm{CC}^{+}$pool of oligodendrocytes. CC1 constitutively labels mature oligodendrocytes, therefore allowed us to test whether dilution of EdU labeling over time could affect the results during the time course of our experiment. We found that while the number of $\mathrm{EdU}^{+} / \mathrm{CC1}^{+} / \mathrm{BCAS1}^{-}$cells increased over time (at day 18), the number of $\mathrm{EdU}^{+} / \mathrm{CC1}^{+} / \mathrm{BCAS1}^{+}$cells, decreased (Figure.1.8. C). These results not only exclude the possibility of EdU dilution influencing the results in our set up, also confirmed our previous conclusion about transient expression of BCAS1 in oligodendrocytes. We observed no alterations in EDU incorporation when premyelinating, and myelin-forming pools of $\mathrm{BCAS}^{+}$cells were analyzed separately (Figure.1.8. E,F). These results suggest active generation of $\mathrm{BCAS}^{+}$cells only in corpus callosum and not in cortex.
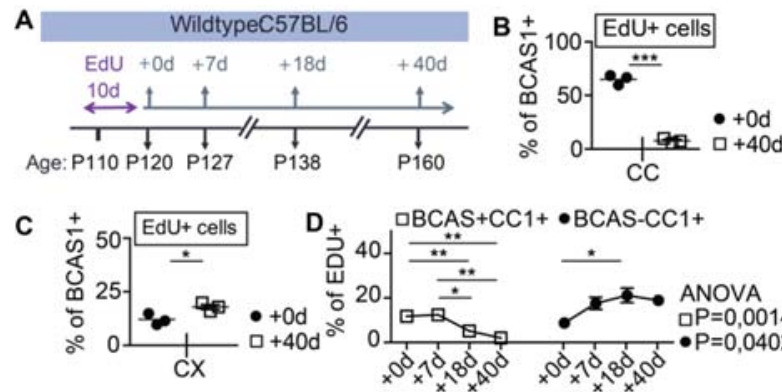

Days after EdU
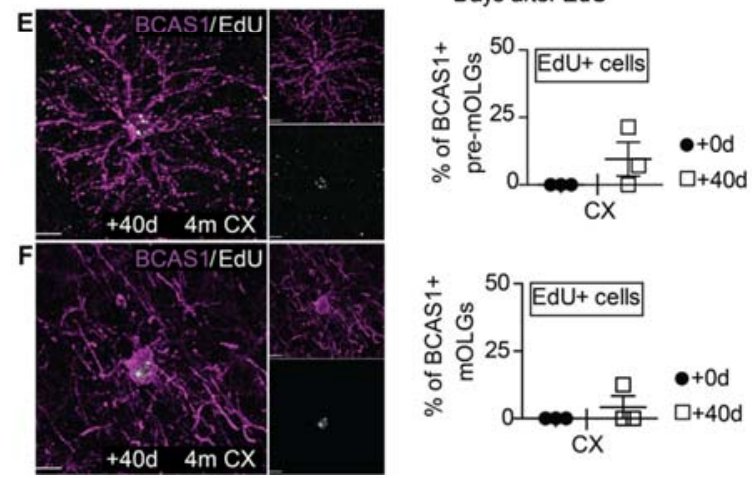

Figure.1.8. BCAS1+ myelin forming cells are actively generated in adult corpus callosum. (A) Experimental design: EdU was administered to 4-monthold mice via drinking water for 10 days and analyses were performed $10(+0 d), 17(+7 d), 28(+18 d)$ and $50(+40 d)$ days after EdU treatment. (B, C) Quantifications show the percentage of EdU+/BCAS1+ cells directly ( 0 days) and 40 days after the end of the treatment. CX=Somatosensory cortex. CC=Corpus callosum. Student's two-tailed t test, unpaired, ${ }^{*} p<0.05,{ }^{* * *} p<0.001$. (D) Line graphs show the fraction of EDU+CC1+ oligodendrocytes that were either BCAS1+ or BCAS1- plotted versus the time after the end of the EdU exposure in corpus callosum. One-way ANOVA, followed by Newman Kuel's post hoc test, ${ }^{*}$ p $<0.05,{ }^{* *}$ $p<0.01$. (E, F) Left: confocal images show EdU incorporation in BCAS1+ (E) premyelinating and (F) myelin forming oligodendrocytes 40 days after EdU treatment ended in somatosensory cortex of 4-month-old mice. Right: quantifications show the percentage of EdU+/BCAS1+ (E) premOLG and (F) mOLG directly ( 0 days) and 40 days after EdU administration was ended. Scale bar, $15 \mu \mathrm{m}$. Student's two-tailed $t$ test, unpaired, for all experiments $n=3,3$ sections per animal. Quantitative data are presented as mean \pm SEM. 


\subsection{BCAS1 ${ }^{+}$myelin-forming cells are slowly generated in adult somatosensory cortex}

Due to limitation in EdU proliferation assay (e.g., EdU labeling dilution in long chase experiment), we could not further explore the dynamics $B C A S 1^{+}$cells using this setup. Hence we used another approach and took advantage of a triple transgenic mouse line "Sox10-iCreERT2;Esco2fl/fl;CAG-EGFP" mouse line to further investigate the rate of $\mathrm{BCAS1}^{+}$oligodendrocyte generation in cortex. "Sox10-iCreERT2; Esco2wt/wt;CAG-EGFP" mice were used for control experiments. For simplicity, we refer to these mice as Sox10Esco2wt and Sox10-Esco2fl mice. Using these mice, we could label the recombined cells permanently and at the same time ablate and proliferating oligodendrocyte progenitor cells $(39,40)$. We applied tamoxifen in adult 6-8 weeks old animals to induce Cre recombination in SOX10-expressing cells (specific for oligodendrocyte lineage). Recombined cells then start to express GFP while the Establishment Of Sister Chromatid Cohesion N-Acetyltransferase 2 (Esco2) is depleted. Esco2 deletion results in a detrimental block of the cohesion apparatus. Therefore, proliferation of the recombined cells in these mice is followed by apoptosis. We quantified the number of $\mathrm{GFP}^{+} / \mathrm{BCAS1}^{+}$ oligodendrocytes in mouse brain sections 6 and 16 weeks after tamoxifen administration (Figure.1.9. A). We analyzed the premyelinating and myelin-forming pool of $\mathrm{BCAS1}^{+}$cell separately. We found that the number of $\mathrm{GFP}^{+}$cells did not differ in either of the BCAS1 ${ }^{+}$ pools 6 weeks post-induction (Figure.1.9. B,C). Although no alterations were found between Sox10-Esco2wt and Sox10-Esco2fl mice, when the analysis was performed later, at 16 weeks after induction, a marked reduction in the number of $\mathrm{GFP}^{+}$cells was observed in both pools (premyelinating $\mathrm{BCAS}^{+}$cells: reduction from $92.1 \% \pm 3.1 \mathrm{SEM}$ in Esco2-wildtype to $29.5 \% \pm 1.3 \mathrm{SEM}$ in the Esco2-floxed animals) and (myelin-forming $\mathrm{BCAS1}^{+}$cells: reduction from 97.6 \% $\pm 2.4 \mathrm{SEM}$ in Esco2-wildtype to $13.9 \% \pm 7.3 \mathrm{SEM}$ in Esco2-floxed animals) (Figure.1.9. B-E). These results clearly indicate that even though in the cortex $\mathrm{BCAS1}^{+}$oligodendrocytes represent a transient cell population and are continuously generated from proliferating oligodendrocyte progenitor cells in adult animals, they have a much longer lifetime in the intermediate stage of lineage when compared to the corpus callosum. 
A

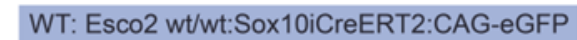

FL: Esco2 fl/fl:Sox10iCreERT2:CAG-eGFP

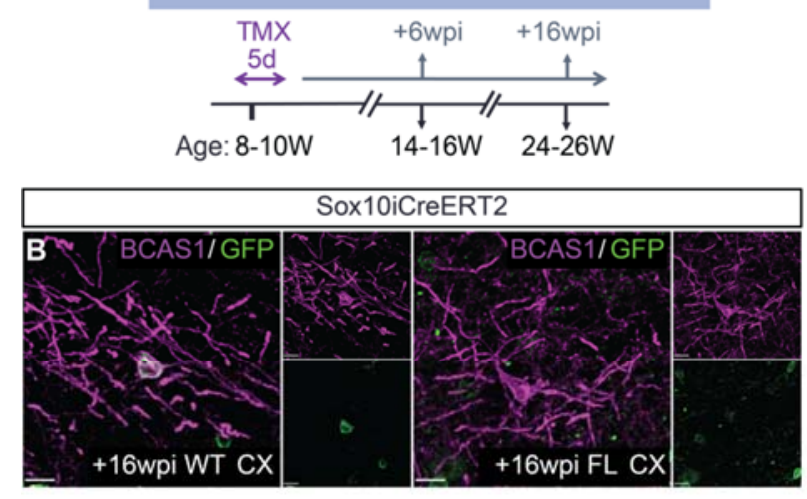

C

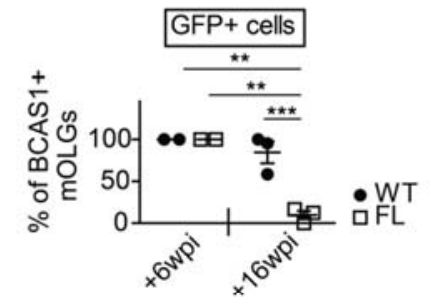

Sox10iCreERT2

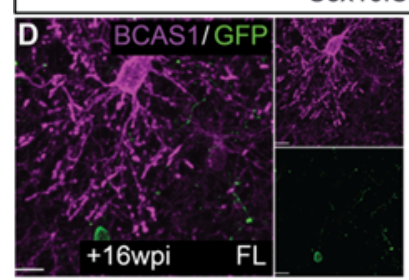

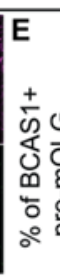

Figure.1.9. BCAS1+ myelin forming cells are slowly generated in adult somatosensory cortex. (A) Experimental design: tamoxifen (TMX) was administered orally in 8-10 week old animals and analyses were performed 6 and 16 weeks post Cre recombination induction. (B) Confocal images show GFP expression in BCAS1+ myelin-forming oligodendrocytes 16 weeks post tamoxifen treatment in somatosensory cortex of transgenic mice. Scale bar, $15 \mu \mathrm{m}$. (C) Quantification show the percentage of BCAS1+ myelin-forming oligodendrocytes (mOLGs) that are positive for GFP at 6 and 16 weeks post induction (wpi) in the somatosensory cortex. Student's two-tailed t test, unpaired, ${ }^{* *} \mathrm{p}<0.01,{ }^{* * *} \mathrm{p}<0.001$. P value, $6 \mathrm{wpi} / \mathrm{WT}$ vs. $16 \mathrm{wpi} / \mathrm{KO}, \mathrm{P}=0.0028,6 \mathrm{wpi} / \mathrm{KO}$ vs. $16 \mathrm{wpi} / \mathrm{KO}$, $\mathrm{P}=0.0028,16 \mathrm{wpi} / \mathrm{WT}$ vs. $16 \mathrm{wpi} / \mathrm{KO}, \mathrm{P}=0.0004$. (D) Confocal images show GFP expression in BCAS1+ premyelinting oligodendrocytes (pre-mOLGs) 16 weeks post tamoxifen treatment in somatosensory cortex of transgenic mice. (E) Quantification show the percentage of $\mathrm{BCAS1}+$ pre-myelinating oligodendrocytes (pre-mOLGs) that are positive for GFP at 6 and 16 weeks post induction (wpi) in the somatosensory cortex. Scale bar, $15 \mu \mathrm{m}$. Student's two-tailed t test, unpaired, ${ }^{* *} p<0.01, * * * p<0.001$. $* * * \mathrm{p} \leq 0.001$. $\mathrm{P}$ value, $6 \mathrm{wpi} / \mathrm{WT}$ vs. $16 \mathrm{wpi} / \mathrm{KO}$, $\mathrm{P}=0.0001,6 \mathrm{wpi} / \mathrm{KO}$ vs. $16 \mathrm{wpi} / \mathrm{KO}, \mathrm{P}=0.0001$, $16 \mathrm{wpi} / \mathrm{WT}$ vs. $16 \mathrm{wpi} / \mathrm{KO}, \mathrm{P}=0.0003$. $\mathrm{CX}=$ somatosensory cortex; for all quantifications, $n=3$ (only for +6 wpi group $n=2$ ), 3 sections per animal. Quantitative data are represented as mean \pm SEM.

\subsection{Transient expression of BCAS1 provides a tool to map}

\section{oligodendrogenesis}

Our cell culture results and in vivo experiment using PLP-EGFP mice and EDU labeling confirm our conclusion that BCAS1 transiently labels oligodendrocytes before they fully mature (Figure.1.10. A). We compared BCAS1 expression with many other different oligodendroglia markers (01, O4, MAG, MBP, PLP, ENPP6 and CC1) in vivo to show its unique pattern of labeling which allow us to analyze individual newly formed oligodendrocytes (Figure.1.10. B). 


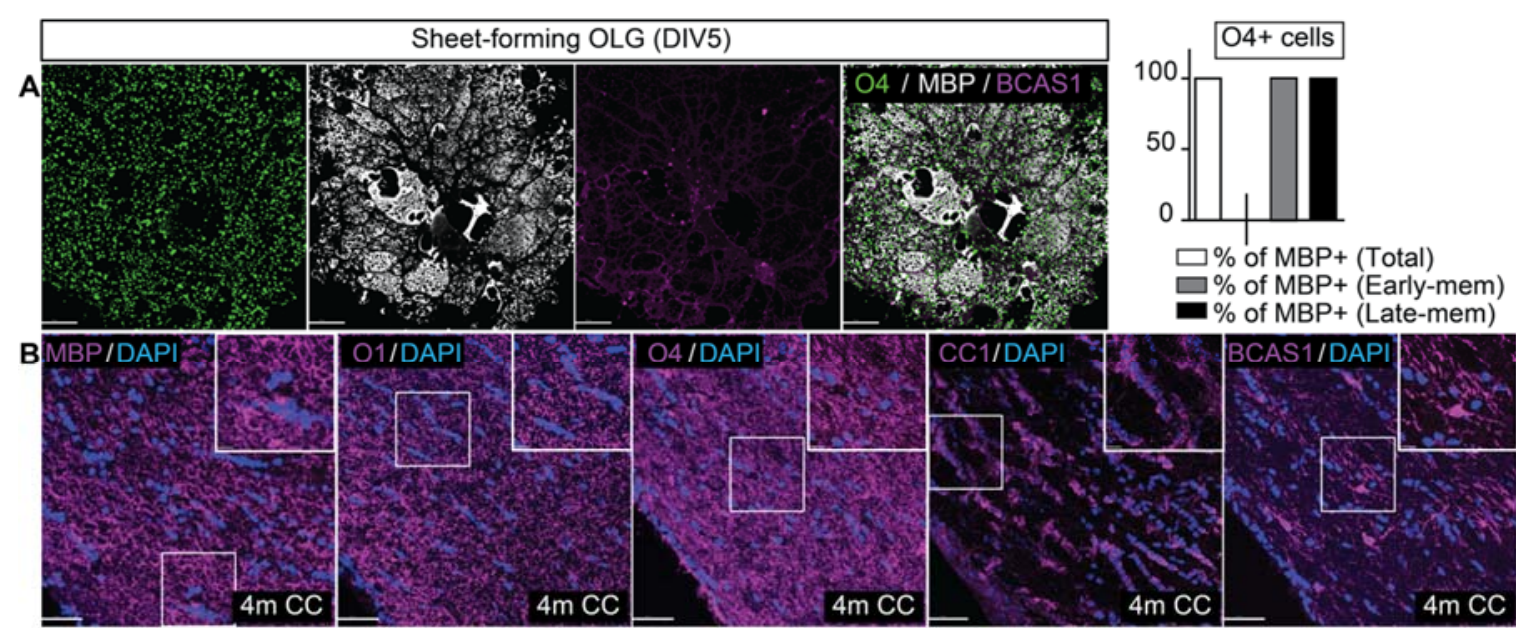

Figure.1.10. Transient expression of BCAS1 provides a tool to map oligodendrogenesis. (A) Left: confocal images show expression of $\mathrm{O} 4, \mathrm{MBP}$ and BCAS1 in sheet-forming primary oligodendrocytes prepared from mice. Right: quantification show \% $\mathrm{O} 4+$ cells in total $\mathrm{MBP}+$ cells, in $\mathrm{MBP}+$ cells with early membrane and in $\mathrm{MBP}+$ cells with late membrane morphology. Oligodendrocytes at 5 days in vitro were grouped into cells with membrane sheets without cytoplasmic veins (early-mem) and membrane sheets with cytoplasmic veins (late-mem). Scale bar, $10 \mu \mathrm{m}$, Quantitative data are represented as mean \pm SEM; $\mathrm{n}=3$ replicates, for each replicate 3 different coverslips were analyzed (99-107 MBP+ cells were analyzed). (B) Immunohistochemistry and confocal images of brain sections of adult mice (4months; corpus callosum) show co-labeling of the nuclear marker DAPI with different oligodendroglia markers (MBP, O1, 04, CC1) and BCAS1.

\subsection{BCAS1 label a subpopulation of peri-neuronal oligodendrocyte in adult somatosensory cortex}

In order to further characterize $\mathrm{BCAS1}^{+}$cell population in adult mouse brains, we compared their density to $\mathrm{NG2}^{+}$oligodendrocyte progenitor cells in young (P40) and adult (4 months) animals in the white (corpus callosum) and grey matter (somatosensory cortex). Our quantification showed that similar cell densities for BCAS1 ${ }^{+}$ and $\mathrm{NG2}^{+}$oligodendrocyte progenitor cells at P40 and at 4 months (Figure.1.11. A). While in 4-month-old mice BCAS1-expressing cells in the corpus callosum reduced compared to younger animals (P40) (Figure.1.11. A), their abundance remained unchanged in somatosensory cortex of adult animals (Figure.1.11. A). Next, we determined both abundance and percentage of $\mathrm{BCAS}^{+}$premyelinating and myelinforming oligodendrocytes up to old age (21-month-old mice) in the somatosensory. Quantifications revealed that the density of $\mathrm{BCAS1}^{+}$myelin-forming oligodendrocytes decreased from P40 to adult ( 4 and 7 months) and from adult ( 4 and 7 months) to old (21 months) animals (Figure.1.11. B, C). We found $\mathrm{BCAS1}^{+}$premyelinating oligodendrocytes at lower densities compared to $\mathrm{BCAS1}^{+}$myelin-forming oligodendrocytes in the somatosensory cortex of young (P40) and adult (4 and 7 
months) mice compared to aged (21 months) mice (Figure.1.11. B, C). The abundance of premyelinating cells was similar in young (P40) and adult (4 and 7 months) animals and only decreased in old (21 months) mice (Figure.1.11. B, C). When we further compared the percentage of $\mathrm{BCAS1}^{+}$cells with pre-myelinating and myelin-forming morphology over time, we found out that their percentages also decline, only, when we compared younger 4 months old adult with 7 and 21 months old animals, while the percentages were similar between P40 and 4 months old animals (Figure.1.11. B, C). These results suggested declined generation of pre-myelinating and myelin-forming oligodendrocytes in older (7 and 21 months) animals. Since cortical BCAS1 ${ }^{+}$cells were frequently found in deeper layers of cortex and according to our experiments represent and differentiated, but still pre-mature oligodendrocytes we tested whether these cells are the previously described peri-neuronal oligodendrocytes with similar reported characteristics $(10,11)$. We used NeuN (a general marker to label neuronal cell bodies) and BCAS1 immunostaining. Our qualifications showed that the cell bodies of almost half of the BCAS1-expressing cells are indeed localized attached to $\mathrm{NeuN}^{+}$cell bodies $\mathrm{n}$ somatosensory cortex (Figure.1.11. D). In order to explore if these neurons belong to a specific type of neurons, we used different neuronal markers. Co-labeling of cortical sections with antibodies against BCAS1 and Tbr1 (a marker which labels mainly glutamatergic neurons) revealed that around $50 \%$ of $\mathrm{BCAS}^{+}$cells are attached to cell bodies of $\mathrm{Tbr}^{+}$neurons (Figure.1.11. D). Similar results were observed when the analysis was performed individually for the myelin-forming pool of $\mathrm{BCAS1}^{+}$cells (Figure.1.11. D). 

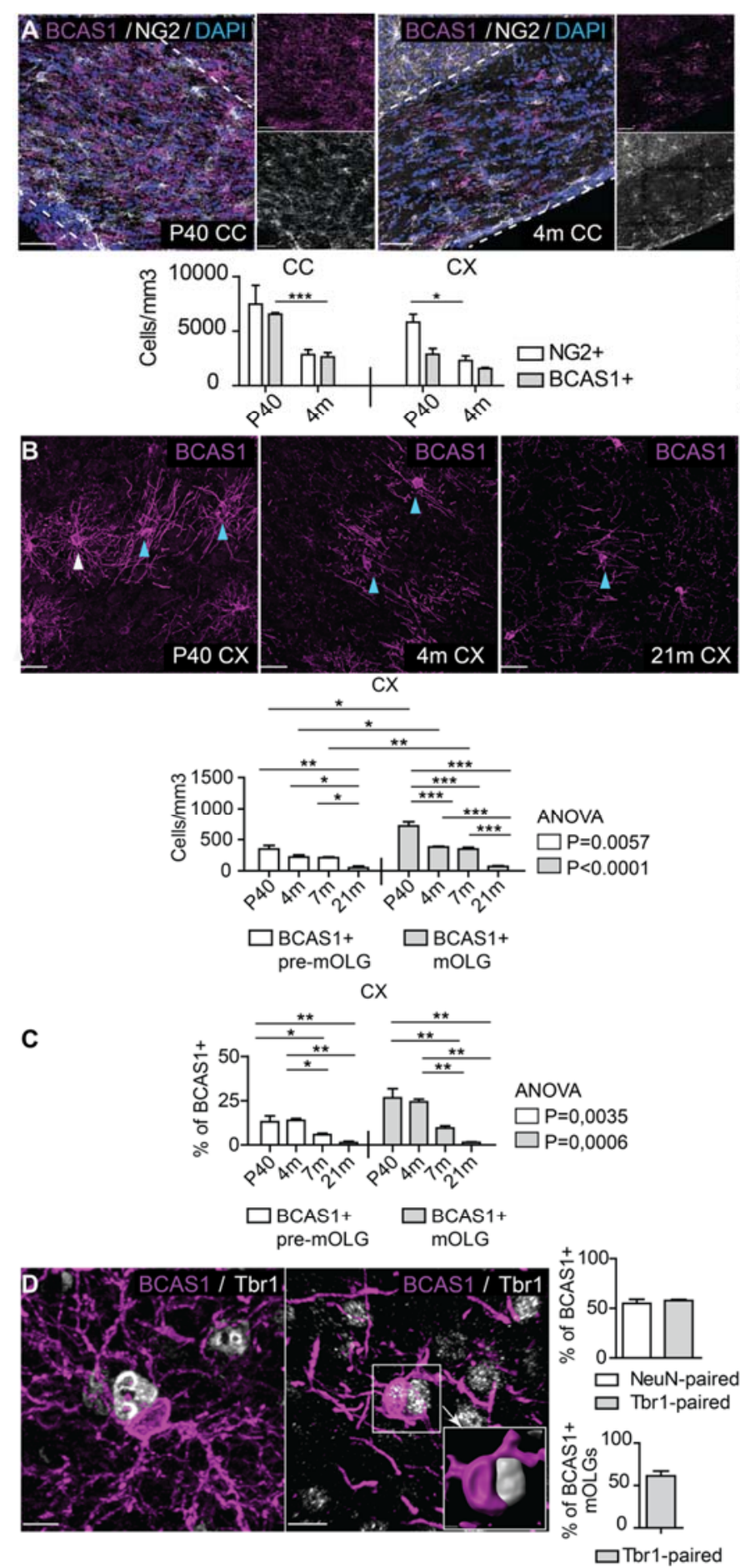

Figure.1.11. Peri-neuronal BCAS1+ oligodendrocytes in somatosensory cortex. (A) Right: Confocal images show BCAS1/NG2/DAPI immunolabelling at P40 and at 4 months in the corpus callosum in mice. Dotted lines represent the border of white and grey matter. Scale bar, $50 \mu \mathrm{m}$. Left: Quantification show density of $\mathrm{NG}^{+}+$and BCAS1 + cells in P40 and 4-month-old mouse corpus callosum (CC, left) and somatosensory cortex ( $C X$, right). Student's two-tailed $t$ test, unpaired, $* p<0.05, * * * p<0.001, n=3,3$ sections per animal. Quantitative data are presented as mean \pm SEM. (B) Confocal images and quantification show BCAS1+ premyelinating (pre-mOLGs) and myelin forming oligodendrocytes (mOLGs) in the somatosensory cortex of P40, 4-, 7-, and 21-months-old mice. Scale bar, 30 $\mu \mathrm{m}$. White and blue arrows indicate BCAS1+ pre-mOLG and BCAS1+ mOLGs respectively. One-way ANOVA, followed by Newman-Keuls' post hoc test, ${ }^{*} \mathrm{p}<0.05, * * \mathrm{p}<0.01$. Student's two-tailed $\mathrm{t}$ test to compare BCAS1+ pre-mOLG vs. BCAS1+ mOLG group, unpaired, $* p<0.05,{ }^{* * *} p<0.001$. $C X=$ somatosensory cortex; $n=3$, 3 sections per animal. (C) Quantifications show percentage of BCAS1+ cells with premyelinating (premOLG) and myelin forming (mOLG) morphology in the somatosensory cortex of P40, 4-, 7-, and 21-months-old mice. Oneway ANOVA, followed by Newman-Keuls' post hoc test, ${ }^{*} \mathrm{p}<0.05, * * \mathrm{p}<0.01$. $\mathrm{CX}=$ somatosensory cortex; $n=3,3$ sections per animal. (D) Left: Confocal images show localization of BCAS1+ and BCAS1+ myelin forming oligodendrocytes attached to Tbr1+ neurons in somatosensory cortex of 4 months old mice. Right: Quantifications show percentage of perineuronal $(\mathrm{NeuN}+$ and Tbr1+ neurons) BCAS1+ oligodendrocytes and percentage of perineuronal (Tbr1+ neurons) BCAS1+ myelin forming oligodendrocytes in somatosensory cortex of 4 months old mice. 


\section{Exceptional characteristics of myelin proteins}

The second aim of this study was to determine the turnover rate of myelin proteins by in vivo labeling of myelin proteins and mass spectrometry. Adult (4 months) and old (18 and 26 months) mice were fed for 30 or 60 days with a diet containing the stable ${ }^{13} \mathrm{C}$ isotope incorporated in lysines ( ${ }^{13} \mathrm{C}$-lysines). We also included young ( 1 month) mice, a time-point when myelination is surely actively ongoing, as a positive control group to our study. After 30 and 60 days, mouse brains were collected, and two different fractions ("myelin-enriched" and "myelin-depleted") were prepared for further analysis by mass spectrometry. We also used our proteomics results to characterize myelin proteome lists obtained by mass spectrometry.

\subsection{Biochemical isolation of myelin proteins}

To prepare the samples for mass spectrometry, we used well described biochemical isolation of myelin. Briefly, myelin fraction was obtained from two-step sucrose gradient followed by ultracentrifugation. We isolated myelin from total brain homogenate with the protocol previously described and extensively used $(24,26)$. To prepare the "myelinenriched" fraction, we collected both the lightweight material accumulating in the interphase of $0,32 \mathrm{M}$ and $0,85 \mathrm{M}$ sucrose after the first ultracentrifugation. We also collected the pellet for preparation of a control fraction which was depleted from myelin, "myelin-depleted" fraction.

After collecting the lightweight interphase which is supposedly enriched with compacted myelin, we subjected it to one additional round of isolation and repeated all the steps to purify it. Hereafter, we refer to this fraction as "myelin-enriched" or "light" fraction. Then, we subjected the pellet (obtained from the first ultracentrifugation) to 4 extra myelin isolation or purification rounds. In each round, we repeated all the steps and collected pellet and not interphase. By using this approach in principle we tried to exclude myelin from our sample as much as possible. We refer to this fraction as "myelin-depleted" or "heavy" fraction (Figure.2.1. A). Next, we employed mass spectrometry to investigate protein content of these two fractions. 


\subsection{Purity of "myelin-enriched" fraction}

When we compared the proteome of "light" and "heavy" fractions, we found that $88.9 \%$ of proteins were found (in $\geq 80 \%$ of our samples) in the "light" fraction were also frequently (in $\geq 80 \%$ of samples) found in "heavy" fraction (Figure.2.1. B) suggesting that as expected many of the proteins found in "light" fraction might represnt contaminants. Therefore, we decided to characterize our proteomics list further before we analyze our results for the turnover rate of myelin proteins.

First, we checked to find the most abundant proteins of each fraction. Then we compared the top 100 most abundant proteins in each fraction to get rid of the contaminants with low abundance. This analysis reduced the overlap between the two pools from 88.9 to $48 \%$. Axonal proteins such as neurofilament $(\mathrm{Nfl}, \mathrm{Nfm}$, and $\mathrm{Nfl})$ were found among the most abundant proteins of "light" as well as "heavy" fraction, even though they evidently do not belong to myelin structure (Figure.2.1. C).The complete list of top 100 most abundant proteins of "light" and "heavy" fractions are presented in tables 1 and 2 respectively.

We then analyzed the cellular localization of "light" and "heavy" fraction proteins to test how the fractionation may alter enrichment or depletion of specific cellular structures. We found that the two fractions are very similar even in terms of their cellular components including proteins of mitochondria, plasma membrane, cytosol, and nucleus. However, "extracellular exosomes" were exceptional in this analysis as they appeared to be more enriched in the "light" compared to "heavy" fraction (60\% of the proteins in "light" vs. $40 \%$ in "heavy")(Figure.2.1. D). Our analysis showed that fractionation clearly isolates and enriches the proteins with similar floating properties; however, they may not be specifically myelin proteins. 
A

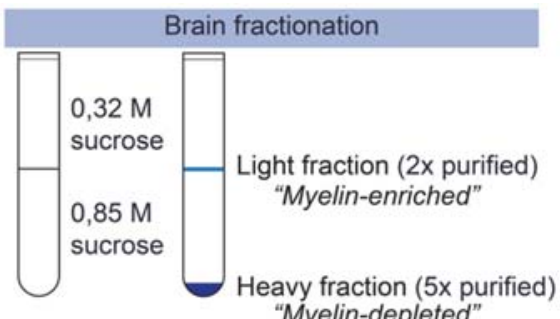

"Myelin-depleted"

B Proteins found in both fractions

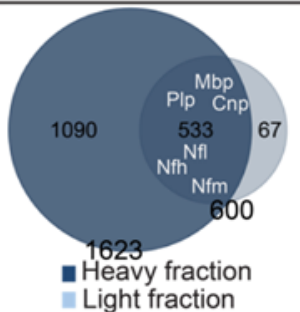

C Top 100 abundant proteins

D

Cellular localization

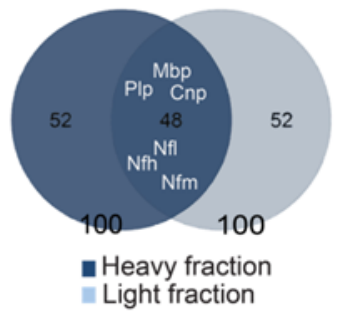

Figure.2.1. Biochemical isolation of myelin is a crude approach to identify myelin proteins. (A) Experimntal design: mouse brains hemogenized in $0.32 \mathrm{M}$ sucrose were subjected to discontinues sucrose density ultracentrifugation. Interface and pellet after first ultracentrifugation were both collected and respectvely subjected to one and four extra rounds of ultracentrifugations in order to prepare pure "light" or "myelinenriched" and "heavy" or "myelindepleted" fractions. (B) Venn digram shows the overlap between proteins that are often identified using mass spectrometry in "light" and "heavy" fraction, including classical myelin proteins: Plp, Mbp and Cnp as well as axonal proteins: $\mathrm{Nfh}, \mathrm{Nfm}$ and $\mathrm{Nfl}$. (C) Venn digram shows the overlap between top 100 most abundant proteins in "light" and "heavy" fraction, including classical myelin proteins: Plp, Mbp and Cnp as well as axonal proteins: Nfh, Nfm and Nfl. (D) Bar graph show cellular localization of proteins in "light" and "heavy" fractions. 
Table1. Top 100 most abundant proteins in "light" fraction

\begin{tabular}{|r|l|l|r|r|}
\hline Rank & Uniprot ID & $\begin{array}{c}\text { Gene } \\
\text { names }\end{array}$ & $\begin{array}{c}\text { Number of } \\
\text { times detected } \\
\text { in "light" } \\
\text { fraction (\%) }\end{array}$ & $\begin{array}{c}\text { Intensity in } \\
\text { "light" fraction } \\
\text { (a.u.) }\end{array}$ \\
\hline 1 & P60202 & Plp1 & 100.00 & 24149.75247 \\
\hline 2 & P04370 & Mbp & 100.00 & 7907.912534 \\
\hline 3 & P16330 & Cnp & 100.00 & 7764.716235 \\
\hline 4 & Q6PIC6 & Atp1a3 & 100.00 & 3282.022015 \\
\hline 5 & P02088 & Hbb-b1 & 100.00 & 1935.814924 \\
\hline 6 & P01942 & Hba & 100.00 & 1391.412104 \\
\hline 7 & Q60771 & Cldn11 & 100.00 & 1183.084464 \\
\hline 8 & P14094 & Atp1b1 & 100.00 & 1027.386058 \\
\hline 9 & P15532 & Nme1 & 100.00 & 730.6909757 \\
\hline 10 & P05213 & Tuba1b & 100.00 & 704.2122894 \\
\hline 11 & P08553 & Nefm & 100.00 & 677.5518495 \\
\hline 12 & P05202 & Got2 & 100.00 & 625.8158622 \\
\hline 13 & Q9D2P8 & Mobp & 100.00 & 590.1330528 \\
\hline 14 & Q8VDQ8 & Sirt2 & 100.00 & 579.7782082 \\
\hline 15 & P08551 & Nefl & 100.00 & 561.5045083 \\
\hline 16 & P62874 & Gnb1 & 100.00 & 477.8268929 \\
\hline 17 & P18872 & Gnao1 & 100.00 & 450.315113 \\
\hline 18 & P60710 & Actb & 100.00 & 403.1817351 \\
\hline 19 & P68372 & Tubb4b & 100.00 & 397.0457374 \\
\hline 20 & P16858 & Gapdh & 100.00 & 389.2579393 \\
\hline 21 & P46660 & Ina & 100.00 & 384.4507929 \\
\hline 22 & O08599 & Stxbp1 & 100.00 & 382.0758886 \\
\hline 23 & P20917 & Mag & 100.00 & 365.7768011 \\
\hline 24 & P15105 & Glul & 100.00 & 346.971745 \\
\hline 25 & P48962 & Slc25a4 & 100.00 & 318.1367872 \\
\hline 26 & Q8VDN2 & Atp1a1 & 100.00 & 303.4503778 \\
\hline 27 & P62631 & Eef1a2 & 100.00 & 278.1579349 \\
\hline 28 & P13595 & Ncam1 & 100.00 & 270.2125325 \\
\hline 29 & P08249 & Mdh2 & 98.77 & 252.0069783 \\
\hline 30 & P40142 & Tkt & 100.00 & 229.1871563 \\
\hline 31 & P56480 & Atp5b & 100.00 & 225.5993182 \\
\hline 32 & P62761 & Vsn1 & 100.00 & 220.0514934 \\
\hline & & & 100.00 & 210.0716065 \\
\hline
\end{tabular}




\begin{tabular}{|r|l|l|r|r|}
\hline 34 & P16546 & Sptan1 & 100.00 & 209.7632632 \\
\hline 35 & P05064 & Aldoa & 100.00 & 209.3269244 \\
\hline 36 & Q03265 & Atp5a1 & 100.00 & 194.1515535 \\
\hline 37 & Q5SYD0 & Myo1d & 100.00 & 186.3906896 \\
\hline 38 & O08553 & Dpys12 & 100.00 & 171.1279681 \\
\hline 39 & P46460 & Nsf & 100.00 & 168.1246599 \\
\hline 40 & P63318 & Prkcg & 100.00 & 162.9381818 \\
\hline 41 & Q7TQD2 & Tppp & 100.00 & 161.286692 \\
\hline 42 & P35700 & Prdx1 & 100.00 & 156.9241957 \\
\hline 43 & Q60932 & Vdac1 & 100.00 & 153.8576043 \\
\hline 44 & P62984 & Uba52;Rp & 100.00 & 145.2405736 \\
\hline 45 & Q62261 & Sptbn1 & 100.00 & 141.0461534 \\
\hline 46 & P39054 & Dnm2 & 100.00 & 140.7861326 \\
\hline 47 & P14824 & Anxa6 & 100.00 & 139.8106165 \\
\hline 48 & P62897 & Cycs & 100.00 & 138.6244403 \\
\hline 49 & P19246 & Nefh & 100.00 & 137.9252146 \\
\hline 50 & P39053 & Dnm1 & 100.00 & 135.3701595 \\
\hline 51 & O88935 & Syn1 & 100.00 & 133.4133051 \\
\hline 52 & P06745 & Gpi & 100.00 & 131.2272334 \\
\hline 53 & P63017 & Hspa8 & 100.00 & 130.3775497 \\
\hline 54 & P12960 & Cntn1 & 100.00 & 111.1819792 \\
\hline 55 & Q61885 & Mog & 100.00 & 110.5425503 \\
\hline 56 & Q99KI0 & Aco2 & 100.00 & 107.4189521 \\
\hline 57 & P35762 & Cd81 & 100.00 & 104.9783921 \\
\hline 58 & Q9Z1G3 & Atp6v1c1 & 100.00 & 103.8346135 \\
\hline 59 & Q68FD5 & Cltc & 100.00 & 99.91141121 \\
\hline 60 & P17182 & Eno1 & 100.00 & 97.20769418 \\
\hline 61 & Q9JHU4 & Dync1h1 & 100.00 & 96.2996022 \\
\hline 62 & Q01768 & Nme2 & 100.00 & 95.85493407 \\
\hline 63 & P55012 & Slc12a2 & 100.00 & 93.48250407 \\
\hline 64 & P68404 & Prkcb & 100.00 & 92.67428039 \\
\hline 65 & P10649 & Gstm1 & 100.00 & 91.73716428 \\
\hline & P50516 & Atp6v1a & 100.00 & 89.98680832 \\
\hline & & & \\
\hline
\end{tabular}




\begin{tabular}{|r|l|l|r|r|}
\hline 67 & P16460 & Ass1 & 100.00 & 86.79419323 \\
\hline 68 & P09671 & Sod2 & 100.00 & 85.5281999 \\
\hline 69 & Q64332 & Syn2 & 100.00 & 83.45350258 \\
\hline 70 & P62835 & Rap1a & 100.00 & 83.19180483 \\
\hline 71 & O55131 & 42620 & 100.00 & 82.89762117 \\
\hline 72 & Q8CHH9 & 42621 & 100.00 & 82.65239911 \\
\hline 73 & P62880 & Gnb2 & 100.00 & 81.92148895 \\
\hline 74 & Q99P72 & Rtn4 & 100.00 & 76.48977181 \\
\hline 75 & Q9QXY6 & Ehd3 & 100.00 & 76.14621583 \\
\hline 76 & P84096 & Rhog & 100.00 & 76.1280368 \\
\hline 77 & Q922J6 & Tspan2 & 100.00 & 75.20330808 \\
\hline 78 & B2RSH2 & Gnai1 & 100.00 & 74.4146316 \\
\hline 79 & P21279 & Gnaq & 100.00 & 69.06814159 \\
\hline 80 & P51881 & Slc25a5 & 100.00 & 68.990429 \\
\hline 81 & Q80YN3 & Bcas1 & 100.00 & 68.71163579 \\
\hline 82 & O70318 & Epb41/2 & 100.00 & 67.09485284 \\
\hline 83 & Q91X97 & Ncald & 96.30 & 66.78348358 \\
\hline 84 & Q60930 & Vdac2 & 100.00 & 66.75231265 \\
\hline 85 & P62259 & Ywhae & 96.30 & 65.40957747 \\
\hline 86 & P62482 & Kcnab2 & 100.00 & 65.3984259 \\
\hline 87 & Q8BH59 & Slc25a12 & 100.00 & 65.24066827 \\
\hline 88 & P60766 & Cdc42 & 100.00 & 65.15871622 \\
\hline 89 & Q61879 & Myh10 & 100.00 & 65.14866527 \\
\hline 90 & Q9DB77 & Uqcrc2 & 100.00 & 62.93312126 \\
\hline 91 & Q8VEM8 & Slc25a3 & 100.00 & 62.88166226 \\
\hline 92 & Q04447 & Ckb & 100.00 & 62.24718637 \\
\hline 93 & Q9QYR6 & Map1a & 100.00 & 60.88564847 \\
\hline 94 & P97370 & Atp1b3 & 100.00 & 60.45838601 \\
\hline 95 & P68369 & Tuba1a;T & 100.00 & 58.86923875 \\
\hline 96 & P40240 & Cd9 & 100.00 & 58.72869642 \\
\hline 97 & Q810U3 & Nfasc & 100.00 & 58.51660744 \\
\hline 98 & Q9R0K7 & Atp2b2 & 100.00 & 58.4054152 \\
\hline 99 & P61264 & Stx1b & 100.00 & 57.63972312 \\
\hline 100 & P63001 & Rac1;Rac: & 100.00 & 57.05668119 \\
\hline & & & & \\
\hline
\end{tabular}


Table2. Top 100 most abundant proteins in "heavy" fraction

\begin{tabular}{|c|c|c|c|c|}
\hline Rank & Uniprot ID & $\begin{array}{c}\text { Gene } \\
\text { names }\end{array}$ & $\begin{array}{c}\text { Number of } \\
\text { times detected } \\
\text { in "heavy" } \\
\text { fraction (\%) }\end{array}$ & $\begin{array}{l}\text { Intensity in } \\
\text { "heavy" fraction } \\
\text { (a.u.) }\end{array}$ \\
\hline 1 & P48962 & Slc25a4 & 100.00 & 2136.176449 \\
\hline 2 & P56480 & Atp5b & 100.00 & 2120.708965 \\
\hline 3 & Q6PIE5 & Atp1a2 & 100.00 & 2079.443691 \\
\hline 4 & Q03265 & Atp5a1 & 100.00 & 1672.641786 \\
\hline 5 & Q6PIC6 & Atp1a3 & 100.00 & 1585.482183 \\
\hline 6 & P60202 & Plp1 & 100.00 & 1564.281134 \\
\hline 7 & P02088 & $\mathrm{Hbb}-\mathrm{b} 1$ & 100.00 & 1393.533974 \\
\hline 8 & P01942 & $\mathrm{Hba}$ & 100.00 & 1378.558627 \\
\hline 9 & Q60932 & Vdac1 & 100.00 & 1180.834946 \\
\hline 10 & 008599 & Stxbp1 & 100.00 & 1016.762692 \\
\hline 11 & P16330 & Cnp & 100.00 & 949.3181362 \\
\hline 12 & P08249 & Mdh2 & 100.00 & 888.8893281 \\
\hline 13 & P62806 & Hist1h4a & 100.00 & 883.3361748 \\
\hline 14 & P14094 & Atp1b1 & 100.00 & 874.4483663 \\
\hline 15 & P51881 & Slc25a5 & 100.00 & 751.1070005 \\
\hline 16 & P62631 & Eef1a2 & 100.00 & 739.1911231 \\
\hline 17 & P43006 & Slc1a2 & 100.00 & 722.6950618 \\
\hline 18 & 088935 & Syn1 & 100.00 & 718.8851691 \\
\hline 19 & P05202 & Got2 & 100.00 & 711.4234155 \\
\hline 20 & P17710 & Hk1 & 100.00 & 684.4723583 \\
\hline 21 & Q99KIO & Aco2 & 100.00 & 651.8015519 \\
\hline 22 & Q60930 & Vdac2 & 100.00 & 591.1000703 \\
\hline 23 & P16858 & Gapdh & 100.00 & 583.4517387 \\
\hline 24 & P08553 & Nefm & 100.00 & 574.6573334 \\
\hline 25 & Q8VEM8 & SIc25a3 & 100.00 & 539.569119 \\
\hline 26 & P04370 & $\mathrm{Mbp}$ & 100.00 & 514.240743 \\
\hline 27 & P11798 & Camk2a & 100.00 & 488.2377628 \\
\hline 28 & P63260 & Actg1 & 100.00 & 486.6768555 \\
\hline 29 & P68372 & Tubb4b & 100.00 & 472.4293229 \\
\hline 30 & P43274 & Hist1h1e & 100.00 & 470.9305321 \\
\hline 31 & P08551 & Nefl & 100.00 & 468.8189111 \\
\hline 32 & P46660 & Ina & 100.00 & 454.2738127 \\
\hline 33 & P18872 & Gnao1 & 100.00 & 446.6172597 \\
\hline
\end{tabular}




\begin{tabular}{|r|l|l|r|r|}
\hline 34 & P05064 & Aldoa & 100.00 & 443.5508248 \\
\hline 35 & P52480 & Pkm & 100.00 & 434.6503417 \\
\hline 36 & Q9DB77 & Uqcrc2 & 100.00 & 425.5370181 \\
\hline 37 & Q8BH59 & Slc25a12 & 100.00 & 406.2727727 \\
\hline 38 & Q8VN2 & Atp1a1 & 100.00 & 403.5500343 \\
\hline 39 & O08749 & Dld & 100.00 & 360.1659458 \\
\hline 40 & P03995 & Gfap & 100.00 & 350.554776 \\
\hline 41 & P16546 & Sptan1 & 100.00 & 347.148641 \\
\hline 42 & P26443 & Glud1 & 100.00 & 335.529416 \\
\hline 43 & P35802 & Gpm6a & 100.00 & 326.8664375 \\
\hline 44 & Q91VR2 & Atp5c1 & 100.00 & 324.3544843 \\
\hline 45 & P46460 & Nsf & 100.00 & 315.9036613 \\
\hline 46 & Q62261 & Sptbn1 & 100.00 & 315.8374341 \\
\hline 47 & P62874 & Gnb1 & 100.00 & 308.6266589 \\
\hline 48 & Q64332 & Syn2 & 100.00 & 296.9959012 \\
\hline 49 & Q91VD9 & Ndufs1 & 100.00 & 296.8758929 \\
\hline 50 & G5E829 & Atp2b1 & 100.00 & 287.4945773 \\
\hline 51 & Q68FD5 & Cltc & 100.00 & 277.1383512 \\
\hline 52 & P39053 & Dnm1 & 100.00 & 273.856221 \\
\hline 53 & P15105 & Glul & 100.00 & 269.8771063 \\
\hline 54 & O08553 & Dpys12 & 100.00 & 268.802855 \\
\hline 55 & Q60931 & Vdac3 & 100.00 & 266.0229099 \\
\hline 56 & Q7TSJ2 & Map6 & 100.00 & 249.5048109 \\
\hline 57 & P14231 & Atp1b2 & 100.00 & 245.9045616 \\
\hline 58 & P63038 & Hspd1 & 100.00 & 239.342014 \\
\hline 59 & Q8CAQ8 & Immt & 100.00 & 232.5850095 \\
\hline 60 & Q8BMF4 & Dlat & 100.00 & 231.065323 \\
\hline 61 & Q60771 & Cldn11 & 100.00 & 229.4364871 \\
\hline 62 & P30275 & Ckmt1 & 100.00 & 229.0799905 \\
\hline 63 & Q9CZU6 & Cs & 100.00 & 227.7300968 \\
\hline 64 & Q9DB20 & Atp5o & 100.00 & 224.7575218 \\
\hline 65 & P46096 & Syt1 & 100.00 & 223.3041767 \\
\hline 66 & P62983 & Rps27a & 100.00 & 222.8706167 \\
\hline & & & & \\
\hline
\end{tabular}




\begin{tabular}{|r|l|l|r|r|}
\hline 67 & Q9CZ13 & Uqcrc1 & 100.00 & 221.5491551 \\
\hline 68 & P63017 & Hspa8 & 100.00 & 211.1791126 \\
\hline 69 & O88343 & Slc4a4 & 100.00 & 209.1686594 \\
\hline 70 & Q9D051 & Pdhb & 100.00 & 206.2857196 \\
\hline 71 & P10922 & H1f0 & 100.00 & 192.2098753 \\
\hline 72 & P61264 & Stx1b & 100.00 & 188.6057894 \\
\hline 73 & Q9DCX2 & Atp5h & 100.00 & 188.2378172 \\
\hline 74 & Q64521 & Gpd2 & 100.00 & 185.6696394 \\
\hline 75 & Q9WUM5 & Suclg1 & 100.00 & 180.2351242 \\
\hline 76 & P13595 & Ncam1 & 100.00 & 179.5393958 \\
\hline 77 & Q9CQQ7 & Atp5f1 & 100.00 & 178.4431067 \\
\hline 78 & Q9CR62 & Slc25a11 & 100.00 & 177.3109636 \\
\hline 79 & Q8K2B3 & Sdha & 100.00 & 174.1343403 \\
\hline 80 & O55143 & Atp2a2 & 100.00 & 169.8530809 \\
\hline 81 & P63011 & Rab3a & 100.00 & 166.5884325 \\
\hline 82 & P19246 & Nefh & 100.00 & 162.9953768 \\
\hline 83 & Q91YT0 & Ndufv1 & 100.00 & 160.8048541 \\
\hline 84 & Q9R0K7 & Atp2b2 & 100.00 & 159.891946 \\
\hline 85 & Q9DBG3 & Ap2b1 & 100.00 & 157.4969181 \\
\hline 86 & P58281 & Opa1 & 100.00 & 156.3967468 \\
\hline 87 & Q62277 & Syp & 100.00 & 153.2683094 \\
\hline 88 & P31650 & Slc6a11 & 100.00 & 151.4847416 \\
\hline 89 & Q62108 & Dlg4 & 100.00 & 145.4184415 \\
\hline 90 & P12960 & Cntn1 & 100.00 & 142.2284585 \\
\hline 91 & Q9D0M3 & Cyc1 & 100.00 & 141.7116577 \\
\hline 92 & Q9Z1G4 & Atp6v0a1 & 100.00 & 139.539062 \\
\hline 93 & P28652 & Camk2b & 100.00 & 138.1137949 \\
\hline 94 & Q91V14 & Slc12a5 & 100.00 & 136.5423026 \\
\hline 95 & Q99LC3 & Ndufa10 & 100.00 & 130.4074916 \\
\hline 96 & Q8CHC4 & Synj1 & 100.00 & 128.0172024 \\
\hline 97 & Q9QZQ8 & H2afy & 100.00 & 124.0913207 \\
\hline 98 & Q8BMS1 & Hadha & 100.00 & 118.7163072 \\
\hline 99 & P06745 & Gpi & 100.00 & 118.0162397 \\
\hline 100 & Q9CPQ8 & Atp5I & 100.00 & 117.2811175 \\
\hline & & & & \\
\hline
\end{tabular}




\subsection{Myelin proteins are exceptionally long-lived}

One of the very well accepted characteristics of myelin protein is their remarkable stability and hence their very long lifespan. A recent study using in vivo stable isotope labeling with amino acids in rats showed that myelin proteins are even among the most long-lived proteins in brain(30). As described previously and as demonstrated in Figure.2.2.A the feeding of mice with SILAC food was performed and mouse brains were collected for further fractionation processes. Lifetime of proteins was calculated using ratio of ${ }^{13} \mathrm{C}$-lysines incorporated into proteins to the amount of native ${ }^{12} \mathrm{C}$-lysines.

We found proteins with relatively long half-life ( $\geq 30$ days) not only in "light" but also in "heavy" fraction. For simplicity we showed only the top 50 most long-lived proteins of each fraction in figure.2.2.B (Figure.2.2. B). Our analysis showed that classical myelin proteins are indeed among the top 50 long-lived proteins of both fractions reconfirming the exceptional long lifespan of these proteins. Unexpectedly, we observed classical myelin proteins in both brain fractions and more surprisingly we observed that some of them had different half-time in a fraction-dependent manner (Figure.2.2. B), an interesting observation that we would discuss in later sections.

Nevertheless, our analysis also revealed that "light" fraction to be more enriched with slow turnover proteins compared to "heavy" fraction ( 25\% of proteins in "light," 9\% of proteins in "heavy" fraction were long-lived $\geq 30$ days) (Figure.2.2. C). We determined cellular localization of these proteins. Our analysis indicated that although long-lived proteins are found in various cellular localizations they are particularly found in "extracellular exosomes" and "mitochondria" (Figure.2.2. C). 
A
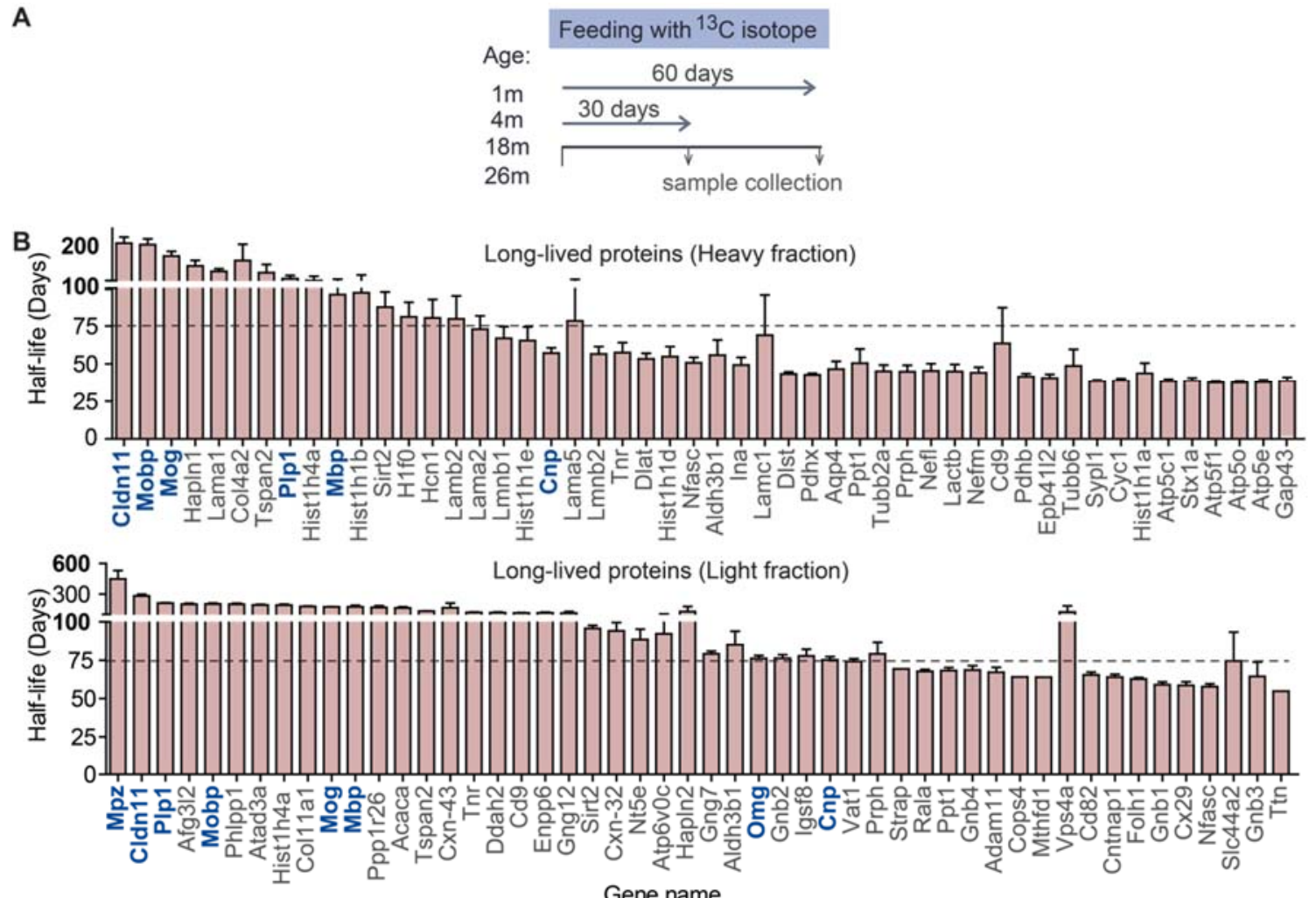

C

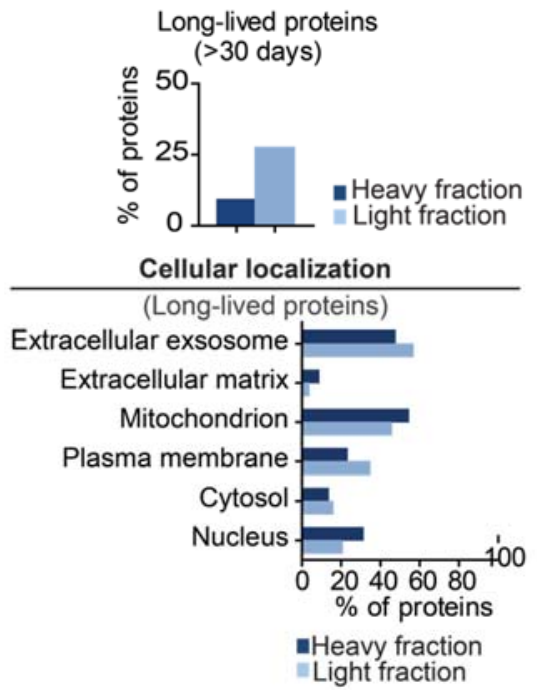

Figure.2.2. Myelin proteins are exceptionally longlived. (A) Experimental design: 1-, 4-, 18- and 26-month-old mice were fed with a diet containing lysine labeled with $13 \mathrm{C}$ (13C-lysines). After 30 or 60 days (feeding period), brains were collected and used for preparation of "light" and "heavy" fraction. Using mass spectrometry analysis the $13 \mathrm{C} / 12 \mathrm{C}$ ratio and half-life of proteins were calculated. Error bars indicate $95 \%$ confidence interval. (B) Top: bar graph shows the most (top 50) long-lived proteins in "heavy" fraction. Bottom: bar graph shows the most (top 50) longlived proteins in "light" fraction. Classical myelin proteins including Plp, Mbp and $\mathrm{Cnp}$ are in both lists, however with different half-lives. (C) Top: bar graph shows percentages of long-lived (minimum = 30 days) proteins of "light" compared to "heavy" fraction. Bottom: bar graph shows cellular localization of both fractions long-lived proteins.

\subsection{Myelin proteins are enriched in "light" fraction}

In order to investigate the effect of fractionation in the proteome content, we also analyzed enrichment of proteins in each fraction. To determine proteins enriched in "light" fraction we used the signal intensities obtained by mass spectrometry for each individual protein from each fraction and then divided the intensities from "light" fraction to the intensities from "heavy" fraction for each given protein to calculate an index for enrichment as reported in table 3. It is of course self-evident that this analysis was only feasible for proteins found in both fractions. To gain a better resolution about 
proteins enriched in "light" fraction we decided to focus on proteins with higher abundance as low abundance by nature could lead to high enrichment index while it most likely would not be biologically significant. To clarify what this means the reader should imagine an analysis for proteins $A$ and $B$ for which signal intensity obtained by mass spectrometry in "light" and "heavy" fraction was respectively 4 and 2 and 2000 and 1000. The calculated enrichment index in "light" fraction for both proteins A and B in this analysis would be 2 , although the analysis for protein $B$ may be more interesting for data mining purposes as it may represent a more prominent biological importance. Therefore, we compared the most abundant proteins (top 100) with the most enriched proteins (top 100) of "light" fraction to find which proteins are both abundant and enriched in the "light" fraction. There was only a very small overlap (27\%) between the two groups (Figure.2.3. A). This analysis indeed showed that many of the proteins frequently found in myelin proteome lists are indeed very abundant but not enriched in this fraction. The best example of these proteins may be the neurofilaments ( $\mathrm{Nfl}, \mathrm{Nfm}$, and $\mathrm{Nfl}$ ) which are all classical axonal proteins frequently reported as a part of myelin proteome $(26,41)$. Using this approach, we also observed exclusion of many of mitochondrial proteins which were in fact one of the major contaminations of myelin isolation protocol (Figure.2.3. B).

A

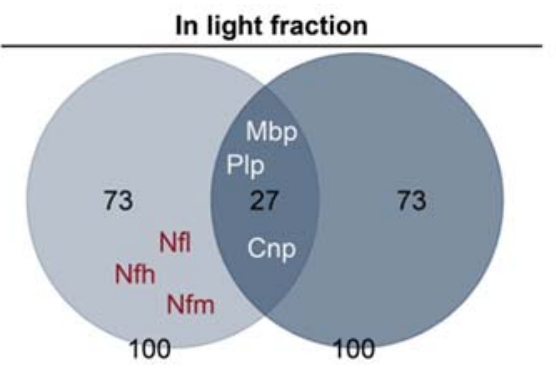

B

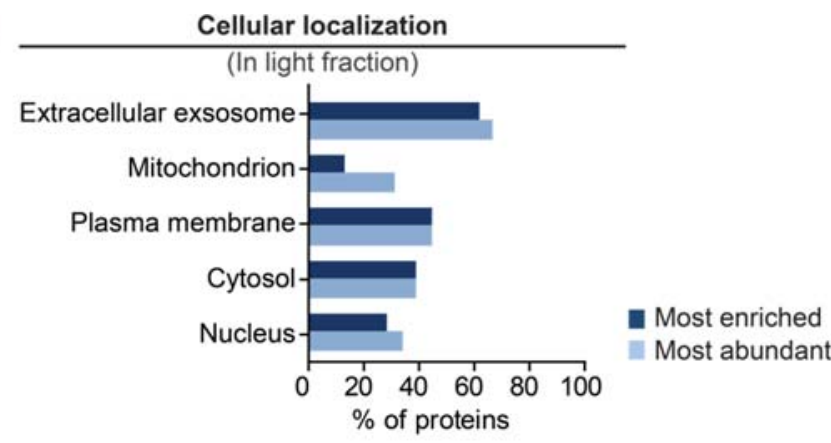

Figure.2.3. Myelin proteins are enriched in "light" fraction. (A) The most (top 100) abundant and most (top $100)$ enriched proteins of "light" fraction were identified using the intensities obtained by mass spectrometry. Venn digram shows the overlap between the most abundant (top 100) and the most enriched (top 100) proteins of "light" fraction indicating high abundance, but not enrichment of axonal proteins; Nfh, $\mathrm{Nfm}$ and $\mathrm{Nfl}$ in "light" fraction, while classical myelin proteins; Mbp, Plp, and Cnp are both abundant and enriched. (B) Bar graph shows cellular localization of top 100 abundant and enriched proteins in "light" fraction. Bar graph shows lower percentage of mitochondrial proteins (one of the most frequent non-myelin contaminant of "light" fraction) in top 100 enriched poroteins. 
Table3. Enrichment index for the top $\mathbf{1 0 0}$ most enriched proteins in "light" fraction

\begin{tabular}{|c|c|c|c|c|c|}
\hline Rank & Uniprot ID & Gene names & \begin{tabular}{|c|}
$\begin{array}{c}\text { Intensity in } \\
\text { "light" fraction } \\
\text { (a.u.) }\end{array}$ \\
\end{tabular} & $\begin{array}{c}\text { Intensity in } \\
\text { "heavy" fraction } \\
\text { (a.u.) }\end{array}$ & $\begin{array}{c}\text { Enrichment } \\
\text { index in "light" } \\
\text { fraction }\end{array}$ \\
\hline 1 & P60710 & Actb & 403.1817351 & 1.371033729 & 294.0713467 \\
\hline 2 & Q08642 & Padi2 & 41.59067186 & 0.227661937 & 182.6861024 \\
\hline 3 & Q8R4V2 & Dusp15 & 19.73981207 & 0.255908656 & 77.13616411 \\
\hline 4 & P15532 & Nme1 & 730.6909757 & 10.98450783 & 66.52013788 \\
\hline 5 & Q01768 & Nme2 & 95.85493407 & 1.61033338 & 59.5249004 \\
\hline 6 & P16054 & Prkce & 14.03988329 & 0.294494225 & 47.6745624 \\
\hline 7 & Q91X97 & Ncald & 66.78348358 & 1.631272604 & 40.93949928 \\
\hline 8 & P20917 & Mag & 365.7768011 & 10.81919211 & 33.80814367 \\
\hline 9 & Q9WV80 & Snx1 & 7.444647471 & 0.248416221 & 29.96844342 \\
\hline 10 & Q8R3P0 & Aspa & 3.114365282 & 0.11070167 & 28.13295652 \\
\hline 11 & Q3USB7 & $\mathrm{Plcl} 1$ & 3.815853158 & 0.139496814 & 27.3544109 \\
\hline 12 & Q9D1G5 & Lrrc57 & 30.37473911 & 1.178930782 & 25.76465013 \\
\hline 13 & Q60790 & Rasa3 & 9.450200424 & 0.373677614 & 25.28971518 \\
\hline 14 & P63141 & Kcna2 & 44.06561849 & 1.832258546 & 24.04989109 \\
\hline 15 & P62761 & Vsnl1 & 220.0514934 & 9.428768529 & 23.33830688 \\
\hline 16 & Q8BGN3 & Enpp6 & 47.77650439 & 2.148452641 & 22.23763441 \\
\hline 17 & Q9JL62 & Gltp & 16.03128755 & 0.735497927 & 21.79650948 \\
\hline 18 & Q8VEJ9 & Vps4a & 19.08074717 & 0.894347365 & 21.33482795 \\
\hline 19 & Q6X893 & Slc44a1 & 21.94231998 & 1.04171323 & 21.06368562 \\
\hline 20 & 070172 & Pip4k2a & 5.959264332 & 0.291633893 & 20.43405951 \\
\hline 21 & Q5M8N0 & Cnrip1 & 20.68189945 & 1.042436591 & 19.83995921 \\
\hline 22 & A2APV2 & $\mathrm{Fmnl} 2$ & 14.45501939 & 0.760721631 & 19.00171995 \\
\hline 23 & P05213 & Tuba1b & 704.2122894 & 38.00241808 & 18.53072317 \\
\hline 24 & Q8BGZ1 & Hpcal4 & 12.18033045 & 0.660177584 & 18.45008183 \\
\hline 25 & P84096 & Rhog & 76.1280368 & 4.672103887 & 16.2941661 \\
\hline 26 & P60202 & Plp1 & 24149.75247 & 1564.281134 & 15.43824313 \\
\hline 27 & P04370 & Mbp & 7907.912534 & 514.240743 & 15.3778413 \\
\hline 28 & Q62465 & Vat1 & 17.24317519 & 1.152678097 & 14.95922864 \\
\hline 29 & Q5SYD0 & Myo1d & 186.3906896 & 12.73282451 & 14.63859723 \\
\hline 30 & Q9D2P8 & Mobp & 590.1330528 & 44.88931049 & 13.14640493 \\
\hline 31 & P34884 & Mif & 17.80336623 & 1.36946304 & 13.00025317 \\
\hline 32 & Q9QY42 & Gpr37 & 1.983427392 & 0.156971505 & 12.63558885 \\
\hline 33 & P62748 & Hpcal1 & 43.61192327 & 3.460081625 & 12.60430476 \\
\hline
\end{tabular}




\begin{tabular}{|c|c|c|c|c|c|}
\hline 34 & P16460 & Ass1 & 86.79419323 & 6.926156814 & 12.53136416 \\
\hline 35 & Q9WVK4 & Ehd1 & 18.69689618 & 1.495763785 & 12.49989896 \\
\hline 36 & Q8BNY6 & Ncs1 & 13.95877898 & 1.136099594 & 12.28658038 \\
\hline 37 & Q9D8B7 & Jam3 & 15.32731649 & 1.258104099 & 12.18286825 \\
\hline 38 & Q80V42 & Cpm & 16.28178955 & 1.417625271 & 11.48525629 \\
\hline 39 & P28867 & Prkcd & 1.62747606 & 0.143987134 & 11.30292697 \\
\hline 40 & Q5EBJ4 & Ermn & 29.07556776 & 2.675980903 & 10.86538687 \\
\hline 41 & P27573 & Mpz & 43.65519341 & 4.111314316 & 10.61830598 \\
\hline 42 & Q9D154 & Serpinb1a & 7.601124469 & 0.725557511 & 10.47625358 \\
\hline 43 & P68404 & Prkcb & 92.67428039 & 8.850937085 & 10.47056142 \\
\hline 44 & P28661 & Septin4 & 36.19710925 & 3.506773453 & 10.32205522 \\
\hline 45 & Q8VDQ8 & Sirt2 & 579.7782082 & 58.79393186 & 9.861191279 \\
\hline 46 & P20444 & Prkca & 10.45297049 & 1.066160641 & 9.804310988 \\
\hline 47 & Q80U19 & Daam2 & 9.792802333 & 1.031871635 & 9.490329998 \\
\hline 48 & P63028 & Tpt1 & 3.242675987 & 0.341890256 & 9.48455222 \\
\hline 49 & P13020 & Gsn & 23.31379739 & 2.575842133 & 9.050941861 \\
\hline 50 & P70452 & Stx4 & 5.522862115 & 0.611160298 & 9.036683386 \\
\hline 51 & Q921C1 & Gjc3 & 4.080355606 & 0.457956293 & 8.909923657 \\
\hline 52 & 009117 & Sypl1 & 21.65729085 & 2.463417755 & 8.791562374 \\
\hline 53 & P60843 & Eif4a1 & 1.017008035 & 0.117737743 & 8.637910075 \\
\hline 54 & P61027 & Rab10 & 54.37596869 & 6.341969839 & 8.573987275 \\
\hline 55 & P51910 & Apod & 3.795911925 & 0.445771207 & 8.515381582 \\
\hline 56 & Q8BR63 & Fam177a1 & 12.88468746 & 1.520017085 & 8.476672787 \\
\hline 57 & P16330 & Cnp & 7764.716235 & 949.3181362 & 8.179256183 \\
\hline 58 & Q91XV3 & Basp1 & 28.92141683 & 3.575272474 & 8.089290268 \\
\hline 59 & Q922J6 & Tspan2 & 75.20330808 & 9.343957016 & 8.048336261 \\
\hline 60 & Q9QYB1 & Clic4 & 10.17154182 & 1.293606218 & 7.862935168 \\
\hline 61 & P40237 & Cd82 & 22.95211894 & 2.954320781 & 7.769000267 \\
\hline 62 & Q9EQK5 & Mvp & 7.776249255 & 1.011693714 & 7.686367081 \\
\hline 63 & Q922B1 & Macrod1 & 1.712975239 & 0.228797383 & 7.48686553 \\
\hline 64 & Q8K406 & Lgi3 & 33.97654783 & 4.70555549 & 7.220517939 \\
\hline 65 & Q99PT1 & Arhgdia & 10.02046496 & 1.413550408 & 7.088862839 \\
\hline 66 & P61164 & Actr1a & 18.1064325 & 2.607216484 & 6.944736891 \\
\hline
\end{tabular}




\begin{tabular}{|c|c|c|c|c|c|}
\hline 67 & Q8BGX0 & Trim23 & 7.049526371 & 1.068134469 & 6.599849151 \\
\hline 68 & P63321 & Rala & 35.10204628 & 5.579560292 & 6.291185048 \\
\hline 69 & P63318 & Prkcg & 162.9381818 & 25.99600695 & 6.267815749 \\
\hline 70 & P62331 & Arf6 & 14.02246997 & 2.287917774 & 6.12892217 \\
\hline 71 & P55012 & Slc12a2 & 93.48250407 & 15.47126568 & 6.042330731 \\
\hline 72 & Q8C522 & Endod1 & 7.894940069 & 1.310724296 & 6.023341518 \\
\hline 73 & Q80Y17 & LIg|1 & 1.051569328 & 0.176055101 & 5.972955745 \\
\hline 74 & Q8K4ZO & Lgi2 & 11.72181991 & 1.980254483 & 5.919350273 \\
\hline 75 & Q60770 & Stxbp3 & 6.146386357 & 1.050493476 & 5.850951477 \\
\hline 76 & Q62433 & Ndrg1 & 14.68012036 & 2.528118993 & 5.806736313 \\
\hline 77 & Q61885 & Mog & 110.5425503 & 19.17826372 & 5.76394985 \\
\hline 78 & P05480 & Src & 13.18188051 & 2.293095021 & 5.748510373 \\
\hline 79 & Q9QXY6 & Ehd3 & 76.14621583 & 13.2798386 & 5.733971485 \\
\hline 80 & Q91W69 & Epn3 & 1.287594416 & 0.226117815 & 5.694351927 \\
\hline 81 & Q6PDLO & Dync1li2 & 2.535881258 & 0.447936295 & 5.66125426 \\
\hline 82 & P62835 & Rap1a & 83.19180483 & 14.93740341 & 5.569361859 \\
\hline 83 & P61750 & Arf4 & 1.669867389 & 0.302912505 & 5.512705358 \\
\hline 84 & P40240 & $\mathrm{Cd} 9$ & 58.72869642 & 11.09225577 & 5.294567457 \\
\hline 85 & Q61768 & Kif5b & 0.986090279 & 0.186736811 & 5.280642161 \\
\hline 86 & 035409 & Folh1 & 16.21013641 & 3.111309617 & 5.210068557 \\
\hline 87 & Q60771 & Cldn11 & 1183.084464 & 229.4364871 & 5.156479159 \\
\hline 88 & Q8C3W1 & & 1.281635348 & 0.25580028 & 5.010296891 \\
\hline 89 & Q91WA3 & Hdac11 & 3.937283613 & 0.790322798 & 4.981867688 \\
\hline 90 & P60766 & Cdc42 & 65.15871622 & 13.34701356 & 4.881894809 \\
\hline 91 & P35288 & Rab23 & 2.681357269 & 0.551905328 & 4.858364526 \\
\hline 92 & Q921E2 & Rab31 & 1.73189803 & 0.380284465 & 4.554217142 \\
\hline 93 & P48036 & Anxa5 & 28.94613834 & 6.505579644 & 4.44943263 \\
\hline 94 & Q9R0P9 & Uchl1 & 3.438418633 & 0.806069996 & 4.265657633 \\
\hline 95 & P62746 & Rhob & 34.84319362 & 8.330894608 & 4.182407203 \\
\hline 96 & P09528 & Fth1 & 16.70371862 & 4.012969382 & 4.162433606 \\
\hline 97 & P39054 & Dnm2 & 140.7861326 & 34.63317624 & 4.065065579 \\
\hline 98 & Q9R1V7 & Adam 23 & 42.04993104 & 10.36362526 & 4.057453831 \\
\hline 99 & P70122 & Sbds & 6.109691897 & 1.517855661 & 4.02521271 \\
\hline 100 & Q9Z1G3 & Atp6v1c1 & 103.8346135 & 26.4713666 & 3.922525613 \\
\hline
\end{tabular}




\subsection{Myelin proteins turover rate in different stage of mouse life}

One other characteristic of myelin proteins is how aging may affect turnover rate of myelin proteins. Myelin turnover rate at both cellular and molecular level has been a very interesting and important topic in myelin biology field. However due to complex and unique characteristics of it is not trivial at all and follows many challenges such as finding the best labeling approach, obtaining pure myelin, lack of enough knowledge about myelin proteins synthesis/degradation/trafficking machineries and etc. We used our best understanding to design our pulse-chase SILAC experiment to investigate turnover rate myelin proteins in different ages. Using our SILAC mice (as treated and describe in previous sections) we used the incorporation of ${ }^{13} \mathrm{C}$-lysines into proteins by mass spectrometry and calculated the synthesis rate of myelin proteins in mouse brain at different ages. We observed that while the ${ }^{13} \mathrm{C}-/{ }^{12} \mathrm{C}$-lysine ratio of neurofilaments were at similar levels when we compared adult ( 4 months) and aged (18 and 26 months) animals, the incorporation of the ${ }^{13} \mathrm{C}$-lysines into classical myelin proteins including Mbp, Plp and Cldn11 was much higher in 4 months- old mice in comparison to 18 and 26 month -old animals (Figure.2.4. A) This result indicated active synthesis of myelin proteins in adult brain which declines later in old (18- and 26-months) animals. Declined synthesis rate could reflect slower turnover of the proteins in aged animals, however it could also be caused by the continued growth and maturation of myelin which is completely independent from molecular turnover of myelin proteins. In order to test how substantial myelin grows in adult brain, we performed fate-mapping experiments on developmentally-born myelin-forming oligodendrocytes using the PLP-CreERT2 $x$ R26R-td-tomato-mEGFP reporter mice. From our other project (section 1 of this thesis) we already knew that new myelin-forming oligodendrocytes are continuedly added to myelin-forming population. Here we were also interested to know if the myelin content produced by the existing pool also undergoes maturation in adult brain. Therefore, we induced the expression EGFP by tamoxifen at P30 when myelination is actively ongoing and then technically tracked the fate of the developmentally-born oligodendrocytes. We followed these cells for up to 11 months of age and found an increase in EGFP signal intensity with time (Figure.2.4. B-E), even though quantification of the density of GFP+ cells in the somatosensory cortex did not show any alterations in total pool over the 11 months of chase (Figure.2.4. F-H). This result indicates that developmentally-born 
myelin-forming oligodendrocytes are not only exceptionally stable their maturation also extends into late-adulthood in mice. Therefore active synthesis of myelin proteins in adult brain is largely to provide myelin components for still growing myelin. Unfortunately due to extensive increase in myelin volume in adult brain, the synthesis rate of myelin proteins did not reach to their steady-state in our adult cohorts (4months followed by 1 or 2 months of SILAC feeding) therefore, we could not make any precise comment or evaluation on whether or not or how much aging may affect the turnover rate of myelin proteins. 

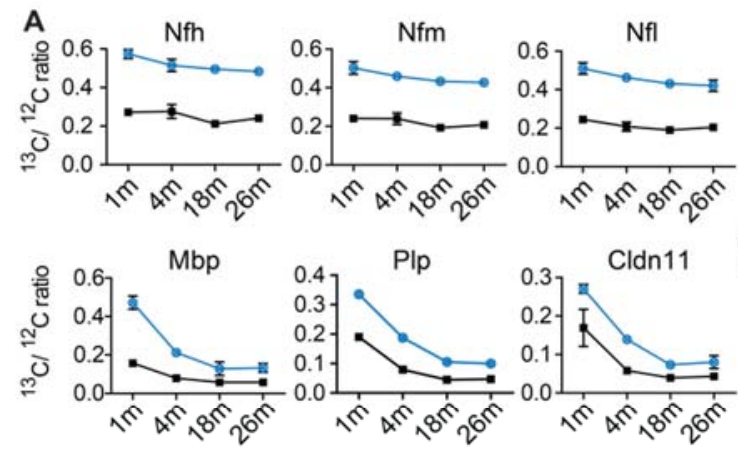

$\odot+60 d$

B

\section{PLPCreERT2: R26R-tdtomato-mEGFP}

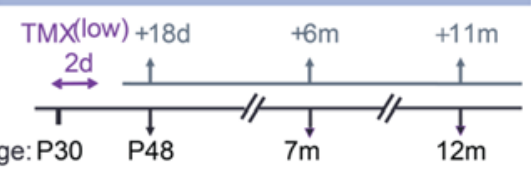
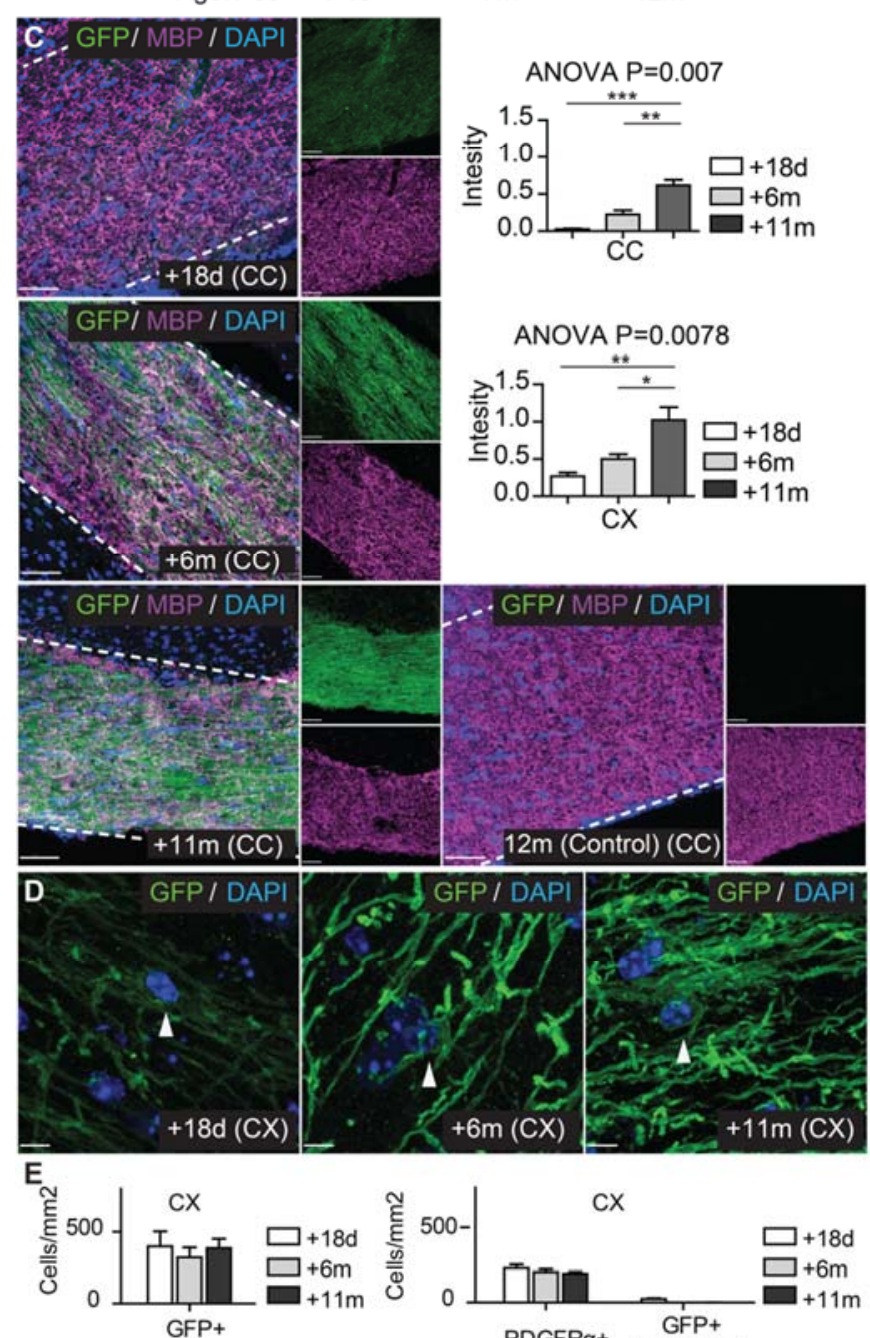

$\mathrm{CX}$

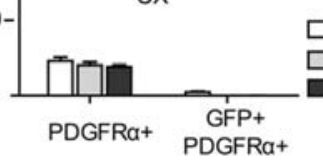

Figure.2.4

Maturation

of devlopmentaly-generated myelin sheets continues in adult brain. (A) The $13 \mathrm{C}$ isotope incorporation rates (13C-lysines /12C-lysines ratio) are shown for three axonal proteins ( $\mathrm{Nfh}, \mathrm{Nfm}$ and $\mathrm{Nfl}$ ) and for the three major myelin proteins (Plp, Mbp and Cldn11); 4 animals per group, 4-monthold group vs. aged mice, one-way ANOVA, followed by Bonferroni's post hoc test P-value, 30 days feeding, Plp, $\mathrm{P}<0.0001$, Mbp, $\mathrm{P}=0,0226$, Cldn11, $\mathrm{P}<0.0001 ; \mathrm{Nfh}$, $\mathrm{P}=0,0800, \mathrm{Nfm}, \mathrm{P}=0,2355, \mathrm{Nfl}, \mathrm{P}=0,2700$; P-value, 60 days feeding, Plp, $P<0.0001$, Mbp, $P=0,0016$, Cldn11, $P<0.0001$, Nfh, $P=0,1338, N f m, P=0,0671, N f l, P=0,0229$ ). $n=4,3$ technical replicates. Error bars indicate standard deviation (SD). (B) Experimental design: tamoxifen (TMX) injection was used at P30 to induce permanent expression of membrane-targeted EGFP (mEGFP) in oligodendrocytes as demonstrated in the scheme. Mice were analyzed 18 days, 6 months and 11 months after tamoxifen induction. (C) Cofocal images show GFP/MBP/DAPI labeling in corpus callosum of tamoxifen treated animals. Control animals that did not receive tamoxifen did not express mEGFP. Dashed line indicates border of white and grey matter. Scale bar, 50 $\mu \mathrm{m}$. Quantifications show the average GFP fluorescence intensity in corpus callosum (CC) and somatosensory cortex (CX). One-way ANOVA, followed by Bonferroni's post hoc test, ${ }^{*} p<0.05$, ${ }^{* *} p<0.01,{ }^{* * *} \mathrm{p}<0.001$. (D) Cofocal images show GFP/DAPI labelling in somatosensory cortex of tamoxifen treated animals. White arrows show single myelin forming GFP+ cells. Scale bars, $5 \mu \mathrm{m}$. (E) Right: Bar graphs show GFP+ cell number in somatosensory cortex (CX) of tamoxifen-treated transgenic animals. Left: The number of PDGFR $\alpha+/$ GFP+ cells was counted in somatosensory cortex to rule out labeling of OPCS with GFP in tamoxifen treated mice. One-way ANOVA, followed by Bonferroni's post hoc test. $\mathrm{CC}=$ corpus callosum; $C X=$ somatosensory cortex; $n=3,3$ sections per animal. Quantitative data are represented as mean \pm SEM.

\subsection{Exceptional characteristics of myelin proteins}

By using different analysis, we identified 5 exceptional characteristics of myelin proteins, including their high abundance and their enrichment in "light" fraction, their reamrkable long life-span and their active synthesis in adult brain compared to old animals 
(Figure.2.5. A). After screening our "light" fraction dataset using these criteria, we found that only 13 proteins overall fulfilled all of these 4 characteristics (Figure.2.5. B). These proteins not only were long-lived ( $\geq 30$ days) but also, they had active synthesis in adult brain compared to older animals and were among the most abundant and the most enriched proteins in "light" fraction. However, among those, only Cldn11, Plp1, Mobp, Mog, Mbp, Tspan2, Cd9, Sirt2 and Cnp had exceptional long lifespan ( $\geq 73$ days), while Mag, Rap1a, Myo1D, and Rhog (with 51,2 \pm 2,1, $47.9 \pm 1,75,32,45 \pm 0,35$ and 32,45 \pm 0,35; Half-life (days) \pm confidence interval) had relatively shorter lifetimes (Figure.2.5. C). Cldn11, Plp1, Mbp, Cnp, Cd9 and Tspan2 contain membrane bound domains which may be important for their long life-time and slow turnover.

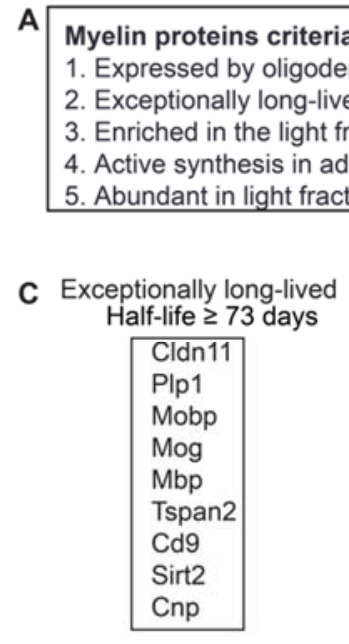

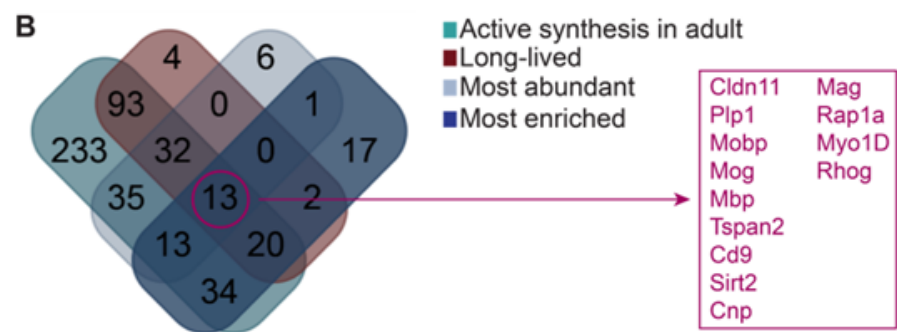

Figure.2.5. Short list of myelin proteome. (A) Boxed area show the criteria to define short list of myelin proteome. (B) Venn digram shows the overlap between proteins that are 1 . actively synthesized in adult brain 2. long-lived (minimum: 30 days) 3. among the top 100 abundant 4 . among the top 100 enriched lists. Table shows the only 13 proteins that had all 4 characteristics, potential myelin proteins. (C) Table shows the short list of myelin proteome: all of these proteins are specifically expressed by oligodendrocytes (except for $\mathrm{Cd} 9$ ) and are exceptionally long-lived.

\subsection{Identification of proteins with dual turnover rate in "light" versus}

\section{"heavy" fraction}

In addition, screening our two datasets obtained from "light" and "heavy" fractions revealed fraction-dependent turnover rate for some proteins. We observed that around $25 \%$ of the proteins that were often (in $\geq 80$ of samples) found in "light" fraction had longer lifespan when they were analyzed in "light" fraction. Among the proteins with dual and life-time were also classical myelin proteins including Mbp, Plp1 and Cnp (Figure.2.6. A). Given that protein lifespan may reflect the different turnover of proteins according to difference in the metabolic activity of their resident environment, we were interested to find out which proteins in our proteome list have dual turnover rate. In order to characterize these proteins, first, we checked their cellular localization. We found that many of these proteins may be located in extracellular exosomes, 
mitochondria and plasma membrane (Figure.2.6. B). It is noteworthy to state that 42.77 $\%$ of these proteins (out of "light" fraction) were relatively short-lived (<30 days) (Figure.2.6. C)and despite statistical significance, lifespan of many of them were also comparable in "light" and "heavy" fraction and may not be biologically important. To screen the potential biologically meaningful differences we decided to set cut-off of at least $70 \%$ for differences in fold between the lifetime analyzed in "light" versus "heavy" fraction. Interestingly majority of the proteins from our lists did not pass this screening which left us with only 30 proteins Figure.2.6. C). This analysis mainly removed the mitochondrial proteins from our screening and left the long-lived proteins (Figure.2.6. C,D) suggesting that long-lived proteins may have faster turnover rate presumably due to their multiple cellular localization. To characterize these proteins further we investigated their biological function. Interestingly we found that majority of them belong to only two biological processes; cell adhesion (43\%) including proteins of paranodal complexes (Cntn1, Cntnap1, and Cntnap2) and signal transduction (20\%) (Figure.2.6. E). One possible explanation for dual turnover rate of these proteins is their expression by different cell types in the brain, while the other explanation may be their localization in different cellular compartments or subdomain within one cell type. Using online RNA-Seq transcriptome and splicing database of glia, neurons, and vascular cells of the cerebral cortex. (https://web.stanford.edu/group/barres lab/brain rnaseg.html) we found that among the 30 proteins that has passed our screening, only Mbp, Plp1, and Prph were cell specific proteins (MbP and Plp1: oligodendrocytes and Prph, neurons) while the rest could all be expressed by different cell types in brain. Since the two most abundant and may be most important myelin proteins $\mathrm{Mpb}$ and Plp1 showed substantial different lifetimes in "light" compared to "heavy" fraction, we wondered about the rest of our short list of myelin proteome with exceptional characteristics (analyzed in the previous section). This was especially interesting as majority of our short list (except for Cd9) were all specifically expressed by newly formed and myelin-forming oligodendrocytes and they were exceptionally long-lived, therefore not only dual life-time for those may have more biological significance but essentially could also suggest dual turnover rate of the proteins within one cell-type. Interestingly, 5 out of 8 proteins of our short list including Plp1, Mbp, as well as Cldn11, Cd9 and Cnp showed increased life-span in "light" fraction (as much as $98 \%$ for Plp1 and 81\% for Mbp). 
A

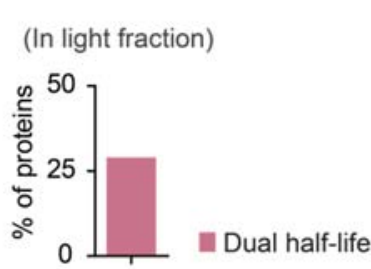

C

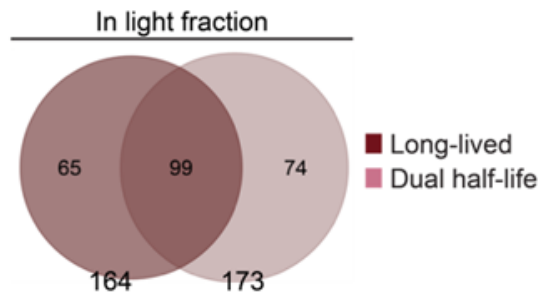

B

Cellular localization
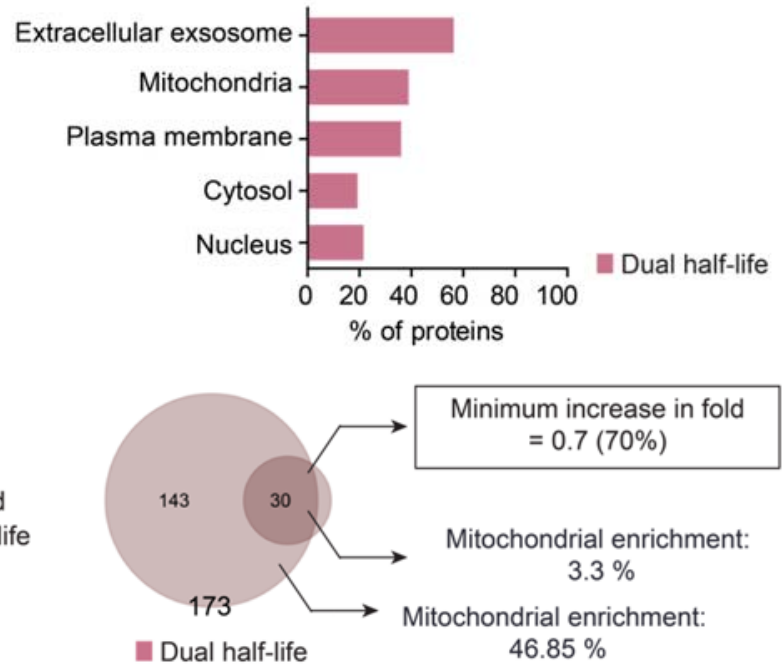

Dual half-life $46.85 \%$

D

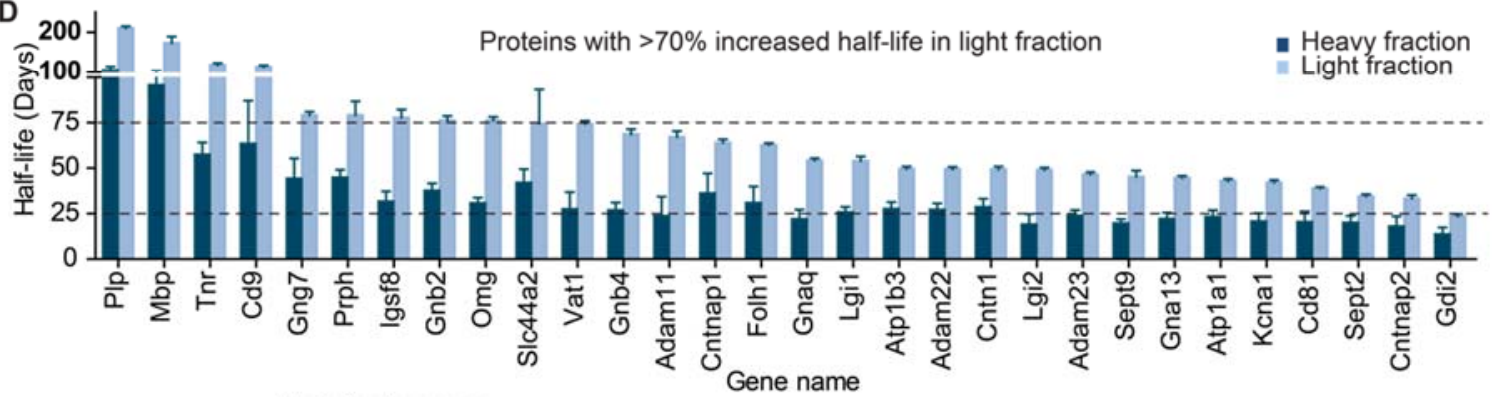

E
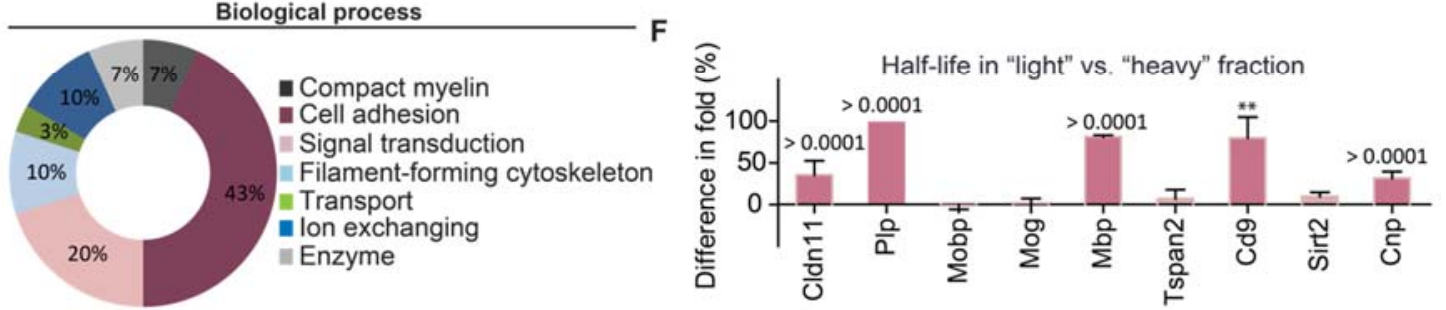

Figure.2.6. Identification of myelin proteins with dual turnover rate in "light" vs. "heavy" fraction. (A) Bar graph shows the percentage of proteins in "light" fraction that have different lifetime in "heavy" fraction. (B) Bar graph shows cellular localization of proteins with dual half-life. (C) Right: venn diagram is used to show pecentage of short- and long-lived proteins with dual half-life in "light" fraction. Left: Fold change analysis was perfomed to identify the proteins with highest increase (at least $70 \%$ ) in their lifespan in "light" fraction. (D) Bar graph is used to show the half-life of proteins with increased (fold change $\geq 0.7$ ) lifespan in "light" fraction. (E) Dounat chart is used to show the classification of proteins with at least $70 \%$ increased lifetime in "light" fraction accroding to their biological roles. $43 \%$ of these proteins are involved in cell adhesion. (F) Fold change analysis was perfomed on myelin proteome short list to show different dual turnover rate for Cldn11, Plp, Mbp, Cd9 and Cnp. All of these proteins (except for Cd9) are specifically expressed by oligodendrocytes and are exceptionally long-lived (minimum = 73 days) in "light" fraction. (This will be discussed as evidence for possible existance of different subdomains within myelin sheets.) 


\section{Chapter 4}

\section{Discussion}

\section{Identification of a unique subpopulation of oligodendrocytes}

\subsection{BCAS1: A cellular marker for premyelinating and early myelin- forming oligodendrocytes}

Oligodendrocytes were discovered as a morphologically heterogeneous cell population by Del Rio Hortega in 1928 (8). Since their discovery, the heterogeneity of oligodendrocyte lineage has been one of the most puzzling topics in studying brain complexity. Despite the wide morphological heterogeneity observed in oligodendrocyte lineage thus far only two main oligodendroglia cell populations could be characterized by using cellular markers; one being the proliferative progenitor pool, and the other the post-mitotic pool which enwrap axons. The progenitor pool can be identified in histochemistry approaches by their specific reactivity to PDGFR- $\alpha$ and NG2. It is noteworthy that in vivo NG2 is expressed also by pericytes however; these cells can be easily recognized by their very distinct morphology from the oligodendrocytes progenitors. On the other hand, APC/CC1 is the most commonly used cellular marker for differentiated oligodendrocytes, although it cannot distinguish between newly differentiated pool oligodendrocytes and the existing pool. Therefore, up to this point there was a missing tool in the field to visualize and to distinguish the newly formed oligodendrocytes and basically the intermediate stage of the lineage. Nonetheless, existence of the intermediate oligodendroglia was reported by using other markers for example myelin protein PLP in rat brain during development(7). These cells were characterized as "pre-myelinating" oligodendrocytes and were reported to have a very distinct morphology compared to both the progenitor and the myelin-forming pools(7, 42). Reportedly, newly differentiated oligodendrocytes at an intermediate stage had ramified morphology and early expression of PLP even prior to enwrapping axons. Unfortunately, when analyzing rat somatosensory cortex, these cells were only found during early postnatal stages and not in adults' brain. There could be two explanations for loss of premyelinating pool in adult brains; first explanation is thatthese cells are hidden from detection due to wide expression of PLP in adult brain in already 
myelinated areas. The second explanation is that the PLP-positive premyelinating oligodendrocytes are indeed limited to developmental stage of life and they genuinely do not exist in the adult brain. Testing these two explanation and especially finding out if there is developmental restricted pool of premyelinating oligodendrocytes even though was very important for our overall understanding of oligodendrocyte lineage and myelination, unfortunately, using the current tools and markers, so far it was not possible. Therefore, lack of sufficient means to investigate which possibilities holds true in vivo highlight the importance and necessity of introducing new markers for studying oligodendrocyte lineage. In this project, we characterized a new cellular marker, BCAS1, for oligodendrocyte lineage which we believe can overcome many challenging limitations and difficulties in studying the myelinating lineage of glia cells.

From our previous works and from our proteomics database we knew that BCAS1 is highly enriched in newly differentiated oligodendrocytes. We generated a polyclonal antibody against BCAS1 and to characterize the marker we first used SOX10, OLIG1 and OLIG2 immunoreactivity, all specific makers of oligodendrocytes, in BCAS1-positive cells to show specificity of BCAS1 for oligodendrocyte lineage. Then, we used in vitro and in vivo approaches and showed that BCAS1 is highly enriched in newly differentiated oligodendrocytes and that its expression is down-regulated in fully matured myelinforming oligodendrocytes. Due to its transient expression, BCAS1 can be used as a cellular marker to label the intermediate stage of oligodendrocytes and to map generation of new oligodendrocytes in healthy adult brain. We also found that BCAS1 not only labels the premyelinating oligodendrocytes, it also labels earlier stages of myelin-forming cells. This observation is exceptionally important as it means the newlyformed "young" myelin sheaths are positive for BCAS1, however the existing or the "old" sheaths lack BCAS1 immunoreactivity. This finding in principle means that BCAS1 can be used as a tool to distinguish "young" versus "old" myelin or "remyelinated" from "myelinated" areas in demyelinating/remyelinating and in disease studies.

\subsection{BCAS1 uncover PLP- premyelinating oligodendrocytes during development and adulthood}

Even though oligodendrocyte heterogeneity has been always an interesting topic, so far all studies could only discuss about it under representation of different maturation 
stages of cells. Due to lack of suitable markers only few studies could address whether or not different subtypes of oligodendrocytes also exist. As an example in a very recent study by Marques et al 2016 analyzing single-cell transcriptome described molecular differences in the gene expression profileof oligodendrocytes(9). Marques et al then grouped the oligodendroglia lineage into up to 12 subclasses based on their RNA profiles (9). Majority of these subclasses were described as different stages in the continuum of oligodendrocyte lineage differentiation. They reported uniform differentiation throughout CNS at earlier stages. They also proposed that is possible myelin-forming oligodendrocyte in later postnatal stages undergo further specification into different subtypes in a region-specific manner(9). In this project we used BCAS1 to investigate oligodendrocyte heterogeneity in developing and adult mouse brain and it provided us with new insights about oligodendrocytes different subtypes in brain.

Although the premylinating oligodendrocytes were initially discovered and morphologically characterized by using early PLP expression as a cellular marker, PLP fails to visualize and distinguish this cell population in adult brain. One reason can be wide expression of PLP in adult brain when myelin fibers are very abundant(7). In developing brain, using PLP expression failed to explain all the observations as they were suggesting heterogenous PLP expression in the premyelinating pool of oligodendrocytes $(3,43)$. Studying spinal cord myelination in PLP-reporter mice were suggesting that some oligodendrocytes start PLP expression prior to their maturation into myelin-forming cells while others only start to express PLP after interacting with axons (43). In this study, we identified premyelinating oligodendrocytes using BCAS1 immunolabelling. We showed that BCAS1 is a more genral marker for visualizing the intermediate satge compared to PLP as PLP labels only a fraction of premyelinating oligodendrocytes in mouse somatosensory cortex while a much larger pool could be detected by BCAS1. Our data suggests that maturation and aging of oligodendrocytes is associated with BCAS1 downregulation in such a way that only a small fraction of BCAS1positive myelin forming oligodendrocytes can be detected at any given time in adult healthy brain. Therefore, restricted expression of BCAS1 in premyelinating and newlyformed myelin forming cells enable us to study the intermediate stage not only in developmental stage but also in adult brain. We observed that while PLP positive and PLP negative premyelinating oligodendrocytes were found in developing brain, no PLP- 
positive premyelinating oligodendrocyte could be detected in adult brain. These results suggested that either these two pools merely represent two different stages of maturation or they genuinely represent two different subtypes of premyelinating oligodendrocytes. Our further analyses on these cells were more supportive for the later. We found BCAS1-positive PLP-negative myelin-forming cells in abundance in developing and adult brain. Existence and abundance of BCAS1-positive/PLP-negative myelin-forming cells lead us to conclusion that PLP-negative/BCAS1-positive premyelinating cells, most if not all, remain PLP-negative even in the initial stages of interacting and enwrapping axons. Therefore, absence of BCAS1-positive/PLP-positive premyelinating oligodendrocyte from adult brain evidently shows continued oligodendrogenesis in adult brain only by PLP-negative/BCAS1-positive subpopulation of premyelinating oligodendrocytes.

\subsection{BCAS1+ myelin-forming oligodendrocytes in adult somatosensory cortex}

By using in vitro and in vivo approaches, we found that in vivo BCAS1 is highly expressed in newly-generated myelin-forming oligodendrocytes. BCAS1-positive myelin forming cells could easily be identified by their very distinct morphology. These cells have BCAS1positive processes aligned around axons as shown by co-immunolabeling of BCAS1 and neurofilaments (a neuronal marker to label neuronal fibers mainly axons). Similar to our results for premyelinating cells, we could also detect both PLP $^{-}$and PLP $^{+}$BCAS1expressing myelin-forming oligodendrocytes in developing mouse brain while in adults only PLP-negative BCAS1-positive myelin forming oligodendrocytes could be identified. These results were in complete agreement with our conclusion that there is a unique subpopulation of premyelinating oligodendrocytes that participates in myelination and is restricted to developmental stage of mouse life. We also checked the expression of other myelin proteins namely MAG and MBP in BCAS1-positive myelin-forming oligodendrocytes in adult brain to investigate whether the heterogeneity is merely PLPdependent or if it shows a maturation-dependent heterogeneity. MAG is a myelin protein which is involved in cell-cell adhesion between oligodendrocytes and neuronal membrane. While MAG is not an essential component of myelin membrane, MBP and PLP had been shown to be more important constituent of myelin structure as MBP is the only essential protein of myelin and PLP has been suggested to be important for stability 
of myelin structure. Indeed, we found that "young" myelin-forming oligodendrocytes in adult brain while all positive for MAG, all lack MBP in addition to PLP expression. Although using these results we could not make any comments or suggestions about the functional and/or physiological importance of these two different subtypes of oligodendrocytes, we could clearly observe a difference in the timing of myelin proteins expression in the cells destined to myelinate. Existence of PLP-negative/BCAS1expressing myelin-forming oligodendrocytes in developing and adult somatosensory cortex excludes the possibility that PLP- premyelinating oligodendrocytes represent an earlier stage in premyelinating oligodendrocytes rather than a distinct subpopulation. These results also strongly suggest that only one premyelinating subpopulation continues adult oligodendrogenesis

We were specifically interested to know the generation rate of premyelinating and myelin-forming oligodendrocytes in adult brain as it has been one of the most important questions in the field, a question that so far only could be addressed by using inducible transgenic reporter mice and upon tamoxifen administration. Using BCAS1 immunolabeling we had the tools to address this question for the first time in wildtype animals without any prerequisite manipulations. In order to explore the dynamics of BCAS1-positive cells generation and maturation in adult somatosensory cortex we used EdU pulse-chase experiments in wildtype animals. We observed that EDU positivity increased very fast (more than $60 \%$ of BCAS1-positive cells were EDU-positive only after 10 days of labeling) in white matter while only a very subtle increase was observed in grey matter (only around $12 \%$ of BCAS1-positve cells were EDU-positive after 10 days of EDU administration). We also observed fast reduction of EDU-positive BCAS1-positve cells in the white matter (only around 7\% of BCAS1-positve cells remained EDU+ after 40 days of chase) while no reduction was found in the EDU-positive BCAS1-positve cells of grey matter. Our results suggested that BCAS1-positive oligodendrocytes continuedly are generated in adult white and grey matter in a region-dependent manner.

However, the very slow rate of BCAS1-positive cells renewal in grey matter made us wonder how substantial the rate is in grey matter of adult mice. This was specifically important for us as BCAS1-positive cells in adult mouse brain contained the premyelinating and the young- and yet not fully matured myelin-forming 
oligodendrocytes. To further analyze the renewal rate of BCAS1-positive cells in adult grey matter we used a triple transgenic reporter mouse line called Sox10iCreERT2;Esco2;CAG-EGFP mice. GFP expression in the recombined cells upon tamoxifen administration in these mice indicates Esco2 deletion which leads to stimulation of apoptosis an ultimately cell deaths of recombined cells preceded by cell proliferation. Therefore, by using these mice for our fate-mapping experiment we expected to see reduction in BCAS1 positivity in GFP-positive cells presumably that generation of BCAS1postive cells continues in adult grey matter. We indeed observed that BCAS1-positivity declined in GFP-positive cells Sox10-iCreERT2;Esco2;CAG-EGFP mice, however the reduction did not happen even after 6 weeks after tamoxifen administration and it could only be observed after longer time (16 weeks after induction).

Our results indicated very slow rate of generation as well as maturation in BCAS1expressing myelin-forming oligodendrocytes in adult mouse grey matter. As oligodendrogensis in old brain also has been always a very important question in myelin field, we used BCAS1 immunoreactivity to address this question. Moreover, we tested if BCAS1-positve premyelinating and myelin-forming BCAS1-expressing oligodendrocytes still can be found in old mouse brain or basically if oligodendrogenesis still continues in aged brain. This was especially important for us, as it has been always a question if aging-associated demyelination in old animals could actually stimulate oligodendrogenesis. We found that BCAS1-positve premyelinating and myelin-forming oligodendrocytes were almost abolished in somatosensory cortex of very old animals. While the overall population of BCAS1-positve cells had slightly increased (data not show), majority of these cells were found with a very immature morphology without long and ramified process resembling the morphology of progenitor cells.

\subsection{BCAS1+ perineuronal oligodendrocytes in adult somatosensory cortex}

Our data thus far has suggested that BCAS1-positve myelin-forming cells in adult brain, especially in adult cortex represent a pool of "young" oligodendrocytes. Although these cells appear to interact with neurons (as shown by alignment of their BCAS1-positive processes alongside axons and by their MAG-positivity), they are not yet capable of making fully mature, compacted (as suggested by their lack of MBP expression) and/or 
stable myelin sheaths (as suggested by their lack of PLP expression). We have also observed these cells more frequently in deeper layers of cortex, all of which were reminding of a specific and long debated sub-population of oligodendrocytes, "perineuronal" or "satellite" oligodendrocytes $(10,11)$. Perineuronal oligodendrocytes were first discussed by Ludwin et al in 1979 using electron microscopy approaches(10). These cells were first characterized as "non-myelinating" oligodendrocytes in close vicinity of neuronal cell bodies. These cells were more frequent in remyelinating areas and hence it was believed that they might be involved in remyelination. Since there were so far no cellular markers to distinguish the perineuronal oligodendrocytes by histological approaches our knowledge about them has been very limited. Nonetheless some histological studies using PLP-EGFP mice provided some evidence that these cells exist in adult mouse brain most likely as non-myelinating oligodendrocytes and they appear to interact specifically with glutamatergic neurons. In 2016 Battefledet al showed that perineuronal satellite oligodendrocytes are not limited to non-myelinating cells. By using a PLP-ECFP reporter mice they found the first evidence for a pool of myelinforming perineuronal satellite oligodendrocytes(12). These findings highlight the possibility that neurons and oligodendrocytes subtypes may have preferable intercellular interactions probably to generate a functional glia-neuron network in brain. Therefore, we also investigated if perineuronal oligodendrocyte could also be found in "young"er and presumably more dynamic pool of oligodnendrocytes. Therefore, we used NeuN as a general marker for labeling neurons cell bodies together with BCAS1. We identified BCAS1-expressing oligodendrocytes (as well as $\mathrm{BCAS1}^{+}$myelin-forming oligodendrocytes) as a subpopulation of perineuronal oligodendrocytes in somatosensory cortex. Then, we used Tbr1 as a marker for labelling of glutamatergic neurons to find out if as shown by other studies, the BCAS1-positive oligodendrocytes may also preferably interact with glutamatergic neurons. Our analysis indeed showed that BCAS1-positve oligodendrocytes (either the total or the myelin-forming pool) specifically were localized in the vicinities of Tbr1-postive neurons. This finding can be particularly important given that BCAS1-positve premyelinating and myelin-forming cells are abolished from aged brain. 


\subsection{Summary and future perspectives:}

In this study we introduced BCAS1 as a new tool for studying oligodendrocytes and for myelination/remyelination researches. Our study also focused on characterizing BCAS1expressing oligodendrocytes during development and in adult mouse brain. Using BCAS1 we could also provide new insights about myelination in development, in adult and in aged mouse brain. Our results up to our knowledge for the first time provide evidence for existence of different subtypes of premyelinating oligodendrocytes in mouse brain. These different subtypes appear to be cells with different programing for at least the two most abundant proteins of myelin structure, MBP and PLP. Although the functional importance of finding of these two distinct subpopulations remains to be elucidated, our data strongly suggest that one of these two pools is restricted to developmental stage. Our study does not provide any information about if the properties of myelin produced by these two distinct pool such as its function, stability and dynamics are similar or not, however all these questions are very important and need to be addressed by further studies. Identification of developmentally restricted pool of oligodendrocytes might be in particular important when studying myelin involvement in pathobiology of neurodevelopmental disorders including schizophrenia and autism as continuedly more studies highlight myelin dysfunction and alteration in these disorders(44). Our results shed new lights on adult-oligodendrogenesis as we showed that generation of new oligodendrocytes is carried out only by one oligodendroglia subpopulation which follows a very slow maturation rate. The existence of an abundant pool of premyelinating and a pool of premature myelin-forming oligodendrocytes must be always kept in mind when dealing with neuronal and myelin plasticity experiments. This project in agreement with previous reports provides evidence for existence of perineuronal oligodendrocytes in adult somatosensory cortex. Given the robust reduction of BCAS1-positve differentiated oligodendrocytes in aged brain, preferred interaction of BCAS1-positive oligodendrocytes with Tbr1-positive subtype of neurons in cortex, may be a new field of research in studying oligodendrocytes and myelin involvement in aging-related neurological disorders such as Alzheimer's and Parkinsons' disease. 


\section{Turnover and characteristics of myelin proteins}

\subsection{Exceptional characteristics of myelin proteins}

Myelin is a highly specialized structure enwrapping axons as a multi-layered isolating sheet. Protein and lipid content of myelin has been widely studied, although the function and significance of each individual component is still not well-known. Unlike any other biological membranes, proteins only comprise around $30 \%$ of myelin dry weight (compared to $50 \%$ for other biological membranes). Plp1, Mbp and Cnp are the three most abundant proteins of myelin and however it is still a matter of debate, Plp1 and $\mathrm{Mbp}$ alone may account for $70 \%$ of myelin protein content. Recent proteomics studies believe that this percentage may be highly overestimated considering that new proteomics approaches provide us with much larger myelin proteome lists and therefore lead to lower estimation for Plp1 and Mbp share. Nonetheless Plp1 and Mbp are still considered as the two main protein constituent of myelin structure. While Plp1 and Mbp are both located in the compacted domains, Cnp the other abundant myelin protein is usually found in non-compacted myelin domains. Compacted and non-compacted domains of myelin are respectively cytoplasm-depleted and cytoplasm-enriched areas of myelin which are in fact the major specialization of myelin membrane in the vertebrates. These domains are believed to be different in terms of their molecular composition and they may also generate metabolic ally different environments with different molecular dynamics within the myelin sheaths. Indeed, due to its unique structure, myelin dynamics and in particular the turnover of myelin components has been always very appealing questions. What is clear is that like all other biological structures, molecular turnover of components is crucial for myelin maintenance and integrity; however it is still not very well known how they may access cellular synthesis and degradation machineries. It is not even still known if oligodendrocytes are alone capable of myelin turnover or if they may rely on other neuroglia cell types such as microglias or neurons for that.

In the second part of this project we focused on protein composition, turnover rate and effect of aging on synthesis rate of myelin proteins. Isolation and purification of myelin for proteomics studies relies on two-step sucrose gradient followed by ultracentrifugation a widely used protocol introduced by Norton et al1973 (24). This 
protocol is developed on the basis that due its high lipid to protein ratio myelin has lighter weight compared to any other biological membranes, therefore by using discotinious sucrose gradient and ultracentrifugation it accumulates at the interface between the upper and the lower sucrose layers. The whitish light-weight materials that accumulates in the interphase between $0.32 \mathrm{M}$ and $0.85 \mathrm{M}$ sucrose during the isolation protocol usually is collected and subjected to additional purification steps. This whitish material is what is regarded as "myelin" or "myelin-enriched" fraction. This method has been shown to be highly reproducible and therefore it is commonly used for biochemical and proteomics studies. It is self-explanatory that one pitfall of this approach is copurification of any other proteins with similar floating properties as myelin; for example mitochondrial and synaptic vesicles proteins (26). Therefore, to obtain a better resolution about myelin proteins, we decided not only to analyze the interphase; "myelin-enriched" fraction, but also to purify and analyze the proteome of the pellet as a "myelin-depleted" fraction. We used the "myelin-depleted" fraction as a control in our study. In order to highlight the true nature of fractionation by isolation protocol we preferred to use the terms "light" and "heavy" when comparing these two fractions and in discussing the results. Surprisingly when we compared the two proteomics lists ("light" and "heavy") we found that majority of the proteins found in the "light" fraction could still also be found in the "heavy" fraction including all the classical myelin proteins; Mbp, Plp1, Cnp etc. This was surprising given that both fractions were extensively purified and hence either highly enriched or highly depleted from myelin ( 2 rounds of purification for "light" and 5 rounds of purification for "heavy" fraction). In principle from total 600 proteins that were found in the "light" fraction (in $\geq 80 \%$ of our samples), only 67 proteins seemed to be specifically found in the "light" fraction. Even when we took the abundance of proteins in the consideration, assuming that the contamination may be trivial, we found that almost $50 \%$ of the most abundant proteins in each fraction were also similar including classical myelin proteins; Mbp, Plp1, Cnp and classical neuronal proteins; $\mathrm{Nfh}, \mathrm{Nfm}, \mathrm{Nfl}$ which were found among the top 100 most abundant proteins of both "light" and "heavy" fractions. These results suggested that fractionation may indeed be a very crude approach for myelin isolation and therefore we decided to characterize our proteomics lists with more cautions and attention. 
Considering the basis of the isolation protocol and the previous reports we hypothesized that although the fractionation my not provide us with very pure "myelin-enriched" fraction it may have enriched myelin proteins in the "light" fraction. Therefore, to obtain a more informative view about our myelin proteomics list, we decided to investigate which proteins were preferably enriched in the "light" fraction. This could simply be done by comparing the signal intensities obtained by mass spectrometry for each protein in the "light" versus "heavy" fraction, however this analysis was only limited to the proteins that were found in both fractions which basically covered $89 \%$ of our "light" fraction including all the known classical myelin proteins. Using this approach, we calculated an "enrichment index" for each protein with highest index being 249x for Actb and lowest being around 0.009x for GFAP and Slc4a4. After calculating the "enrichment index" of the proteins we noticed that in order to interpret the data we should also take the protein abundance into account, as the enrichment analysis were prone to make high enrichment indexes for low abundance proteins which were could result to false positive results. Therefore, to focus on the enrichment indexes that were more likely to represent biologically importantresults we compared the top 100 most abundant and top 100 most enriched proteins of the "light" fraction. As speculated, the enrichment analysis excluded many proteins that were always considered as contaminant of myelin isolation protocol such as axonal and mitochondrial proteins.

To be able to address the turnover rate of myelin proteins, we had fed adult (4 months) and old (18 and 26 months) mice for 30 or 60 days with a diet containing ${ }^{13} \mathrm{C}$-lysines. This approach enabled us to label the newly synthesized proteins with ${ }^{13} \mathrm{C}$-lysines which helped us to estimate the synthesis rate of proteins in mouse brain in different stages of life. To calculate synthesis rate of proteins, we determined ${ }^{13} \mathrm{C}$-lysines and ${ }^{12} \mathrm{C}$-lysines ratio for each individual proteins. By using these data and also with the assumption that the final volume of the proteins remains stable, we also calculated the proteins halflives. After 1 or 2 months of SILAC feeding (protein labeling) was finished the animals were sacrificed and their brains were used for brain fractionation. We found that classical myelin proteins as reported previously were exceptionally long-lived. Our synthesis rate analysis also suggested active synthesis of classical myelin proteins (Mbp, 
Plp, and Cldn11) in adult brain which was in contrast to other proteins such as axonal filaments (Nfh, $\mathrm{Nfm}$, and $\mathrm{Nfl}$ ).

\subsection{Maturation of developmentally-born myelin sheaths continues into late adulthood in mouse brain}

Our in vivo SILAC labeling strongly suggested active synthesis of myelin proteins even in 6-8 months old mice. Although our SILAC results were a direct indication of active adult myelination, it could not show us if it was merely representing extensive adultoligodendrogenesis or if it was caused by ongoing myelination of the existing cells. Adult myelination in rodents has been extensively investigated in recent years by development of genetic fate-mapping approaches. Different studies so far have reported extensive generation of oligodendrocytes in adult mouse brain as an indicator of adult myelination $(13,14,45)$. It is currently a general acceptance in the field that adultoligodendrogenesis may be required in adult brain to compensate for myelin loss and basically to replace the dying myelin-forming oligodendrocytes. Another explanation may be that the new oligodendrocytes are mainly required for remodeling of myelin sheaths by addition of short internodes between existing myelin segments which presumably occurs commonplace in mature adult brain (13). Providing direct evidence for either of these two hypotheses is technically very challenging and therefore, none of them have been strongly backed-up yet. The major presumption for extensive myelin replacement hypothesis in adult brain is substantial myelin loss; therefore we decided to test if this holds true in vivo. In order to investigate whether or not myelin loss is commonplace in adult brain we labelled and tracked the fate of developmentally-born myelin-forming oligodendrocytes until 12 months of age in mice corpus callosum and somatosensory cortex. We used PLP-CreERT2 x R26R-td-tomato-mEGFP reporter mice in which tamoxifen injection induces expression of membrane-bound GFP in PLPexpressing oligodendrocytes. We induced GFP expression when the mice very young (at P30) and myelination was actively ongoing. Using this approach, we could label and track the developmental pool of myelin. We found out that not only this pool is extremely stable in both regions, the maturation of myelin sheaths generated by this pool also continued into late adulthood. In regards to these observations, we believe that our results strongly suggest that a substantial part of adult-myelination indeed 
occurs as continuous maturation of developmentally-generated myelin sheaths rather than a mechanism to replace dying myelinating cells.

\subsection{Different pools of myelin or different microdomains within myelin sheaths}

Turnover rate of proteins is by large determined by the metabolic activity of their resident environment and their function. While short-lived proteins are for example mainly enzymes and are usually found in cytoplasmic regions and metabolically active environments, long-lived proteins are usually structural proteins located in less metabolically active environments or in areas far from cellular synthesis and degradation machineries. Previous reports had identified long-lived proteins in many essential cellular structures presumably to enforce their stability(30). Given the unique and complex architecture of myelin membrane, it is not surprising that myelin proteins are also among the most long-lived proteins of brain. However it was surprising that in our analysis for most of the classical myelin proteins we found two different turnover rates. Basically, we found that for some of the proteins the calculated synthesis rate (and as a result their estimated half-lives) varied when the proteins were analyzed in "light" or in "heavy" fraction. This finding was in contrast to the assumption that the common proteins between the two fractions ("light" and "heavy") are merely contaminants as contaminants would expectedly show similar turnover rates. Different lifespan for same proteins clearly indicated that these proteins may be present in the two fractions due to their multiple localizations within the cells. This could in principle mean that proteins may have different location-dependent stability and dynamics within the cells. Of course, one other explanation could be that proteins may have different turnover rate when they are expressed by different cell types or that our results represent different localization and turnover rate for different isoforms of the proteins

Given that dual half-life of proteins could reflect their dual localization and hence their different renewal rate, we decided to screen and characterize all of the proteins with dual half-lives in our proteomics lists. We found that only a very small number from our proteomics lists showed fraction-dependent turnover rates. Many of these proteins were located in extracellular exosomes, mithochondria or in the plasma membrane. The common but not absolute rule was that these proteins showed longer life-time when 
they were analyzed in the "light" fraction. However more strict analysis revealed that only 30 of these proteins had more that $70 \%$ difference in fold in their lifespan (when analyzed in "light" compared to "heavy" fraction). Majority of the proteins with dual half-life seemed to be somehow a part of myelin or myelin associated structures. The largest turnover rate difference was found for $\mathrm{Mbp}$ and Plp1, the two most abundant proteins of myelin that are both located in the compacted areas and according to previous studies they may be involved in generation and stability of compacted domains within myelin sheaths. Among the proteins with dual lifespan were also proteins involved in cell-cell adhesion. These adhesion molecules including $\mathrm{Tnr}, \mathrm{Cd} 9, \mathrm{Igsf} 8, \mathrm{Omg}$, Adam11, Cntnap1, Lgi1, Adam22, Cntn1, Lgi2, Adam23, Cd81 and Cntnap2 are reported to be localized in different domains of myelin. Among them we could also find several interacting groups; for example different components of paranodal complexes (Cntn1, Cntnap1, and Cntnap2) and a few members of ADAM metalloproteinases family together with their ligands (Adam11, Adam22, Adam23, Lgi1 and Lgi2). While some of these interacting groups were located in myelin innermost layer such as paranodal proteins and Adam family metalloproteinases, some ( $\mathrm{Cd} 9, \mathrm{Cd} 81$ and Igsf8) were or predicted to be localized in the outermost layer of myelin. In addition, we found Oligodendrocyte Myelin Glycoprotein (Omg) an adhesion molecule presumably involved in cytoskeleton remodeling regulation by Rho GTPases as well as several G proteins involved in signaling transduction (Gng7, Gnb2, Gnb4, Gnaq and Gna13) among these proteins. Nonetheless it is worth highlighting that not all the 30 proteins of our list were myelin proteins, as an example for that we also found Tenascin-R (Tnr) a neural extracellular matrix protein and ion exchanging proteins (Atp1b3, Atp1a1, Kcna1) in our list which are expected to be localized in nodal areas. Lastly, we also found Filamentforming cytoskeletal proteins (Sept2, sept9, Prph), transporters (SIc44a2, Gdi2) and even enzymes (Vat1, Folh1) in this list. Although we using our results we cannot argue the underlying reason for dual lifetime of these proteins, but one speculation may be stabilization of variants interacting with myelin.

Given that many of these proteins are expressed by different cell types it is also possible that their different stabilities are caused by metabolically different environments within their resident cell type, however this cannot explain why proteins specifically expressed 
by only one cell type show dual lifespan. While proteins such as Mbp, Plp1, Tnr, Cntn1 and Kcna1 are almost oligodendrocyte lineage specific proteins, there were also proteins specific for other gila cell types with dual turnover rates including Prph (neurons), Slc44a2 (highly enriched in microglias), Folh1 (astrocytes). On the other hand, Cntnap1, Lgi1, Lgi2, Adam22 and Adam23 were highly expressed by neurons and cells of oligodendrocyte lineage whereas Cntnap2 and Sept9 were highly enriched in astrocytes and neurons. Therefore, more studies are required to elucidate the underlying cause of proteins dual turnover rates. Some of these proteins such as Atp1b3, Atp1a1 and Kcna1 are part of bigger complexes and it is not clear for us why we only found one subunit of the complex with dual half-life and not the others. It is also important to confirm if similar protein isoforms were analyzed in our two proteomics list as it can be that different isoforms may be localized in different cellular compartments and have different stabilities.

Unfortunately, current understanding about the cellular and molecular mechanisms that oligodendrocytes employ to renew myelin sheaths and maintain its functional integrity is very limited. Although our study consistent with many other studies shows very slow turnover rate of myelin proteins, myelin still is massive bulk of materials for cellular degradation machinery and moreover is far from the oligodendrocytes cell body where the lysosomes are located. It is possible that the classical idea that turnover happens as an equal force between synthesis of new materials and degradation of old materials does not apply for myelin meaning that even though very slowly, myelin may be produced much faster than it is degraded which can also explain why its maturation continues into late adulthood and why the total myelin volume seems to continuedly increase before it starts to degrade in older ages. It is also possible that oligodendrocytes may collaborate with other glial cell types for example microglias and neurons to get rid of old components and make room for new proteins and lipids. Lastly we have also observed that proteins localized within compacted domains of myelin (Plp1, Mbp, Cldn11, Mpz) and myelin outermost layer (Cd9, Mog) seem to have relatively higher lifespan compared to those localized in non-compacted domains (Cnp) and myelin innermost layer (Mag and other paranodal proteins) which may hint to higher dynamics in the inner layers of myelin. 


\subsection{Summary and future perspectives:}

Dynamics and turnover of myelin sheaths is a very important question and therefore it has been extensively studied. All the previous studies consistently concluded that myelin is composed of stable and exceptionally long-lived components, although the cellular and molecular mechanisms that oligodendrocytes use to renew myelin are still open questions and need to be elucidated. Consistent with previous reports we saw that myelin proteins seem to be very long-lived. We also observed that myelin maturation continues in mice even into late adulthood. To our knowledge our study is the first to show evidence for substantial share of developmental-born oligodendrocytes in adult myelination. Our study not only provided new biological insights about turnover of myelin proteins in adult and aged mouse brain, but also provides a detailed technical characteristic about proteomics data obtained from isolated myelin... By comparing "myelin-enriched" and "myelin-depleted" fractions we could categorize myelin proteomics according to their abundance and enrichment in "myelin-enriched" fraction. Moreover, we detected two different pools of myelin proteins with different replacement rates in mouse brain proteome which may reflect heterogeneity within myelin sheaths. In principle, in our study we tried to draw an informative picture about the myelin proteomics data and what is regarded and studied as myelin fraction in the field and by showing proteins with dual lifespan we open and propose new questions about myelin structure which need to be addressed by future researches. 


\section{References}

1. Dimou L, Götz M. Glial cells as progenitors and stem cells: new roles in the healthy and diseased brain. Physiological reviews. 2014;94(3):709-37.

2. Kessaris N, Fogarty $M$, lannarelli $P$, Grist $M$, Wegner $M$, Richardson WD. Competing waves of oligodendrocytes in the forebrain and postnatal elimination of an embryonic lineage. Nature neuroscience. 2006;9(2):173.

3. Spassky N, Olivier C, Cobos I, LeBras B, Goujet-Zalc C, Martínez S, et al. The early steps of oligodendrogenesis: insights from the study of the plp lineage in the brain of chicks and rodents. Developmental neuroscience. 2001;23(4-5):318-26.

4. Le Bras B, Chatzopoulou E, Heydon K, Martinez S, Ikenaka K, Prestoz L, et al. Oligodendrocyte development in the embryonic brain: the contribution of the plp lineage. International Journal of Developmental Biology. 2003;49(2-3):209-20.

5. Villegas EP, Olivier C, Spassky N, Poncet C, Cochard P, Zalc B, et al. Early specification of oligodendrocytes in the chick embryonic brain. Developmental biology. 1999;216(1):98-113.

6. Spassky N, Goujet-Zalc C, Parmantier E, Olivier C, Martinez S, Ivanova A, et al. Multiple restricted origin of oligodendrocytes. Journal of Neuroscience. 1998;18(20):8331-43.

7. Trapp BD, Nishiyama A, Cheng D, Macklin W. Differentiation and death of premyelinating oligodendrocytes in developing rodent brain. The Journal of cell biology. 1997;137(2):459-68.

8. del Río-Hortega P. Tercera aportacion al conocimiento morfologico e interpretacion funcional de la oligodendroglia1928.

9. Marques S, Zeisel A, Codeluppi S, van Bruggen D, Falcão AM, Xiao L, et al. Oligodendrocyte heterogeneity in the mouse juvenile and adult central nervous system. Science. 2016;352(6291):1326-9.

10. Ludwin S. The perineuronal satellite oligodendrocyte. Acta neuropathologica. 1979;47(1):49-53.

11. Takasaki C, Yamasaki M, Uchigashima M, Konno K, Yanagawa Y, Watanabe M. Cytochemical and cytological properties of perineuronal oligodendrocytes in the mouse cortex. European Journal of Neuroscience. 2010;32(8):1326-36.

12. Battefeld A, Klooster J, Kole MH. Myelinating satellite oligodendrocytes are integrated in a glial syncytium constraining neuronal high-frequency activity. Nature communications. 2016;7.

13. Young KM, Psachoulia K, Tripathi RB, Dunn S-J, Cossell L, Attwell D, et al. Oligodendrocyte dynamics in the healthy adult CNS: evidence for myelin remodeling. Neuron. 2013;77(5):873-85.

14. Zhu X, Hill RA, Dietrich D, Komitova M, Suzuki R, Nishiyama A. Age-dependent fate and lineage restriction of single NG2 cells. Development. 2011;138(4):745-53.

15. Simon C, Götz M, Dimou L. Progenitors in the adult cerebral cortex: cell cycle properties and regulation by physiological stimuli and injury. Glia. 2011;59(6):869-81.

16. Dimou L, Simon C, Kirchhoff F, Takebayashi H, Götz M. Progeny of Olig2-expressing progenitors in the gray and white matter of the adult mouse cerebral cortex. Journal of Neuroscience. 2008;28(41):10434-42.

17. Pringle NP, Mudhar HS, Collarini EJ, Richardson WD. PDGF receptors in the rat CNS: during late neurogenesis, PDGF alpha-receptor expression appears to be restricted to glial cells of the oligodendrocyte lineage. Development. 1992;115(2):535-51.

18. Psachoulia K, Jamen F, Young KM, Richardson WD. Cell cycle dynamics of NG2 cells in the postnatal and ageing brain. Neuron Glia Biology. 2009;5(3-4):57-67.

19. McKenzie IA, Ohayon D, Li H, De Faria JP, Emery B, Tohyama K, et al. Motor skill learning requires active central myelination. Science. 2014;346(6207):318-22.

20. Xiao L, Ohayon D, McKenzie IA, Sinclair-Wilson A, Wright JL, Fudge AD, et al. Rapid production of new oligodendrocytes is required in the earliest stages of motor skill learning. Nature neuroscience. 2016;19(9):1210. 
21. Liu J, Dietz K, DeLoyht JM, Pedre X, Kelkar D, Kaur J, et al. Impaired adult myelination in the prefrontal cortex of socially isolated mice. Nature neuroscience. 2012;15(12):1621-3.

22. Makinodan M, Rosen KM, Ito S, Corfas G. A critical period for social experiencedependent oligodendrocyte maturation and myelination. science. 2012;337(6100):1357-60.

23. Saab AS, Tzvetanova ID, Nave K-A. The role of myelin and oligodendrocytes in axonal energy metabolism. Current opinion in neurobiology. 2013;23(6):1065-72.

24. Norton W, Poduslo SE. Myelination in rat brain: changes in myelin composition during brain maturation. Journal of neurochemistry. 1973;21(4):759-73.

25. Deber CM, Reynolds SJ. Central nervous system myelin: structure, function, and pathology. Clinical biochemistry. 1991;24(2):113-34.

26. Jahn 0 , Tenzer S, Werner HB. Myelin proteomics: molecular anatomy of an insulating sheath. Molecular neurobiology. 2009;40(1):55-72.

27. Menon K, Rasband MN, Taylor CM, Brophy P, Bansal R, Pfeiffer SE. The myelinaxolemmal complex: biochemical dissection and the role of galactosphingolipids. Journal of neurochemistry. 2003;87(4):995-1009.

28. Werner HB, Kuhlmann K, Shen S, Uecker M, Schardt A, Dimova K, et al. Proteolipid protein is required for transport of sirtuin 2 into CNS myelin. Journal of Neuroscience. 2007;27(29):7717-30.

29. Snaidero N, Velte C, Myllykoski M, Raasakka A, Ignatev A, Werner HB, et al. Antagonistic functions of MBP and CNP establish cytosolic channels in CNS myelin. Cell reports. 2017;18(2):314-23.

30. Toyama BH, Savas JN, Park SK, Harris MS, Ingolia NT, Yates JR, et al. Identification of long-lived proteins reveals exceptional stability of essential cellular structures. Cell. 2013;154(5):971-82.

31. Shevchenko A, Tomas H, Havlis J, Olsen JV, Mann M. In-gel digestion for mass spectrometric characterization of proteins and proteomes. Nat Protoc. 2006;1(6):2856-60.

32. Olsen JV, de Godoy LM, Li G, Macek B, Mortensen P, Pesch R, et al. Parts per million mass accuracy on an Orbitrap mass spectrometer via lock mass injection into a C-trap. Mol Cell Proteomics. 2005;4(12):2010-21.

33. Tyanova S, Temu T, Cox J. The MaxQuant computational platform for mass spectrometry-based shotgun proteomics. Nat Protoc. 2016;11(12):2301-19.

34. Cox J, Mann M. MaxQuant enables high peptide identification rates, individualized p.p.b.-range mass accuracies and proteome-wide protein quantification. Nat Biotechnol. 2008;26(12):1367-72.

35. Sharma K, Schmitt S, Bergner CG, Tyanova S, Kannaiyan N, Manrique-Hoyos N, et al. Cell type- and brain region-resolved mouse brain proteome. Nat Neurosci. 2015;18(12):1819-31.

36. Huang W, Zhao N, Bai X, Karram K, Trotter J, Goebbels S, et al. Novel NG2-CreERT2 knock-in mice demonstrate heterogeneous differentiation potential of NG2 glia during development. Glia. 2014;62(6):896-913.

37. Muzumdar MD, Tasic B, Miyamichi K, Li L, Luo L. A global double-fluorescent Cre reporter mouse. genesis. 2007;45(9):593-605.

38. Tomassy GS, Berger DR, Chen HH, Kasthuri N, Hayworth KJ, Vercelli A, et al. Distinct profiles of myelin distribution along single axons of pyramidal neurons in the neocortex. Science. 2014;344(6181):319-24.

39. Schneider S, Gruart A, Grade S, Zhang Y, Kroger S, Kirchhoff F, et al. Decrease in newly generated oligodendrocytes leads to motor dysfunctions and changed myelin structures that can be rescued by transplanted cells. Glia. 2016.

40. Whelan G, Kreidl E, Wutz G, Egner A, Peters JM, Eichele G. Cohesin acetyltransferase Esco2 is a cell viability factor and is required for cohesion in pericentric heterochromatin. EMBO J. 2012;31(1):71-82. 
41. Ishii A, Dutta R, Wark GM, Hwang S-I, Han DK, Trapp BD, et al. Human myelin proteome and comparative analysis with mouse myelin. Proceedings of the National Academy of Sciences. 2009;106(34):14605-10.

42. Chang A, Tourtellotte WW, Rudick R, Trapp BD. Premyelinating oligodendrocytes in chronic lesions of multiple sclerosis. New England Journal of Medicine. 2002;346(3):165-73.

43. Spassky N, Heydon K, Mangatal A, Jankovski A, Olivier C, Queraud-Lesaux F, et al. Sonic hedgehog-dependent emergence of oligodendrocytes in the telencephalon: evidence for a source of oligodendrocytes in the olfactory bulb that is independent of PDGFR signaling. Development. 2001;128(24):4993-5004.

44. Deoni SC, Zinkstok J, Daly E, Ecker C, Williams SC, Murphy DG, et al. White-matter relaxation time and myelin water fraction differences in young adults with autism. Psychological medicine. 2015;45(4):795-805.

45. Rivers LE, Young KM, Rizzi M, Jamen F, Psachoulia K, Wade A, et al. PDGFRA/NG2 glia generate myelinating oligodendrocytes and piriform projection neurons in adult mice. Nature neuroscience. 2008;11(12):1392-401.

\section{Collaborators and contributors}

Paula Sánchez1, Sebastian Schmitt1, Sarah Jäkel2, Leda Dimou2,3,4, Sunit Mandad5,6, Henning Urlaub5,6, Eugenio F. Fornasiero5, Silvio Rizzoli5.

\section{Affiliations}

${ }^{1}$ Max Planck Institute of Experimental Medicine, 37075 Göttingen, Germany

${ }^{2}$ Physiological Genomics, Biomedical Center, Ludwig-Maximilians University, Munich, Germany

${ }^{3}$ Molecular and Translational Neuroscience, Department of Neurology, Medical Faculty, Ulm University, 89081 Ulm, Germany

${ }^{4}$ Munich Cluster for Systems Neurology (SyNergy), 81377 Munich, Germany

${ }^{5}$ Department of Neuro- and Sensory Physiology, University of Göttingen Medical Center, 37073 Göttingen, Germany

${ }^{6}$ Max Planck Institute of Biophysical Chemistry, 37073 Göttingen, Germany

${ }^{6}$ University Medical Center Göttingen Bioanalytics Institute for Clinical Chemistry Robert Koch Strasse 4037075 Göttingen, Germany 


\section{Acknowledgments}

We thank our collaborators; Dr. Sarah Jäckel and Prof. Leda Dimou for providing us with the Esco2 animals brain sections; Dr. Sunit Mandad for mass spectrometry data acquisition; Dr. Eugenio F. Fornasiero for calculation of protein half-lives and his assistance in analysing the mass spectrometry data; Prof. Henning Urlaub and Prof. Silvio Rizzoli for supervising the mass spectrometry and protein half-life analysis.

We also thank our colleagues in Max Planck Institute of Experimental Medicine, Dr. Paula Sánchez for her assistance in image acquisition and quantifications of immunohistochemistry experiments and Dr. Sebastian Schmitt for generation of Bcas1 knockout mice; Gieselheid Schulz for her expert technical assistance for primary mouse oligodendrocytes cell culture, Jan-George and Nicola Schwedhelm for performing genotyping for transgenic mouse lines. 


\section{Curriculum vitae}

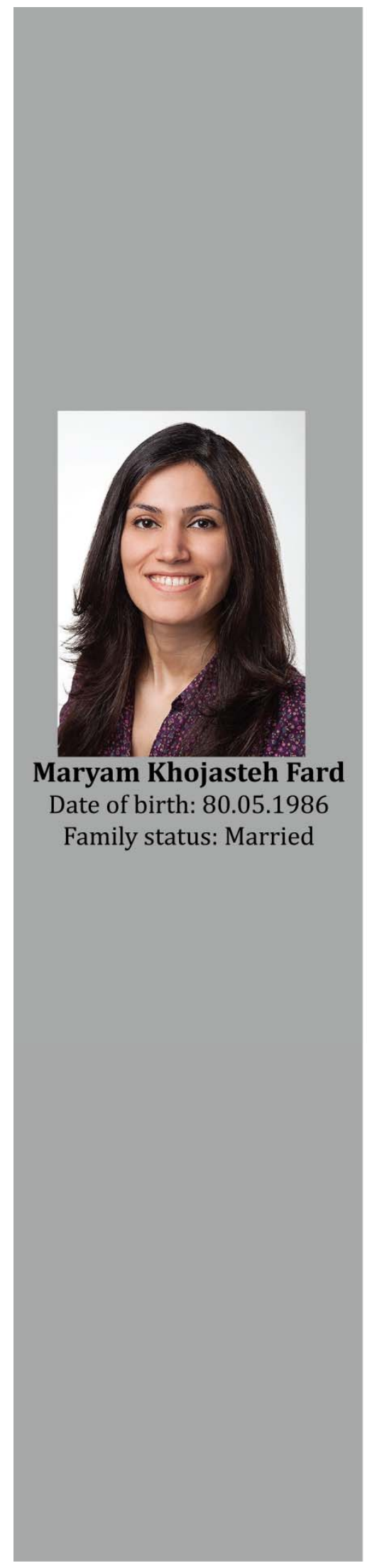

\section{Educational background:}

-2014-expected 2017(December): PhD studies in

„Molecular Physiology of the Brain" doctoral program

Georg August University Göttingen

Max Planck Institute of Experimental Medicine

-2008-2011: Master studies in

"Human Genetics"

Tehran University of Medical Sciences

GPA: 18.06 out of 20

-2004-2008: Bachelor studies in

"Molecular and cellular biology-Genetics"

University of Isfahan

GPA: 16.23 out of 20

\section{Awards:}

4th top student in the national exam for entering M.Sc. programs in medical sciences.

\section{Employments:}

-Feb 2014-currently:

PhD student/Research assistant in Max Planck Institute of Experimental Medicine/Göttingen/Germany

-2011-2013:

Lab manager and research assistant in Royan Institute

Institute for Reproductive Biomedicine (RI-RB)/Tehran/Iran

-2009-2011:

Research assistant in Endocrinology and Metabolism Research Institute Dr. Shariati Hospital/Tehran/Iran

\section{Publications:}

-BCAS1 expression defines a population of early myelinating oligodendrocytes in multiple sclerosis lesions. Maryam K. Fard, Franziska van der Meer, Paula Sánchez, Ludovico Cantuti-Castelvetri , Sunit Manad, Sarah Jäkel, Eugenio F. Fornasiero, Wolfgang Brück, Henning Urlaub, Leda Dimou, Christine Stadelmann, Mikael Simons. Science Translational Medicine, (2017: Under revision), Co-first and co-corresponding author. -IL-23gene expression in PBMCs of patients with coronary artery disease. M Khojasteh-Fard, M Abolhalaj, P Amiri, M Zaki, Z Taheri, M Qorbani, J Tavakkoly Bazzaz, M M. Amoli. Disease markers 2012. DOI 10.3233/DMA-2012-00933.

-Is DNA methylation responsible for immune system dysfunction in schizophrenia? M Khojasteh-Fard, M Tabrizi, MM Amoli -Medical Hypotheses, 2011: 77(4) 573-579.

-RANTES gene mRNA expression and its- 403G/A promoter polymorphism in coronary artery disease.JTavakkoly-Bazzaz, P Amiri, M TajmirRiahi, D Javidi, M Khojasteh-Fard, Z Taheri, A Tabrizi, M Keramatipour, M M. Amoli. Gene 2011: 487(1) 103-106 
